\title{
Messagerunner: Gamifying Behavioural Change Through Mobile Media
}

\author{
A Master's Thesis By \\ Charles (Xudong) Cheng \\ School of Design \\ Victoria University of Wellington \\ Date Delivered: \\ 10/07/2017
}

Supervisor: Tom White

Programme Direction: Media Design

School of Design

Victoria University of Wellington 


\section{Preface}

This research is about designing a mobile application that promotes physical health for young adults. This research is about the design of gamifying behavioural intervention on mobile applications. The app, Messagerunner focuses on combining behaviour change theories and gamification to change young adults' sedentary lifestyle. During the design process, I created interactive prototypes based on collected precedent research and conducted contextual interviews to generate a sound design solution.

Besides the thesis, an online copy of the prototype is available at: https://invis.io/85C1JX5V3\#/239432860_Splash

You may find its video documentation at:

https://vimeo.com/223725091 


\section{Acknowledgement}

I want to dedicate this thesis to my grandfather who passed away when I was studying for my master of design innovation. I would like to thank Tom White, my supervisor, and all the staff of design school for the help and guidance. I would also thank Matty Smith, Tom Petterson for moral support. 


\section{Abstract}

This research proposes a design solution that integrates gamification and behavioural change theories into a mobile fitness application to promote and maintain physical activity for young adults. This research proposes that the usability of mobile apps on behavioural modification can be improved by integrating psychological interventional methods into the product design. The design output, Messagerunner, will provoke critical reflection about the future design of mobile fitness applications. During the design process, I identified and collected related theories to analyse existing precedents, and then extracted design methods and criteria. Various methodologies including literature analysis, contextual inquiry, and iterative prototyping support the design solution.

Messagerunner seeks to balance the tedious exercise routine with the enjoyment from gamification. It uses widely accepted theories and methods on behavioural intervention to promote physical activity. This research was started by analysing the benefits and cost of behavioural intervention counselling and mobile persuasive technologies. Mobile applications have the benefits of being low cost and easy to access, compared to counselling. However, the existing applications have limits compared to professional intervention. Design solutions that combine intervention methods with persuasive technologies could lead to a better management for sedentary lifestyles.

Messagerunner adopts activity promotion methods drawn from a range of theories. These includes the transtheoretical model (TTM), the theory of planned behaviour (TPB), and flow theory. The design of the app is inspired by three precedents: Pokémon Go (Version 0.67.1, Pokémon Go, 2017), Habitica (Version 1.8.1, Habitica, 2017), and Run An Empire (Version 1.13.1, Run An Empire, 2017). To test the method, the design process includes contextual inquiry, prototyping, and user testing. The design outcomes apply to users worldwide and reflect on the design of current commercial fitness apps. The outputs produce a concept and UI design for the final iteration of Messagerunner. This research will provide insightful perspectives for future designs for fitness applications. 


\section{Content}

0 Abstract

1 Literature Review 2

2.1 Sedentary Behaviour 4

2.2 Behavior Change Interventions 6

2.3 Fitness Applications 8

2.4 Conclusion 10

2 Methodology 13

3.1 Literature Analysis $\quad 14$

3.2 Contextual Inquiry 14

3.3 Iterative Prototyping 15

3 Design Process 17

3.1 Theoretical Framework 18

3.1.1 The Transtheoretical Model 19

3.1.2 Psychological Theories 21

3.1.3 Gamification and Flow Theory 23

3.1.4 Conclusion 25

PROGRESSION 25

SELF-EFFICACY 25

FLOW 25

3.2 Precedents Analysis 26

4.2.1 Pokemon Go 27

4.2.2 Habitica 38

4.2.3 Run An Empire $\quad 30$ 
3.3.1 Online Questionnaire

Conclusion

3.3.2 First Iteration

3.3.2.1 the Wireframe and Drawings

3.3.2.2 Swift MVP and QR Code Scanner

3.3.2.3 Contextual Interview

3.3.3 Second Iteration

4.3.3.1 Mockup

4.3.3.2 Contextual Interview

4.3.3.3 Conclusion

3.3.4 Third Iteration

4.3.4.1 Colour Scheme

4.3.4.2 Typography

50

4.3.4.3 Icons

4.3.4.4 User Journey

50

4.3.4.4 User Interface and User Experience

52

53

4 Conclusion

61

5 Discussion

5.1 Social interaction as interventional method

5.2 Gamification as persuasive technology

66

5.3 World wide users

66

5.4 Commercial fitness applications

67

67

Bibliography

69

Appendix 1

75

Appendix 2

79

Appendix 3

81 
Human Ethics Approval

Number: 0000023489 
1. LITERATURE REVIEW 
Young people embrace modern technology, and they adopt it in their daily lives. It is not a surprise that some young adults choose to spend more time with a digital display than with people in reality. The internet has never been more versatile and accessible. People can accomplish various tasks by just tapping buttons on a smartphone. Some may criticise this, saying that new generations are becoming lazier under the influence of the internet. Indeed, a concerning fact is that sedentary lifestyles are spreading among children and adults in both developed and developing countries. Technology has brought convenience and productivity to human society. It also has downsides. For example, people become overly dependent on technology, and then develop a sedentary lifestyle. In this case, people should intervene to help those who suffer from a dependence on technology.

Fortunately, psychologists have developed abundant theories and methods for changing behaviour and preventing addiction. Prochaska et al. combined previously established principles to develop the transtheoretical model of behaviour change: an integrative, biopsycho-social model to describe the process of intentional behaviour change (Prochaska, 2013). The model defines six stages: precontemplation, contemplation, preparation, action, maintenance, and termination. These stages represent progressive changes in people's mental and physical state during their behavioural change. Therapists and psychiatrists can apply appropriate therapy and treatment based on this model to patients in different stages.

Researchers have proven that interventions (therapies and actions intended to change behaviours) are useful treatments for compulsive behaviours (Heron, Smyth, 2010). However, intervention needs time and investment from both professionals and participants. These are not accessible to most young adults. They seek a different approach. Mobile fitness apps may be a great solution. Apps related to fitness and health are popular among young adults. For example, Pokémon Go, a mobile game that promotes physical health, was the most downloaded iPhone app worldwide in 2016. Researchers have also proven that Pokémon Go players are more than twice as likely to complete a goal of walking 10,000 steps a day compared to people who didn't play (Xu et al., 2017). However, like most fitness apps on the market, the popularity of Pokémon Go did not last long. Players quit after a short time, and their sedentary lifestyle returned or remained. One explanation is that most commercial fitness apps do not directly show how users have improved, nor do they provide feedback so that users can update their fitness plans. These are important components of intervention treatment.

This research proposes a design solution that integrates gamification (the application of typical elements of game playing to other areas of activity) and behavioural change theories into a mobile fitness application that promotes and maintains physical activity in young adults. I carry out an iterative design process, and apply various methodologies including literature analysis, contextual inquiry, and iterative prototyping to support my design process.

\section{My research question, aims, and objectives are as follow}

How can designers integrate gamification and behavioural change theories into a mobile fitness application to promote and maintain physical activity among young adults?

\section{My project has the following aims and objectives}

1. I will analyse and summarise design criteria to pursue my research question by:

(a) identifying and collecting related theories

(b) dissecting and collating design methods through analysing existing precedents

2. I will test the design criteria through an iterative design process by

(a) creating prototypes based on collected criteria

(b) developing and testing completed mobile interactions through an iterative design process. 


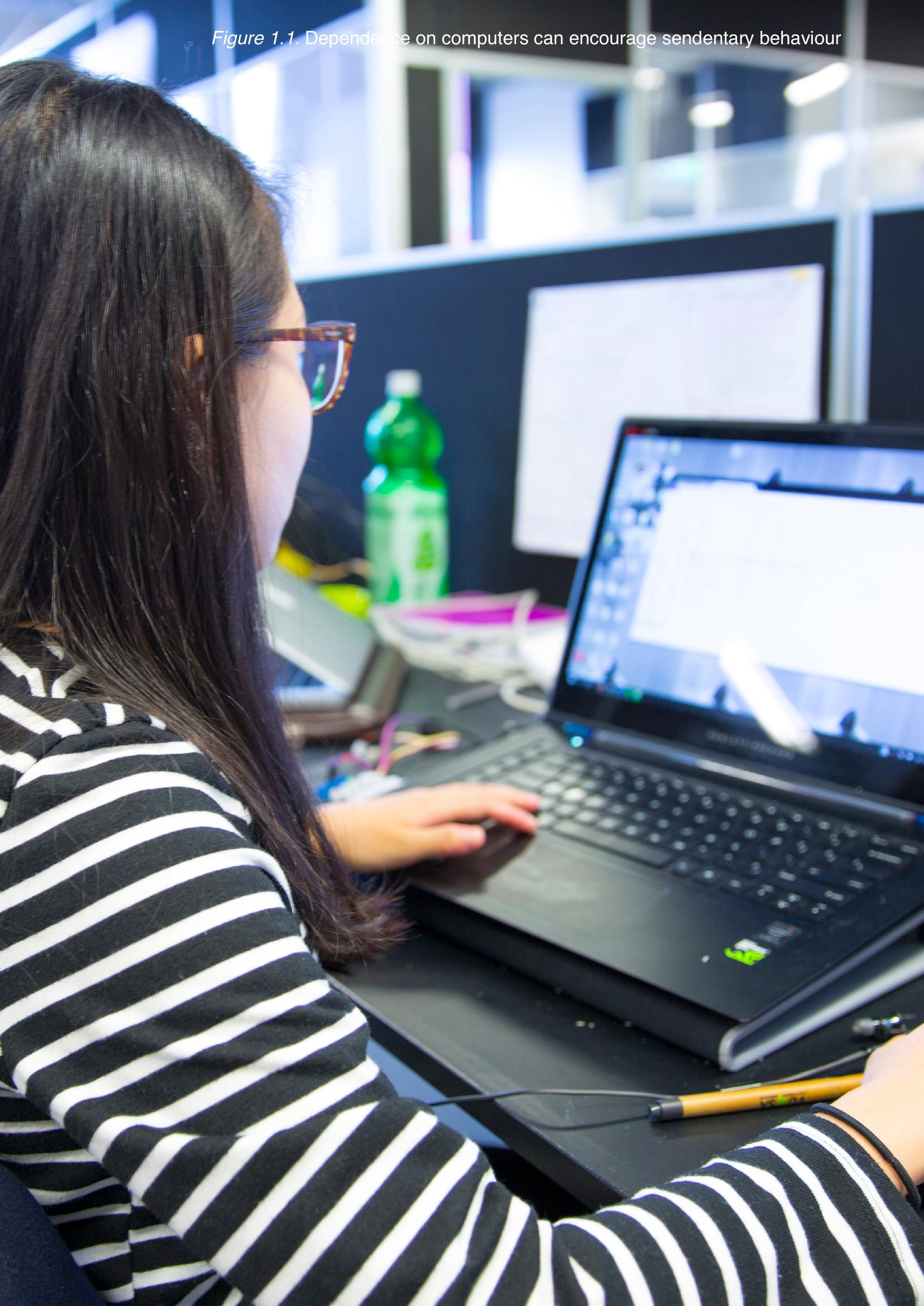




\subsection{Sedentary Behaviour}

People usually think of a sedentary lifestyle as sitting or standing in front of a digital display with little physical exercise. With the growing popularity of gaming and online entertainment, the general public is spending more time sitting or standing in front of screens. Social commentators are concerned about the epidemic of sedentary lifestyles ("Physical inactivity a leading cause," 2002).

Sedentary behaviour is commonly associated with increased risk of cardio-metabolic disease and a variety of physiological and psychological problems (Foley et al.,2011). The World Health Organisation has ranked physical inactivity as the fourth leading risk factor for global mortality. High blood pressure, tobacco use and high blood glucose are ranked the top three (Kohl et al., 2012). Research has linked modern day sedentary lifestyle to the prevalence of obesity in multiple developed countries (De Onis, Blössner, Borghi, 2010). New Zealand is one of the countries that has suffered from a steep rise in obesity rates in both children and adults. There has been much research aimed at finding the solution to this particular issue.

According to "The New Zealand Physical Activity Report Card for Children and Youth", New Zealand children and youth's sedentary behaviour is high, and there is a clear age-related increase in sedentary behaviour. Young people who lead a sedentary lifestyle are more vulnerable to cardiovascular disease, type-2 diabetes, and adiposity, which leads to increased health care costs and lost productivity in the future. The public should come up with robust plans to resolve this issue.

The public should be concerned about a wider range of sedentary behaviour than just watching TV or playing video games. According to research focused on New Zealand youth (Foley et al.,2011), non-screen sedentary time (NSST) made up a significant proportion of young adults' sedentary activities. Foley defines NSST as "the number of waking minutes reported in seated or lying activities not involving a screen". Foley further breaks NSST down into six intuitive sets: socialising, school/work, self-care, passive transport, music and leisure. NZ young people spend a significant number of waking hours in sedentary behaviours. This is true even for the most active subsets of NZ youth. About 420-520 minutes of a young person's day is inactive. This is split into $35 \%$ screen activities and $65 \%$ non-screen activities. 


\subsection{Behaviour Change Interventions}

Clinicians have tested home-based, school-based, and community-based interventions on children and adolescents and proven them to be effective in reducing sedentary behaviours, for example, watching TV (Salmon, Tremblay, Marshall, \& Hume, 2011). Structural interventions refer to public health interventions that promote health by altering the structural context within which health is produced and reproduced (Blankenship, 2006, p 59). Lifestyle interventions were defined as any intervention that included exercise, diet, and at least one other component (e.g., counseling, stress management, smoking cessation) (Sumamo, Ha, Korownyk, Vandermeer, \& Dryden, 2011).

Research aimed at analysing and comparing the efficacy of lifestyle and structured interventions found that 235 participants from both test groups had significant and comparable improvements in physical activity and cardiorespiratory fitness from the start of the experiment. The total cost of the six months lifestyle intervention was $\$ 33,778.53$. Each participant paid $\$ 46.53$ per month. The structured intervention, at six months, was obviously more expensive. Each member paid $\$ 190.24$ per month. Similarly, the total cost of the lifestyle intervention at 24 months was $\$ 49,805.37$ or $\$ 17.15$ per participant per month. The structured intervention at 24 months was $\$ 134,910.67$ or $\$ 49.31$ per participant per month (Sevick et al, 2000).

Despite the fact that intervention and counselling are effective in increasing physical activities, they are time-consuming and expensive. Pressure from school and society makes it difficult for young adults to join counselling programmes. Furthermore, any exercise regime is inevitably costly in time and energy. Young people must overcome the tedious preparation phase before they feel motivated to play sport or engage in other actitivities. A solution with little time investment and engaging content is crucial to increase the amount of physical activity among young adults. 

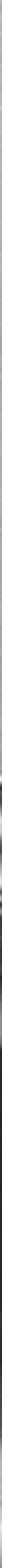

Figure 1.3. An example of a family engaged in sedentary behaviour (Baumgardner, 1958) 


\subsection{Fitness Applications}

Mobile devices have become a part of young adults' everyday life. Researchers and designers use them as an intervention platform to change young people's sedentary lifestyle. Persuasive technology evolving from mobile technology has emerged as a promising method for changing behaviour (Fogg, 2002). For example, some people now use a small wearable device to count the number of steps they have walked, and many cellphones now feature pedometers (Foster et al., 2010).

Pedometers are versatile, and researchers have used them in various motivational methods. One of the most efficient methods is self-monitoring. Many fitness applications, like Fitbit and Jawbone, use self-monitoring as their main motivational feature. They attempt to motivate users to maintain a healthier diet and lifestyle. More importantly, they allow users to track the amount and the duration of physical activity they perform every day, with no greater investment than carrying a cellphone. Bravata (2007) suggests that people who use a pedometer in physical activity may get significant increases in physical activity and significant decreases in body mass index (BMI) and blood pressure.

The popularity of social media provides another widely-used motivational technique: social motivation (Arteaga et al., 2010). Users shared photos that show their transformation on Instagram or Facebook to motivate themselves to maintain their current fitness plans. Likewise, fitness applications usually implemented this approach by allowing users to share their physical activity achievements, and to check out their friends' progress. Social pressure will influence decision making and eventually affect their behaviour. This method proved to be a strong motivator (Foster et al., 2010). Some people criticise this approach for neglecting privacy and safety concerns. However, researchers who support this method argue that careful system design can manage these issues.

Mobile fitness applications also use goal-setting to motivate users' behavioural change. For example, GoalLine (Munson \& Consolvo, 2012) is an app that lets users set weekly physical activity goals, and allows them to keep a record of their physical activity and review their progress in the past. Users adopt the app to set routine goals, backup goals, and challenge goals. They stated that the challenge goals motivated them to go above and beyond their comfort zone.

Gamification has proven to be a useful motivational method (Arteaga et al., 2010; Berkovsky et al., 2010; Chittaro \& Sioni, 2012). Researchers who used games to promote physical health for children and teens reported that children not only increased their physical activity, they enjoyed themselves at the same time (Arteaga et al., 2010). Researchers believe that the latter factor is critical. If users do not enjoy a game, they will stop playing it. There is a lack of similar studies on adults to test the effect of such games. 
The last motivational technique is reward, more specifically virtual reward. For example, in Munson and Consolvo (2012), the user is given a virtual ribbon and trophy as a reward for accomplishing his/her physical activity goal. In Berkovsky et al. (2010), They gave users timebased awards. Munson and Consolvo reported that the reward system failed to motivate the users, while Berkovsky said it did make the users more physically active. One explanation might be that Berkovsky used the reward system in a game context while Munson and Consolvo did not. This explanation may suggest that virtual reward works together with gamification. The age group used to test the application might also explain to these different results. Berkovsky tested it on children between the ages of 9-12 years while Munson and Consolvo tested it on adults between the ages of 21-49. This difference may also link to the game format since games have an impact on children when it comes to physical activity promotion (Arteaga et al., 2010; Berkovsky et al., 2010; Chittaro, \& Sioni, 2012). Khalil (2013) suggests that using virtual rewards as a physical activity promoting tool still needs investigation.

Most of the popular mobile health applications focus on fitness and self-monitoring. According to an article titled: "An Evaluation of Mobile Health Application Tools", among the 400 entries in the category of "health and wellness" of the app store, the average price of the most popular paid applications was US \$2.24 (SD \$1.30). 43.5\% of the 400 samples are fitness/training applications, followed by health resource applications at $15 \%$. The third most common category is diet/caloric intake trackers, at 14.3\%. The research also found out 299 out of 400 apps used self-monitoring as the primary user engagement method. $20.8 \%$ of the apps adopted more than one engagement approach. The most common methods were selfmonitoring and progress tracking (Sama, Eapen, Weinfurt, Shah,\& Schulman, 2014). Apps also use less common methods such as social interaction, goal setting, and gamification.

Despite the low cost and easy access, people usually stop using these fitness technologies after a short period. Most fitness apps give direct feedback of how many steps users took or how many calories they burned. Users may be intrigued by the concept when they start to use these apps. However, they don't understand how these data is related to their health, and they grow tired of the app (Wearable Fitness Technology- Is It Right For You? 2015).

Most fitness apps fail because they miss some critical components of what it takes to change long-term behaviours. Users need to see clear progress in their health and motivation to maintain behavioural change. A counsellor could give direct feedback and guidance to help progress behavioural change. There are connections between the behavioral change techniques described in fitness apps and the psychological theories applied in interventions, delivered in-person to help people increase their physical activity. 


\subsection{Conclusion}

Mobile applications, with their low cost and easy access, are a plausible option for combatting sedentary lifestyle. However, the existing applications have limits compared to professional intervention. I aim to combine the theory behind medical intervention and persuasive technology into a mobile design that could provide a better solution to the sedentary issue.

Figure 1.4. A user opens the app MyFitnessPal (Version 7.18, MyFitnessPal, 2017)

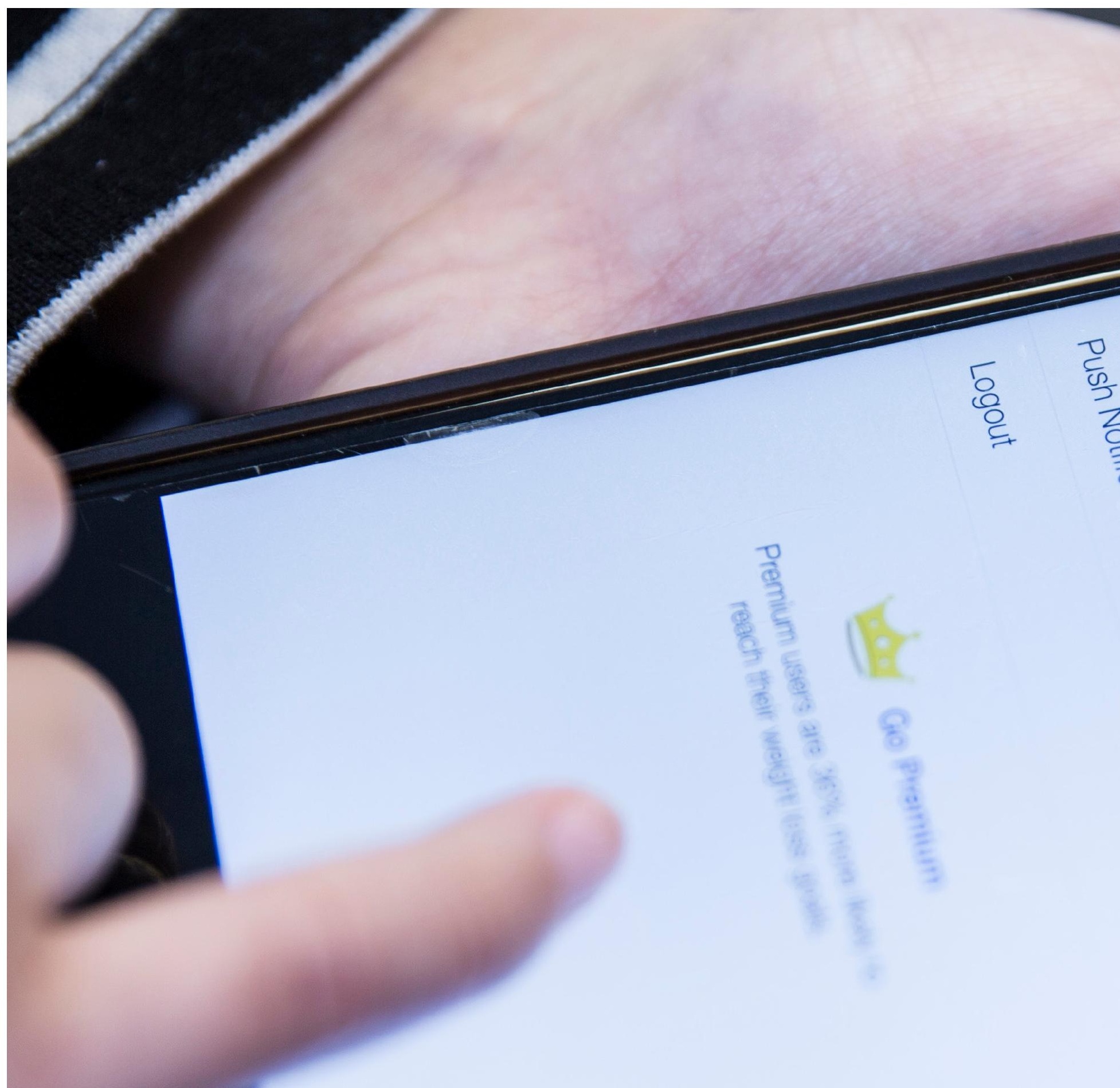




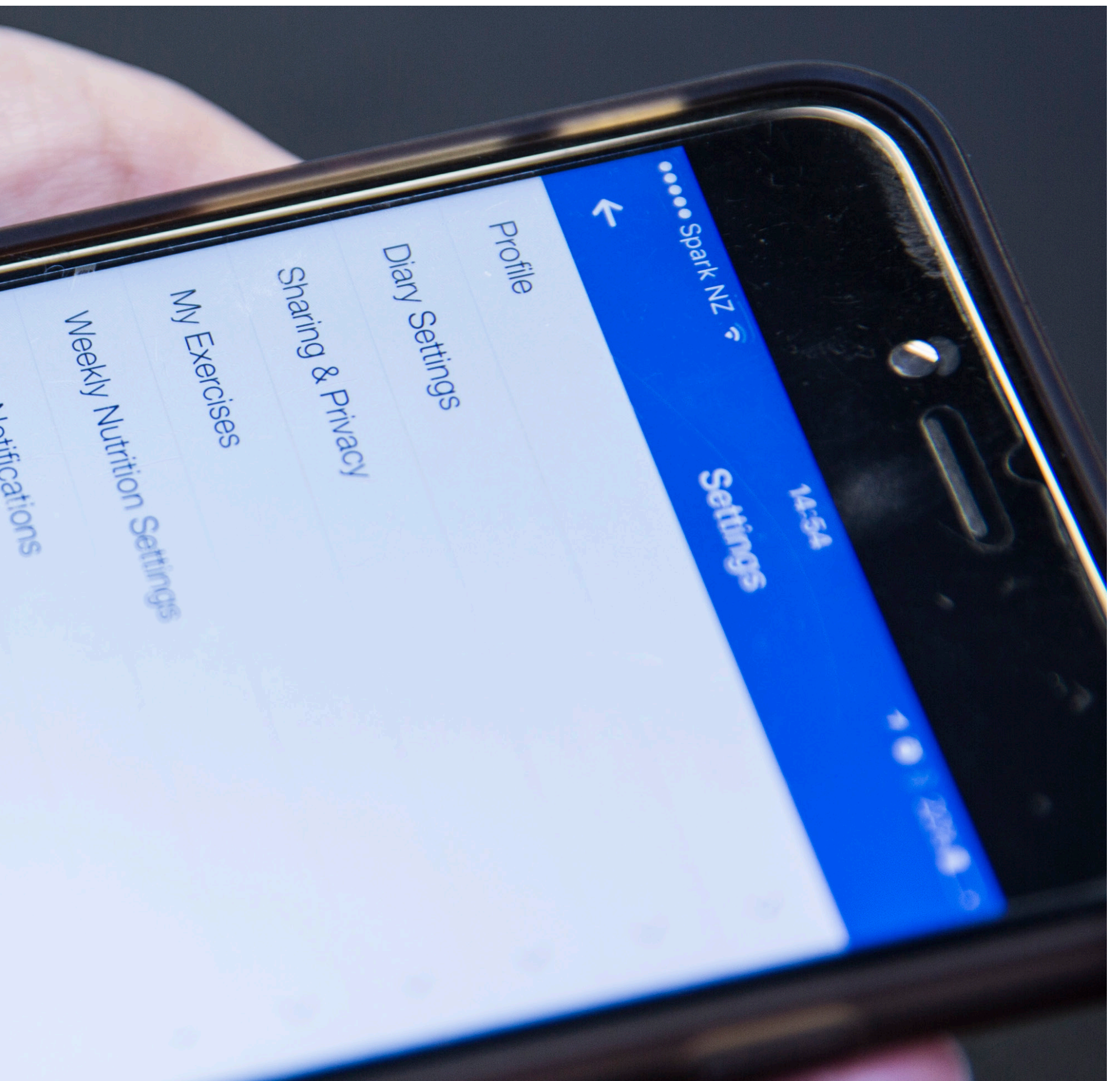


2. METHODOLOGY 


\subsection{Literature Analysis (Jalil, Din,\& Keumala, 2013)}

This research is qualitative and my design process is subjective. I collected and compared existing research related to my design proposal. I gained insightful arguments and knowledge to inform my design process by analyzing precedents. In this way, I can temper the subjectivity in my process with an objective analysis of common practice. Thus, I chose a design through research approach.

Scholars have studied the process of behaviour change thoroughly. By analysing previous literature on behavioural change theories, I collected relevant information and summarised critical guidelines to inform the design process. Similarly, by critiquing successful gamification precedents, I can extract useful features and design methods. It is important to identify and collect existing design methods from literature analysis. It enables me to dissect and collate the proper design for my study, and to develop design criteria to direct user experience. There are three parts of literature analysis: Literature Review, Theoretical Framework, and Precedents Analysis. In the literature review, I identified and explained the necessity of developing a fitness application that integrates gamification and behavioural change theories for young adults. In the theoretical framework, I will collate the necessary methods and literature and come up with design criteria to form an early and adaptable design framework. Finally, I will extract useful mechanics from popular gamified fitness apps and exercise games in Precedents Analysis. I will break down the gamification into features and mechanics, and find connections between these components with criteria from the previous sections.

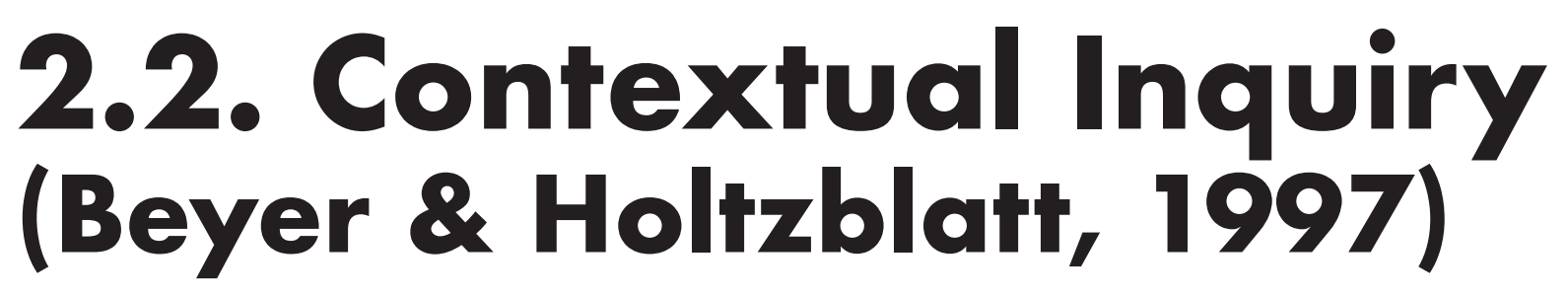

It is essential to get detailed feedback from users, so I choose contextual inquiry method to guide my user testing process. I can understand what users do and why they do it by observing them when they are using the prototype. Firstly, I gave my interpretations and conclusion though the testing phase. The users were free to correct or expand my understanding at the same time. Secondly, I gave interviews to users in their home or work environments, so the analysis data was more realistic than laboratory data. At the end of every session, I conducted a semi-structured interview to obtain information about the users. I asked users a set of standard questions in their living environment. I summarised and categorised the information from the interviews in a table to analyse different aspects of the feedback. I marked keywords in interviews, and interpreted the causes and solutions from the feedback to inform the next iteration. Limited time and funds restricted me to conducting a small number of interviews. I planned to carry out 3-6 interviews to get sufficient qualitative data to critique every iteration. However, it is inevitable that selection bias exists in such a small sample. To correct against this, I included various different age groups and genders within the category of young adults. I recruited respondents online to avoid convenience sampling and ensure neutrality. 
I asked the following interview questions:

-What do you think of the navigation of this application?

- Did you come across any confusion or obstacles when you used this application?

- Do you understand what each page of this application means?

-What do you think of the overall design such as colour scheme, icons, and buttons within this application?

- Would you consider using this application to help you exercise?

-Would you recommend this application to your family and friends?

- Do you have some suggestions on improving the experience of using this application?

- Do you have any advice on the activity promotion method adopted in this app?

-What would the possible reasons stopping you from using this application?

-What would be a great method to motivate you to do more exercise?

\subsection{Iterative Prototyping (Ali,2011)}

Due to the limits of my knowledge and experience, it is impossible for me to develop an entirely functional mobile application. However, this does not interfere with the goal of this research. Iterative prototyping is a repeated and communication-driven approach concentrating on usability and a user interface design heuristic. By applying this method, I could test the potency of my solution without developing a functional app. The iterative design process consists of three stages: Design, prototyping and evaluation. The first step is related to the user needs, goals and design concepts. I conducted an online survey to acquire information and design inspiration. Prototyping is the second phase where I developed a low-fi prototype based on previous research. The third step, I critiqued the prototype based on the contextual interview to check what extent the solution met the behaviour change goals. I then conducted the second iteration. I made an improved high-fi prototype to enhance functionality by introducing more sophisticated UI elements. From the result of the second iteration, I will verify the efficacy of previously concluded criteria and do the third and final iteration. 
3.DESIGN PROCESS 


\subsection{Theoretical Framework}

Behavioural change theories try to establish the environmental, personal and behavioural factors that allow an intervention to fail or succeed. Traditional intervention methods that normally includes one on one conversations and psychotherapy are time-consuming and costly. Young adults as a unique group are usually overlooked when it comes to health issues and financial support. As a result, many adults aged 18 to 40 are suffering from various physical and mental illness without proper social support. Chronic disease related to sedentary lifestyles is as concerning among young adults as among teenagers and children. However, academics and the media put most of their focus on children's obesity and the sedentary behaviours of adolescents. Young adults not only lack support and attention from the public, they also face pressure in their study and work that leaves them little to no time to fix their sedentary behaviours.

At the same time, smart fitness applications have gained a slice of the app market. Compared to traditional behavioural change methods, they are time-saving and more accessible to young adults. There is a chance to use them as an alternative to traditional interventions. However, most users quit an application after a short period, and ultimately find them ineffective. This section discusses how to integrate behavioural change theories into the existing fitness app design framework. After summarising theories, I will test them in an iterative design process. 


\subsubsection{TTM}

The Transtheoretical Model (TTM) argues that behaviour change happens in stages. It integrates major theories on behavioural change interventions (Glanz, Rimer, \& Viswanath, 2008). TTM hypothesises that behaviour change involves six stages: precontemplation, contemplation, preparation, action, maintenance, and termination. Through these six stages, there are ten processes of change: consciousness raising, dramatic relief, self-reevaluation, environmental reevaluation, self-liberation, social liberation, counterconditioning, stimulus control, contingency, and helping relationships (Glanz et al., 2008). These processes affect the way individuals weigh the pros and cons of changing. Glanz terms this decisional balance. Glanz also points out that individuals change their attitude towards unhealthy behaviour throughout these processes.

In each of these processes, an individual's confidence towards coping with high risk situations grows. Glanz terms this self-efficacy. At the same time, an individual' urges to engage in a particular behaviour decreases when they face a stressful situation. Glanz terms this temptation. This model was later expanded to investigate a broad range of health and mental health behaviours including sedentary lifestyles.

It is worth noting that the model reveals that interventions are not always effective when it comes to changing the behaviours of people in early stages. People weigh the costs and the benefits of changing regular habits. When the pros of changing do not outweigh the cons, they get stuck in an ambivalent state where traditional action-oriented programs that expect participants to act immediately are not effective. As a result, interventions are most useful to people in the preparation stage and after.

During the processes of change, according to TTM, people first try to find the solution for a particular problem behaviour. They become more emotional when thinking about their current state during this process. After that, they assess their self-image with and without an unhealthy behaviour, and then how the presence or absence of a harmful behaviour affects their social environment. Some people commit to change after this assessment. They conclude that changing their behaviours is possible and preferable. For instance, some relatively deprived or oppressed individuals will evaluate their current state and compare the social opportunities with or without their problem behaviour. If they commit to change, the increase in social opportunities can boost their confidence. They will eventually substitute problem behaviours with healthier behaviours. Next, they remove cues for unhealthy habits and add prompts for healthier alternatives. To continue the new routine, they use reward and punishment to keep themselves from relapsing. In the end, they will build and manage a friendly environment that supports their new healthy behaviours (Glanz et al., 2008).

However, some researchers argue that stages of change may not apply to physical activity in the long term. Adams and White (Adams \& White, 2004) present three main reasons why: "the complexity of physical activity, the lack of validated staging algorithms and the possibility that the real determinants of activity change are not included in the Transtheoretical Model (TTM)". 
Adam and White investigated the existing evidence for the effectiveness of stage-based behavioural interventions in improving physical activity levels. They found proof that TTM programmes promote short-term behavioural change, but limited evidence on their effects in the long term (Adams \& White, 2004). They also pointed out that the majority of TTM related research is built on comparatively short interventions and follow-up. Moreover, there is little evidence to validate the definitions of different stages in TTM. The stages in TTM are ill-defined, and therefore it is hard to be certain an intervention is targetting the right group (Riemsma et al., 2002). Thus behaviour change does not always follow the stage progression as predicted.

Adams and White also argue that exercise behaviour is influenced by multiple factors that TTM fails to consider, such as age, gender and racial diversity (Adams \& White, 2004). In physical activity related interventions, TTM has only defines a part of determinants of stage transition. Thus, the model of TTM has limits when it comes to evaluating and predicting physical activities (Johannes et al., 2004).

Despite the lack of longitudinal data and related experimental research, the TTM tailored intervention has shown short-term effects on both stage progression and activity levels (Adams \& White, 2004). Thus, TTM does provide useful information about short-term behaviour

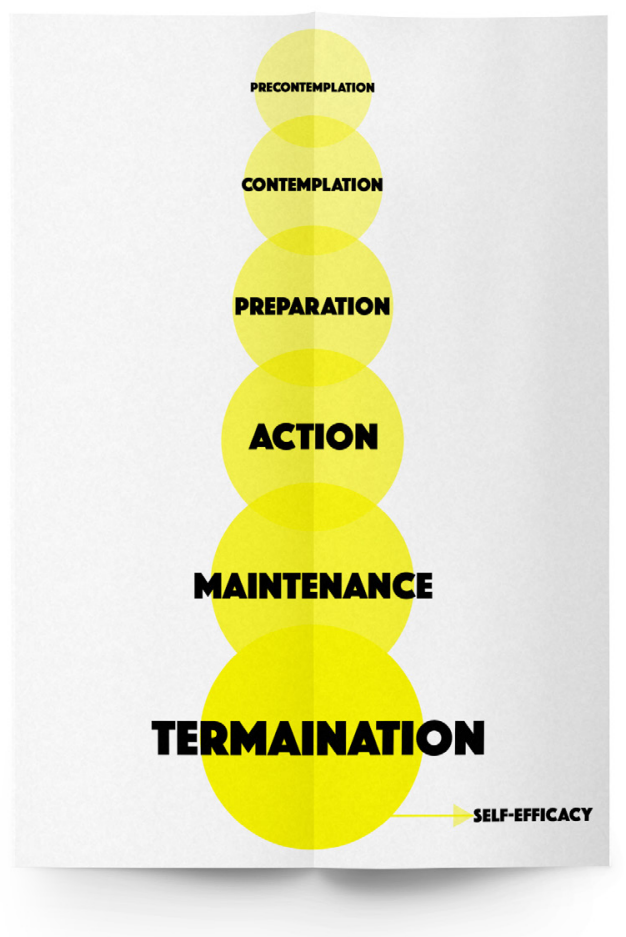

Figure 3.1. TTM stages on a diagram 


\subsubsection{Psychological Theories}

Psychologists have developed various theories to promote physical activity. A prominent one is the self-efficacy theory adapted from Bandura's (1986) social cognitive theory. Self-efficacy refers to people's sense of confidence about performing a particular behaviour (Bandura, 1986, 1997). The notion behind this theory is that "the higher the confidence of an individual to perform an act, the more likely he or she will have sustained engagement in a particular activity" (Khalil \& Abdallah, 2013). In research carried out by Emily and Matthew (Emily \& Matthew, 2008), task and coping self-efficacy on the stage groups action and maintenance increased compared to contemplation and preparatory groups. When they compare their results with several other studies on exercise interventions, they concluded that adherence to exercise was best maintained by participants with high self-efficacy.

Some researchers try to analyse the connection between attitudes and action. Ajzen \& Fishbein introduced another theory related to attitudes and the attitude-behavior relationship, the theory of reasoned action (TRA), to predict behaviours (Ajzen \& Fishbein, 1980). This theory posits that a person's intention to perform a behaviour is determined by his or her attitude towards the behaviour and how others that are important to the individual perceive it. They term this subjective norm. This theory is limited for two reasons. Firstly, the TRA model is set in a world where actions are determined by people's volitional control. However, in the real world, the performance of any activity is affected by non-subjective variables such as environmental obstacles, knowledge, skills, and others' cooperation. A critic of TRA, Sheppard, hypothesises a behavioural intention that is influenced, not only by people's volitional control, but also by non-subjective variables (Sheppard, Hartwick, Warshaw, 1988).

When it comes to fixing the TRA model, another established theory is that of planned behaviour (TPB). This has a close resemblance to TRA. TPB posits three variables predicting possible planned behaviour. The first of these, Ajzen suggests that a person's attitude towards a behaviour may be positive or negative. The second variable is the perceived social pressure on the individual to carry out the action. The third variable is perceived behavioural control, which refers to a person's perceived self-confidence about performing the behaviour (Ajzen, 2011). This third variable is the main difference between TRA and TPB.

Many studies have applied the TPB to the prediction of exercise intentions and behaviour (Conner \& Sparks, 1996). However, the predictive validity of TPB is arguably limited. In an article titled "The theory of planned behaviour: Reactions and reflections" (Ajzen, 2011, p.1114) points out:

"the mean correlation between perceived behavioural control and intention was found to be 0.40 and attitudes, subjective norms and perceived behavioural control produced mean multiple correlations with intentions that ranged from 0.59 to 0.66 ". 
The same article also explains that intentions are poor predictors of behaviour because the intention-behaviour correlation is affected by participants' general capacity to inhibit their impulses. TPB model was criticised of neglecting the affect and emotions of human beings. For example, participants in a negative mood are more likely to emit unfavourable beliefs in their behavioural change process than participants in a positive mood (Ajzen, 2011).

Generally speaking, despite being insufficient to fully explain people's intention and actions, the TPB model does indeed permit a prediction of intentions and behaviours (Ajzen, 2011). The model needs additional predictors that improve accuracy. One of the proven predictors is past behaviour and habit. For example, Abraham and Sheeran reported in a secondary analysis of data, when anticipated regret from past physical activity was included in the calculation, the amount of variance in physical activity analysed by the TPB increased from $36 \%$ to $53 \%$ (Abraham \& Sheeran, 2003). However, the past behaviour is not proven to cause a person's current intention (Ajzen, 2011).

All in all, I decide to adopt TPB theory to guide my user experience design process.

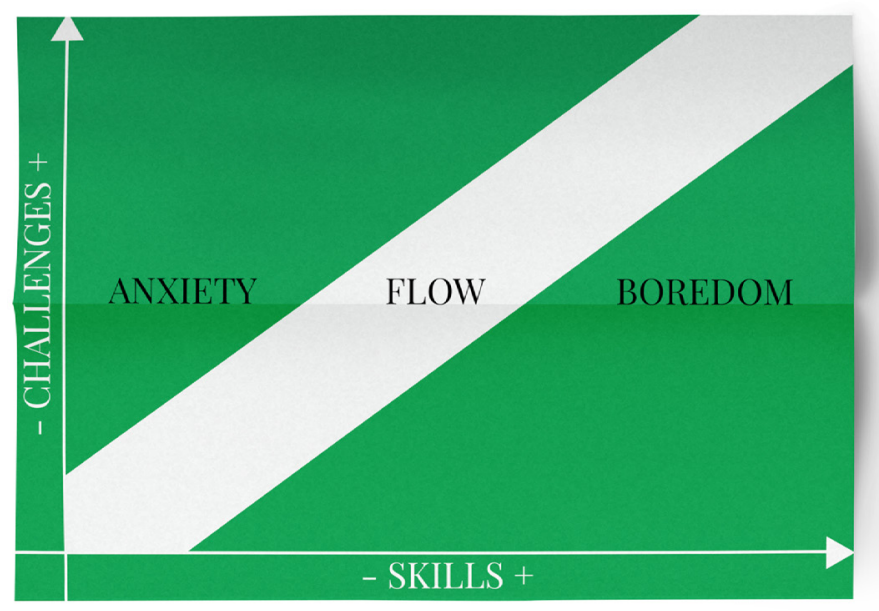

Figure 3.2. Flow diagram inspired by the flow theory 


\subsubsection{Gamification and the Flow Theory}

When designers and researchers try to use gamification to achieve behavioural change, they usually struggle with finding sufficient guideline or framework to guide the design process of behaviour change games. There has not been an established model to predict users' behaviours in these games. In reality, TPB and TTM are often utilised as alternative predictors and protocol to predict and control users' behaviours (Schoech, Boyas, Black, \& Elias-Lambert, 2013).

Choices \& Consequences (Schoech et al., 2013), a social game targeting substance abuse and relationship violence among middle school youths, let players construct a fun and risk-free weekend for a 13-year-old girl or boy within daily scenarios that youths can easily identify. The developers' describe the game as follows:

"Following each challenge, players are presented with five of the many possible actions from which they must select one, like kissing back or hitting in anger. After selecting an action, the players are asked to rate how much fun they consider their action. The player then receives one of the several consequences of the selected action, like being hit back, along with points indicating how successful experts think the selected action is in resolving the challenge. Points accumulated throughout the game could be used to buy hints on how to play the game better, or to purchase space on the welcome page for displaying team names, pictures, audios, and so forth to enhance team spirit and increase friendly competition. Critical feedback is continuously presented via a score box. During gameplay, players can discuss game content with team members using a chat-based social network and by team discussion led by a group facilitator." (Schoech et al., 2013).

The same team developers also concluded that "gamification fostered engagement, motivation, self-disclosure, co-learning, and detailed delivery of a curriculum. Most of our test students preferred the game delivery format to all other prevention formats they had experienced."

From the example above, it is clear that mobile games can set challenges to educate and influence users by immersing users in a set of gameplay scenarios. Through gamification, mobile applications can help users to monitor their behaviour while remaining fun and engaging at the same time.

When people engage in physical activities that fit their body condition and skill level, they perform better and feel more confident. Based on TPB and TTM, the confidence they gained from the process will make them more likely to sustain engagement. As a result, users are likely to reach the maintenance stage of sustained regular exercise.

However, gamified mobile apps may motivate and engage due more to intrinsic rather than extrinsic motivation (Schoech et al., 2013). According to MDA framework (standing for Mechanics, Dynamics, and Aesthetics):"fun in the gameplay can be categorised as eight aspects (Hunicke, LeBlanc, \& Zubek, 2004):

1. Sensation: Game as sense-pleasure;

2. Fantasy: Game as make-believe;

3. Narrative: Game as drama;

4. Challenge: Game as obstacle course 


\section{Fellowship: Game as social framework \\ 6. Discovery: Game as uncharted territory \\ 7. Expression: Game as self-discovery \\ 8. Submission: Game as a pastime".}

Fun gameplay can activate intrinsic motivation. A gamified app can use physical activity as a central component, and the game mechanic can link the mastery of solving gaming challenges with the knowledge of real life exercise. I adopted flow theory to map the relationship between behavioural interventions and gaming. Flow means a mental state in which a person is fully immersed in an activity and enjoying it (Jackson \& Csikszentmihalyi,1999). People face this state in both exercise and video games. Both involve leveling up their skills to match increasingly difficult challenges. Many people give up due to the anxiety they suffer about closing the gap between their competence and the required capacity. Traditional video games gradually increase the difficulty for each level. However, inevitably, experienced players find earlier challenges tedious. Similarly, in sports, both challenges and skills can be progressively developed in precisely defined stages of increasing complexity (Jackson \& Csikszentmihalyi,1999). By changing the challenge-skills balance, people can feel enjoyment and motivation during both games and sport.

The research of Jenova points out that: "If the challenge is higher than the ability, the activity becomes overwhelming and generates anxiety. If the challenge is lower than the ability, it provokes boredom. Fortunately, human beings have tolerance, there is a fuzzy safe zone where the activity is not too challenging or too boring, and psychic entropies like anxiety and boredom would not occur (Jenova, 2006)."

From Figure 4.2., we see can clearly see the balance between the challenges and the abilities would impact the engagement between the activities and the corresponding participants. The activity would become make the participant feel overwhelming and anxious when the challenge is higher than the ability. On the other hand, the participant would feel bored when the challenge is lower than the ability (Jenova, 2006).

Flow is the feeling of complete and energised focus in an activity, with a high level of enjoyment and fulfilment (Jenova, 2006). According to Snyder (Snyder \& Lopez, 2009), Flow research and theory originated from a desire to understand the autotelic activity that rewards in and of itself, regardless of extrinsic rewards that might result from the activity.

Csikszentmihalyi had developed some theories to instruct people how to get into the Flow state. Psychologists and researchers have applied these theories and their corresponding methods to the fields such as sports, learning and games. Game designers like Jenova (2006) used the flow theory to design games with better human interactive experience. Jenova adopted one of the theories on defining the Flow Zone. The flow zone is also known as "the zone" in game design which describes that " people can only maintain the flow experience when the activity they engaged in reaches a balance between the challenges of the event and the abilities of the participant."

Brauner also pointed out that "Flow inspired exergames (video games that require physical activity or moving one's body to play) and GPS (global positioning system) exergames (electronic, location-based games that are played outdoors with the help of GPS in mobile devices carried by players) are rapidly gaining acceptance, and may have the potential to increase physical activity levels among young people" (Brauner, Valdez, Schroeder, \& Ziefle, 2013). 


\subsubsection{Conclusion}

Based on the previous theories and analysis, I chose three keywords and their corresponding 13 design criteria to guide my design process.

\section{PROGRESSION}

1. Changing people's sedentary lifestyles is a process that takes time

2. Persuasive technology can only be a useful intervention when users intend to change their behaviours

3. People reevaluate themselves and environment to find motivations when they try to change their behaviours

4. Social interaction can influence self-liberation and social liberation for to promote health

5. Various stimulation shall apply to different stages of change

\section{SELF-EFFICACY}

(self-efficacy: people's' sense of confidence in their ability to perform a particular behaviour)

6. To boost the sense of confidence in users' ability to perform exercise can positively affect the long-term engagement of their exercise plans

7. The application should trigger user's positive attitude towards changing their sedentary lifestyles

8. The application should use a certain amount of social pressure to increase the chances of successful behavioural change.

9. The past behaviour analysis should be included when it comes to producing practical intervention methods

\section{FLOW}

10. Exercise games should provide a variety of difficulty level to match different individuals' physical strength

11. Behaviour changing games should create challenges related to real life scenarios that players will identify with

12. Young people prefer the game delivery format to all other prevention formats

13. The game should focus on triggering intrinsic motivation for exercise 


\subsection{Precedents Analysis}

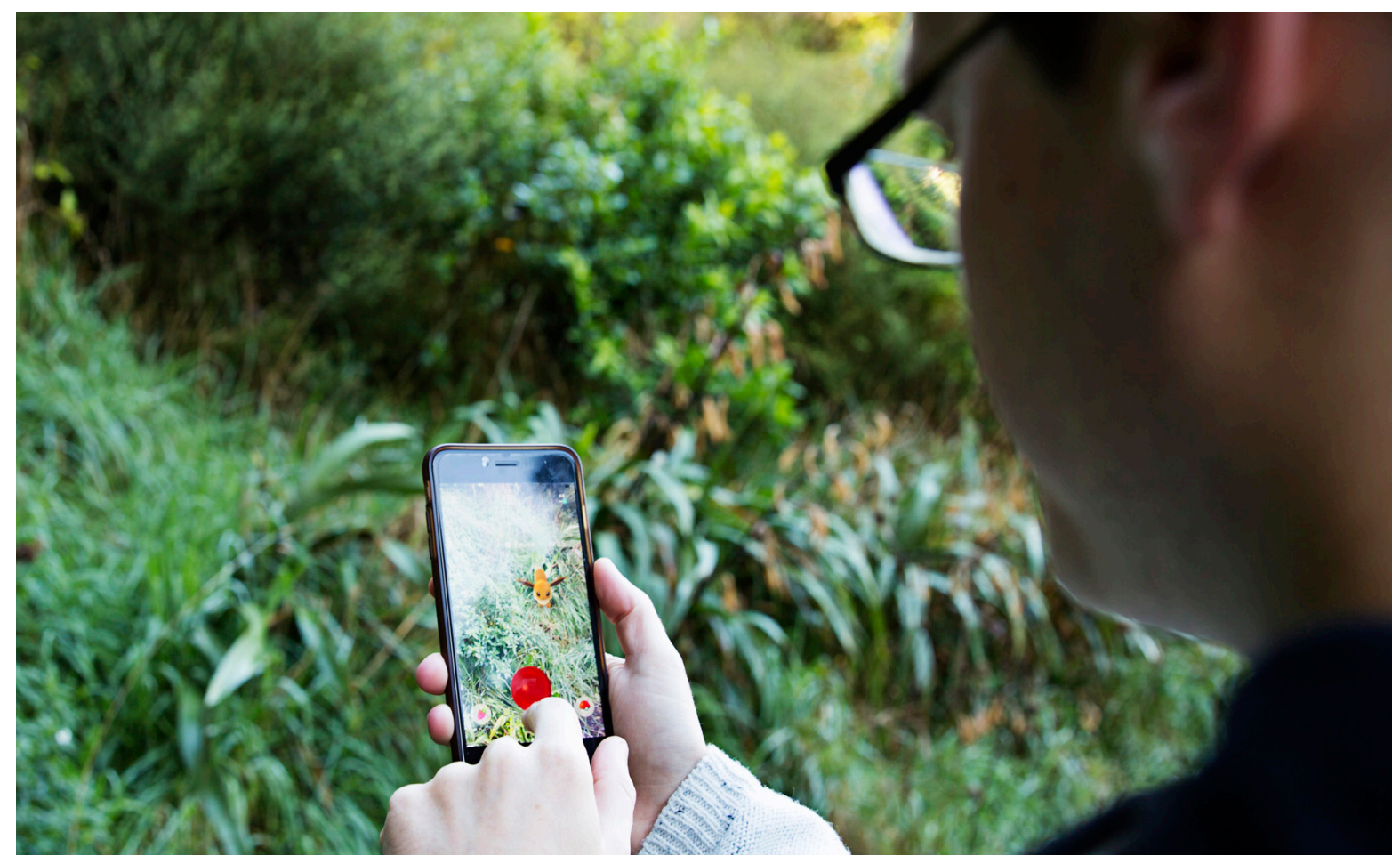

Figure 3.3. A player was playing Pokémon Go

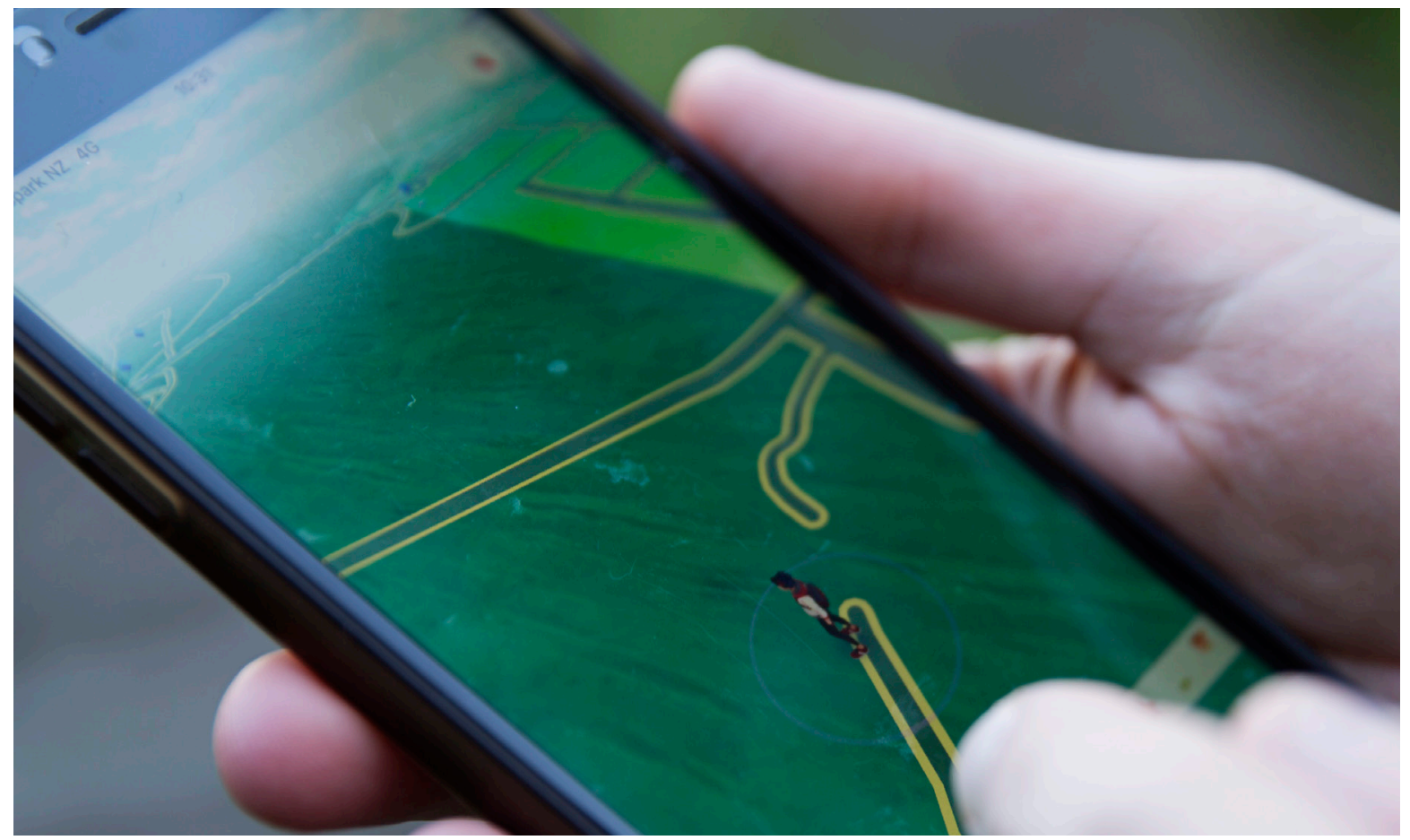

Figure 3.4. A player was playing Pokémon Go 


\subsubsection{Pokémon Go}

Pokémon Go is a location-based augmented reality game. Players use a mobile device's GPS to locate, capture, battle, and train virtual creatures called Pokémon. Critics praised the game for promoting physical activity and indirectly boosting local businesses' growth by increasing foot traffic. It also attracted controversy and criticism for contributing to various accidents, as well as becoming a public nuisance at some locations. It quickly became a global phenomenon in 2016 in spite of mixed reviews, and it was one of the most used mobile apps in 2016.

\section{Location-Based Quest}

The most prominent mechanic in game is that players can hunt and capture virtual creatures in real life locations. The game starts with a three-dimensional, informative, real-time map with augmented reality markers pointing to real-life locations. Pokemon will appear randomly on the map for a limited period of time. Players need to find the corresponding real-life location to catch and collect new Pokémon. The location markers (PokéStops) automatically calculate the distance from players and only allow them to collect virtual items such as: pokéballs, which players throw to catch Pokémon; potions, which players can use to heal the Pokémon injured in battles; incense, which players use to increase chances of encountering new Pokémon; revives, which players use for reviving Pokémon; lucky eggs, which increase experience gain. Pokéstops can also indicate spawns for rare Pokémon that attract players to walk or bike an extra distance to collect them.

I believe this is an effective incentive to increase physical activity. According to a study from the American Heart Association, Pokémon Go players are more than twice as likely to complete a goal of walking 10,000 steps a day compared to people who didn't play. The study also found people who got the least exercise at the start of the study achieved the most improvement once they started playing the game (Xu et al., 2017).

The game uses people's desire to explore the world, and complete their Pokedex, to keep players interested in the gameplay. According to TTM, people who take their own initiative to change their sedentary lifestyle are more likely to achieve behavioural change than people who are reluctant. However, some sedentary Pokémon Go players who do not desire to change their behaviour achieved a sharp increase in physical activity as a result of having fun collecting Pokémon. The game resituates the traditional virtual Pokémon hunt into the physical world by introducing an augmented reality user interface, which indirectly promotes physical activity. In the short term, it decreases the difficulty of promoting exercise among players by skipping the process of building up confidence and determination of changing sedentary behaviour. However, in the long run, Pokemon Go does not change the fact that players lack consciousness about changing their sedentary lifestyle and building up an active daily routine. Based on research from Fiona (2017), counsellors can introduce sedentary people to a more active lifestyle by using games as an interventional tool. According to TPB theory, an intervention should affect a player's attitude, his/her perceived social pressure on himself/ herself and his/her self-confidence in the long run (Khalil \& Abdallah, 2013). If players lose interest in the game, they will return to their previous inactive lifestyle due to lack of motivation. Inspired by Pokémon Go, I would resituate existing services and activity into an augmented 
Inspired by Pokémon Go, I would resituate existing services and activities into a gamified, augmented reality interface where human-powered transportation would be essential to fun. Traditional fitness applications use self-monitoring and social sharing as their main persuasive methods. For example, people share their photos of their body on social media to allow their audience to witness the transformation before and after their workout routines. It is a popular method that uses social pressure to achieve behavioural change. Young adults are spending more time on social media and it becomes a powerful influence to change people's behaviour.

\subsubsection{Habitica}

Habitica (Renelle, 2013) is a task management application that uses gamification as its core feature to promote behaviour change and self-improvement. This app differentiates itself from competitors by adapting the visual elements and game mechanics from an 8-bit RPG. the application automatically assigns each user an avatar with health and experience bars. Users can earn virtual currency through maintaining real-life goals, in the form of Habits, Dailies and To-Dos ("Improve Your Habits by Playing a Game". (n.d.).). When collecting sufficient coins, players may use them in exchange for equipment to increase the chances of winning battles. Winners earn loot boxes containing virtual armor and pets for their avatar.

\section{Habits, Dailies and To-Dos}

As illustrated above, users' real-life tasks (habits, dailies, and to-dos) are turned into 'little monsters" they have to conquer. When creating a task, users can choose between three types: Habits, Dailies, and To-Dos. To-dos are the tasks they will only accomplish one time. Inside the to-do table, users can also set checklists and due time to increase difficulty and productivity. Dailies are the tasks users have to finish by a deadline. Penalties will apply to users who have not accomplished their Dailies on time. In the end, Habits are the tasks that will be repeated multiple time on the long run without a s time limit or penalties when users fail to finish them.

\section{Guild}

The guild system is a feature that introduces social accountability into the game. A group of users can join in a guild to complete a task together. Users would collaborate or compete with each other to earn rewards and experience. For example, a group leader who creates a sequence of tasks can check the progress of each member of the guild and reward individuals who complete the tasks on time. If some members haven't finished his or her tasks on time, the group leader can motivate them by sending messages in the game. 
Gamifying daily tasks is an innovative way to encourage behaviour change. Schwimmer identifies goal setting (Habits, Dailies and To-Dos), self-monitoring (life bar, experience bar), positive reinforcement (Reward) and social support (Guild) as effective tools in weight management programs (Schwimmer,2004). I believe that this application's positive feedback from its users suggests the effectiveness of these tools. The wellbeing of the avatar is directly connected to how well the user has accomplished his or her tasks. The app employs users' empathy towards their avatar to encourage successful behavioural control and change.Guilds provide peer pressure which affects users' decision making. Users would be concerned about the judgement of their teammates and they may avoid failing their tasks.

By completing each task, users do not only acquire virtual rewards, they also improve their proficiency in certain activities, for example, eating healthy and exercising. However, Habitica does not include an effective method against users' cheating. The premise of Habitica is to help users learn good habits, not to stress users out and make them feel guilty. According to TTM (Prochaska, 2013), this app may be effective for users in action and maintenance stages where people have done specific overt modifications of their behaviour. These users keep track of their plans and keep themselves from constantly cheating in the game. On the other hand, people in precontemplation, contemplation and preparation stages still struggle to define their decisional balance (the pro and cons of behaviour change). These users are more likely to cheat and to quit the application due to the shame and lack of confidence in themselves.

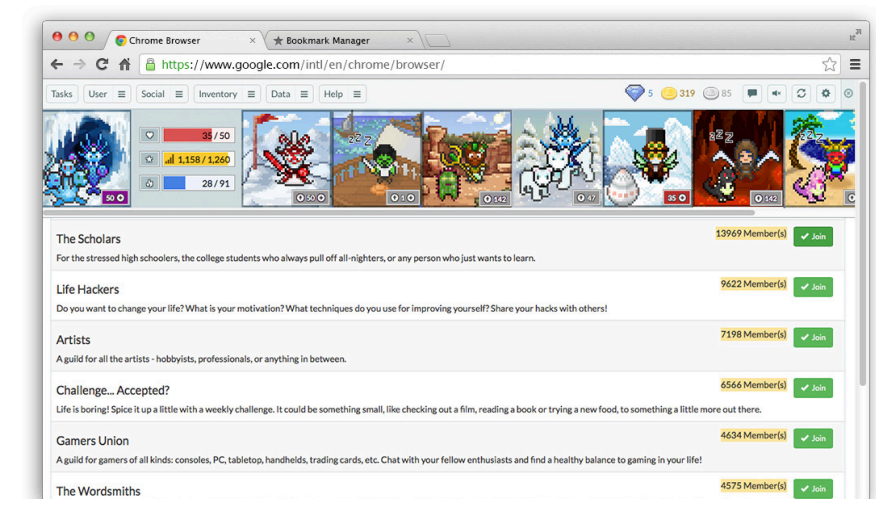

Figure 3.5. The guild page on desktop (Habitica press kit)

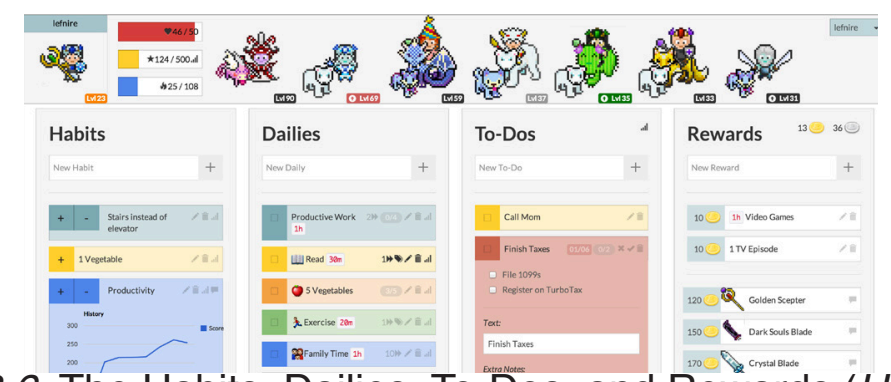

Figure 3.6. The Habits, Dailies, To-Dos, and Rewards (Habitica press kit) 


\subsubsection{Run An Empire}

Run An Empire (Hill, 2016) is a mobile game that challenges both the strength and brain of players. Players need to run (or jog/walk) around a real area to claim a realm in the virtual word. Their kingdoms are shown on an augmented reality map, where other players nearby can react to or even conquer their kingdoms. People can conquer others' countries by running around them multiple times. Similar to Pokemon Go, this location-based running game also uses geolocation as a prominent feature of the gameplay. However, unlike Pokemon Go, players of Run An Empire need to think twice before making a move on the map. Players should consider not only their strength but also a solid strategy for taking over others' kingdoms. Players run or jog around an area to mark their territory, and they can also run across others' land to make it their own. The more often the player moves around his or her acquired territory, the more difficult it is for others to take it over.

This application's mechanics remind me of a story written by Leo Tolstoy: How Much Land Does a Man Need? A famous scene from the novel is when a demon promises the protagonist that

"he can walk around as large an area as he wants, starting at daybreak, marking his route with a spade along the way. If he returns to his starting point by sunset that day, all the land his path encloses will be his, but if he does not reach his point of departure, he will lose his money and receive no property (Tolstoy, Maude, \& Maude, 2012)".

Figure 3.7. Lifestyle shot: app in use (Run An Empire press images, n.d.)

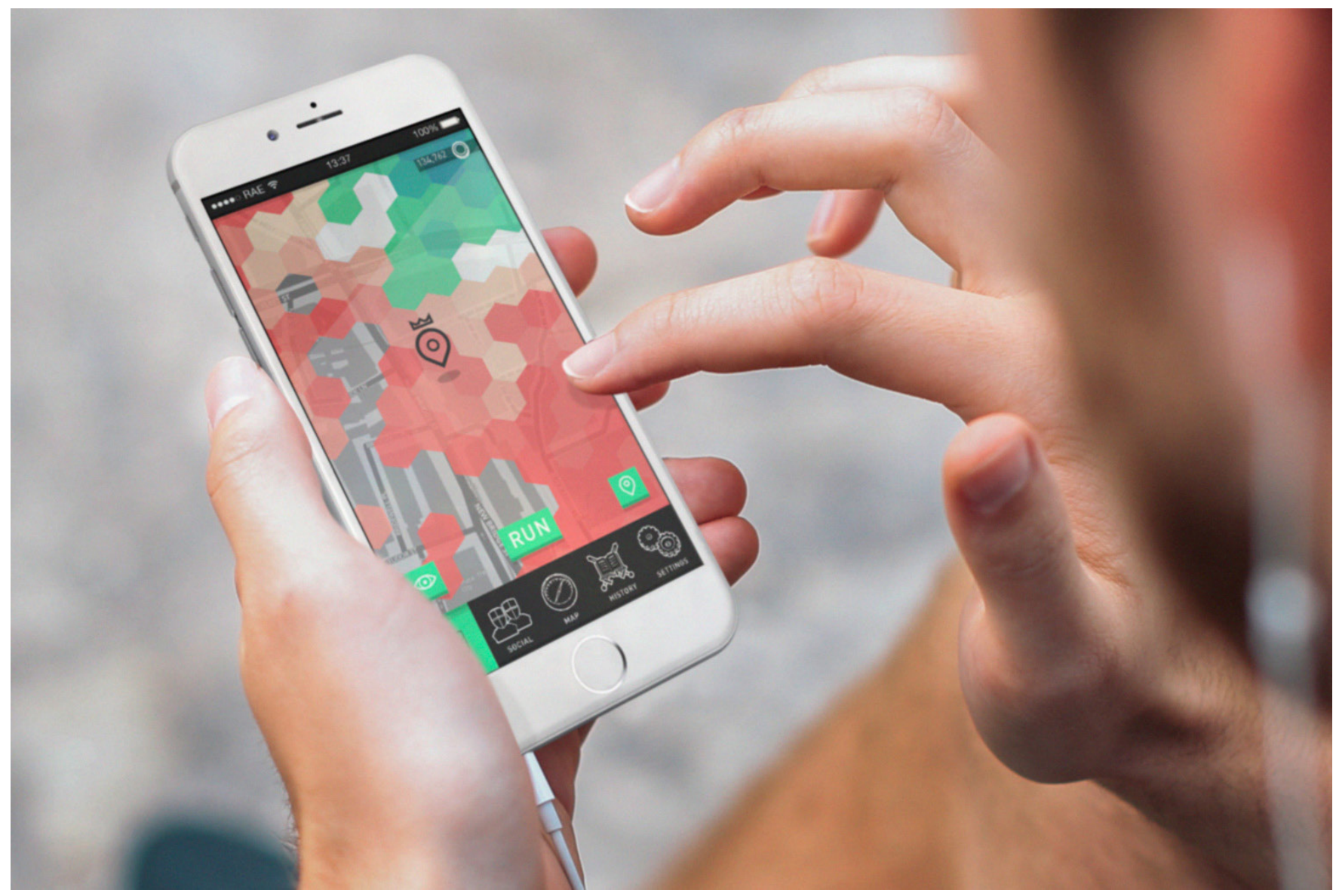


He walked as far as possible and marked out an area as large as possible. Near sunset, he realised that he needed to run back fast because he was far from the starting point. He finally arrived back just as the sun set and dropped dead from exhaustion soon after. In the end, the only land he got was a 6-foot long grave. Players' stamina and skills are crucial for growing his or her "kingdom". Therefore, players can monitor their self-efficacy level and make small progress each they play. According to flow theory:

Balance between the challenges of the activity and the abilities of the participant is necessary. If the problem is higher than the strength to solve it, the task becomes overwhelming and generates anxiety. If the challenge is lower than the ability, it provokes boredom (Jenova, 2006).

Run An Empire motivates players to run more by putting a massive number of players on the same map. No-one would own territory for long, and they need to push their limits to win. Players face more difficulties when they try to occupy larger territory. They need to strengthen their stamina to compete. Better stamina promotes self-efficacy. This positively affects people's sedentary behaviour (Khalil et al., 2013).

Figure 3.8. Game map (Run An Empire press images, n.d.)

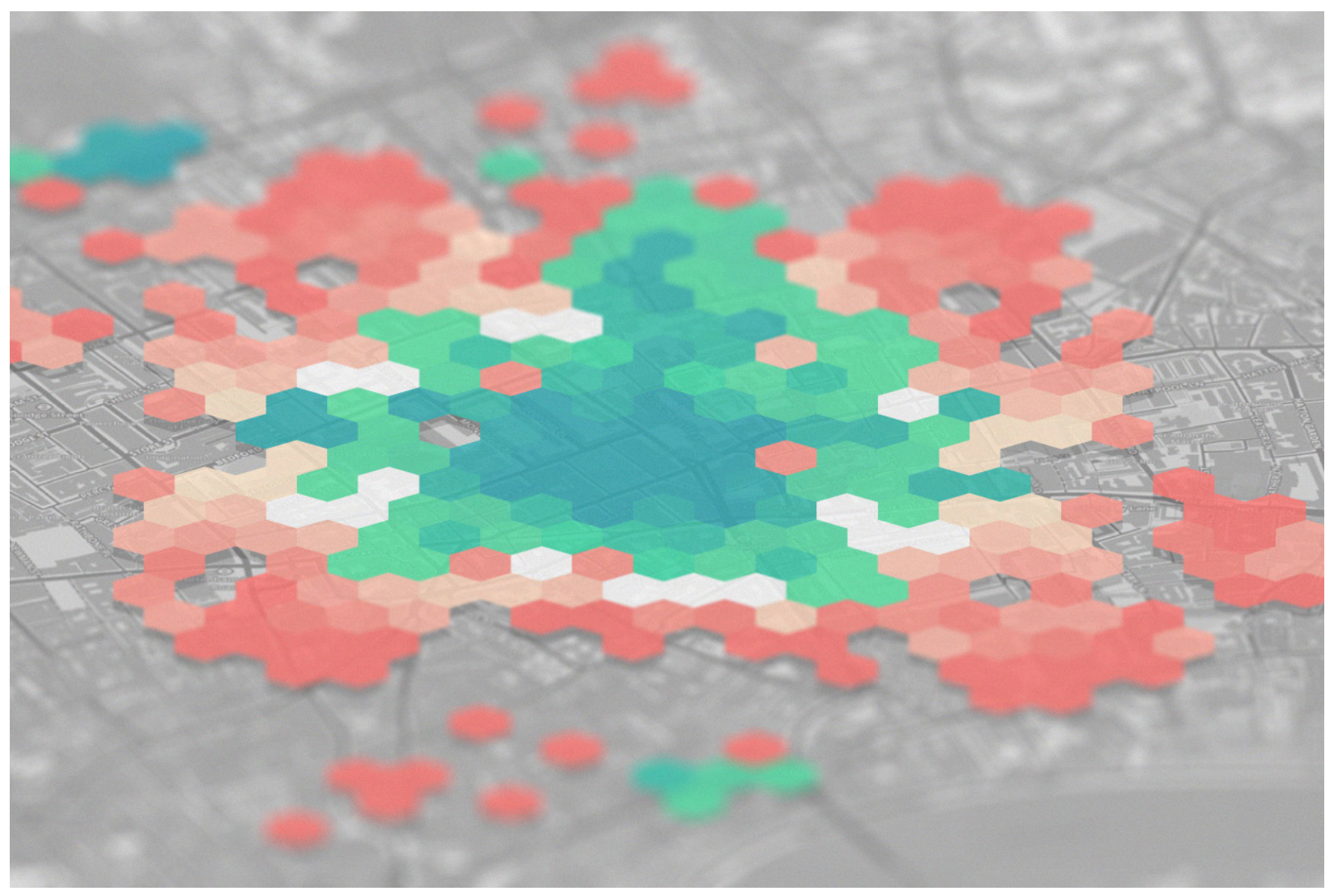




\subsection{Contextual Inquiry}

\subsubsection{Online Questionnaire}

I conducted an online demographic survey through Google forum and Facebook to identify the full spectrum of behavioural contexts in New Zealand young adults. I published this survey on public Facebook groups, and 15 individuals responded.

This survey investigated the usability of fitness applications for young adults. Despite the limitation of small sample size, the participants were anonymous and I only picked people aged from 18 to 40 (Kadam P, 2010). I later used the information and keywords from respondents to assess young people's preferences and expectations for a fitness app.

The questionnaire started by asking about demographics. Over $70 \%$ of the sample were between 20-30 years' old which fits the general definition of young adults. Every participant had access to a smartphone. $93.3 \%$ of the participants' physical activities were below the recommended levels of physical activity for adults aged 18 - 64 years according to the World Health Organisation (Global recommendations on physical activity for health. (n.d.), 2017). Almost $60 \%$ of the sample spent less than an hour on physical activities which echoes the literature review's conclusion that many young adults live a sedentary lifestyle ("The New Zealand Physical Activity Report Card For Children And Youth"). Over $70 \%$ of the participants considered improving their current health status, and $60 \%$ of them had used fitness or health applications before. Besides, $64.3 \%$ of the participants preferred a smartphone to monitor and motivate themselves to human company.

The questionnaire results showed that the main cost of changing current behaviour is making time and plans for exercise within an existing daily schedule. This finding also indicated that a supplementary workout plan may suit sedentary young adults. $53.3 \%$ of the participants believed that they need to improve their health, but $60 \%$ of them were not planning any daily exercise schedule. I identified these individuals were in the early stages of behavioural change. It was not surprising that a majority of the sedentary population were in the precontemplation and contemplation stages. They realised the benefits of changing their current sedentary lifestyle, but they were also conscious of the inconvenience as a result of changing their daily schedule. In most cases, the cons of changing overcame the pros which kept them in old habits (Glanz, 2008). The four things most respondents identified as obstacles to a workout plan were: 
1. I do not have enough time to exercise

2. I am too tired to exercise after work (study)

3. I am too lazy to exercise

4. I have no clear goals or directions for carrying out a workout schedule

From the survey, I inferred that participants need a workout programme that is not too demanding for their time and energy. They need to start gradually, and success will reinforce their positive thinking. This feature can be linked to flow theory where fun is generated through matching players' skills and confidence with challenges (Jenova, 2006).

The participants chose the following methods to motivate a consistent training routine:

1.Listen to workout soundtrack $(50 \%)$

2. Take a break before next session (28.6\%)

3.Share your progress with your workout buddies (28.6\%)

4.Rethink positive thinking $(21.4 \%)$

TPB may explain the third and fourth choices. The first choice was an interesting finding. One explanation is that the tempo of the music may help people to regulate their heart beats during physical activities (cite).

The survey also indicated the importance of social support, since $60 \%$ of the sample pointed out that lack of support from friends or families may make them discontinue their fitness plan. The result is displayed below:

1. You have planned the whole schedule by yourself and lack support from friends or families who have similar goals $(60 \%)$

2. You have few or no company during the exercise session to share your progress $(26.7 \%)$ 3. You find your current workout is boring and easy since workout plan is too sample (sic) and repetitive $(20 \%)$

After collating the keys words from the answers, I analysed the open questions and summarised the following keywords and guidelines.

\section{Positive}

Gamification, Schedule, Physicality, Maps progress, Motivation, Remind, Beautifully, Friends, Autonomy, Countdown, Indication, Achievements, Annoying notifications, Time effectiveness.

\section{Negative}

Not gamified enough, Boring, Too much [sic] functions, Bad UI, Not enough.

The two sets of keywords indicated what young adults expect from an ideal fitness application. After considering the findings from the previous questions, I made the assumptions below:

1. The application should make exercise fun instead of tedious

2. The application should include gamification that brings fun engagement between users and training

3. The application should clearly map the progress of the user and visualise it in a beautiful way

4. The application should give sufficient indications and reminders while also not annoying them

5.The application should have simple functions and choices that will not confuse users. 


\section{Conclusion}

The participants want a mobile fitness application with a gamified interface and a strong focus on social interaction. Furthermore, the primary behavioural change method in the design solution should avoid interrupting users' daily schedules. It should motivate users' social groups to support and drive positive behavioural change. The exercise should fit into young adults' schedule, and increase their physical activity progressively. According to the previous findings, the aim of the app is to improve users' self-efficacy level and slowly shift their attitude toward including a basic exercise routine in their daily activity. The UI should apply gamification by importing the metaphors in traditional game interface design into this application. In the end, the app should be generating a flow experience for self-training purposes.

The questionnaire copy and feedback can be found at Appendix 1 .

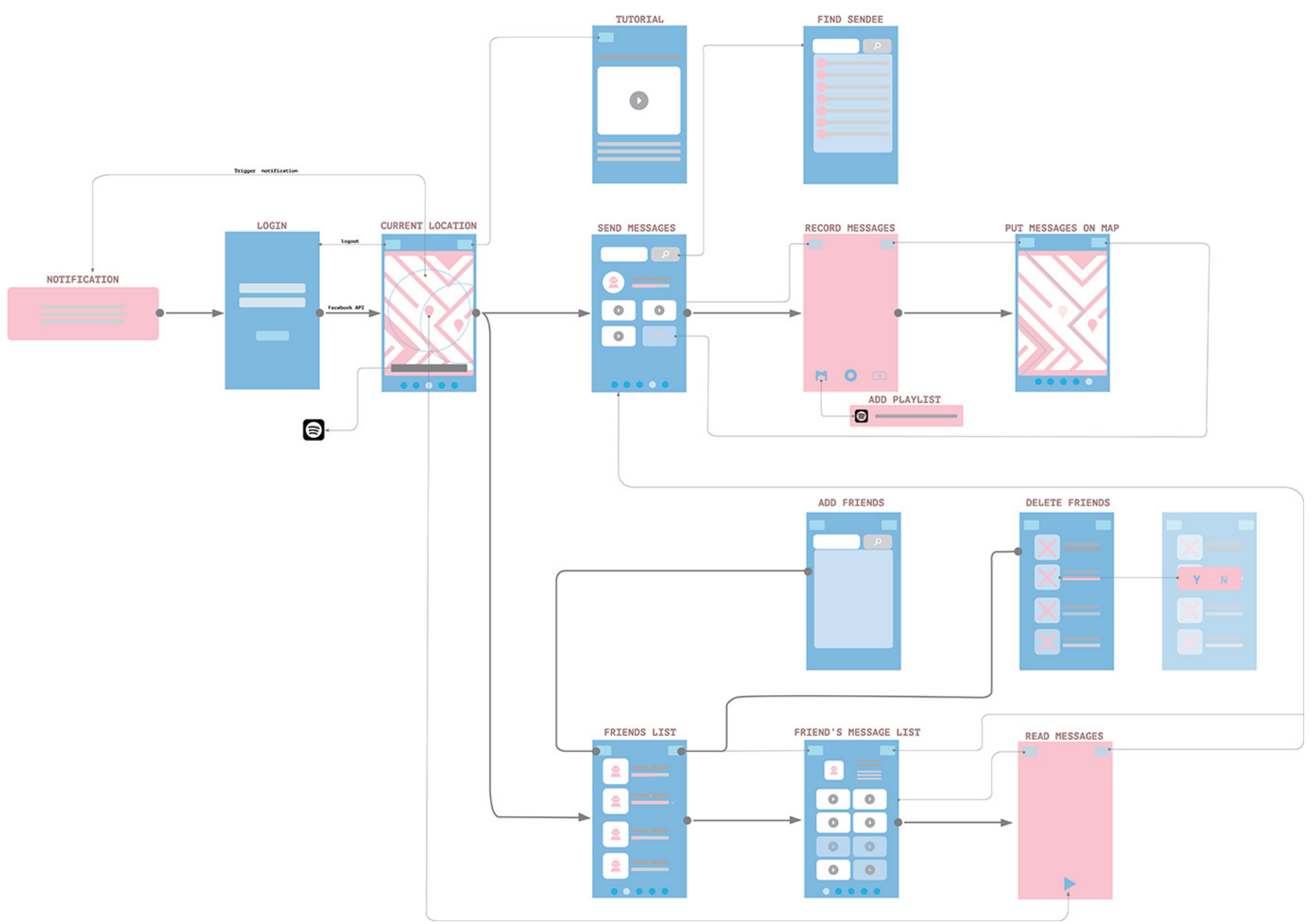

Figure 4.9. Flow chart of user joueney 


\subsubsection{First Iteration}

\subsubsection{The Wireframe and Drawings}

Based on previously collected material, I designed a mobile fitness application that could use people's need for social networking to promote physical activity. In the user interface design, I exploited young people's enjoyment of social media, and I shifted the virtual activity of posting and sharing into a physical activity. Users would have to walk or run a certain distance to read the posts sent by their friends, and they could also send messages to designated locations for friends to find and respond to. I drew the flowchart (Figure 4.9) to organise my ideas and apply collated information to the interaction design.

Users receive a notification when they pass by locations where unread messages sent from their friends are stored. Users automatically log into the home screen when they swipe the notification message and unlock their phone. They see a map that shows locations of nearby checkpoints. They can go to a marked location to receive and reply to messages. They can also navigate to a page where they can review their message history. They can send messages to each other and leave messages in certain locations for the recipients.

The aim of this feature is to use the social interaction between friends to increase their physical activity level unconsciously. The process of finding messages around a city is referencing the game mechanics from scavenger hunt. The surprise and fun of discovering messages from friends will keep users motivated and engaged. The app limits the area where others can leave messages. The area is defined by the recipients' previous daily activity. This feature increases the chance of generating flow experience for recipients. The walking distance will suit the stamina of the recipients. There is no limit on the format of the messages. Thus this app can be used for multiple purposes.

However, I needed to survey if the methods applied to Messagerunner could promote physical activities and change sedentary lifestyle into a more active one. I built a minimal viable product on Xcode (Version 8.3.3, Apple, 2017) to test the feasibility of this design solution.

At first I created low fidelity wireframes (Figure 4.10, Figure 4.11) to iterate through many design options. In the process of wireframing, I tried to identify the basic UI elements and functionality I needed for this iteration. I decided to make a fictional scavenger hunt system, which allows users to find messages in Wellington city.

When players open the app, they will first see the home screen: A map showing their current location and the locations of hidden messages. If they click the marker representing where the message is, they will see a small clue about what this message contains and the sender's name. The player has to go to the maker's location where they can scan to read the full message. This application motivates physical activity as an indirect result of socialising and conversing. It will appeal to people in precontemplation and contemplation stages. These people lack the motivation to change their sedentary behaviour. As for people in the preparation stage and above, this would be a great supplement to increase their physical 
activity. By involving friends and family members in the process, the application can improve the user's health through self-liberation and social liberation. There is no limit on when the user has to collect messages. This flexibility allows young adults who are occupied with busy schedules to make time to exercise.

I designed a placeholder of the friend list page to illustrates how users can track their activities or interact with others. When a user has read a particular number of messages from another user, a mystery message will unlock as a reward to encourage a positive attitude towards collecting messages. On the other hand, if a user does not read many messages from another user, he or she might assume that other user feels disappointed or ignored. The user may feel guilty. This social pressure might increase the chances of successful behavioural change.

When it comes to sending messages to a certain user, the application would record this user's past activity and map the active area on the map. The system would automatically draw a reasonable size highlighted area for the user's friends to place messages. The challenges and a user's strength should be matched to create a flow experience, and the past activity is a great indicator to anticipate a user's present strength.

The following example illustrates a typical real life scenario. When a user walks to school on a daily routine, they receive a notification about a nearby message sent by their friends. Since the location is not too far away and it is in the same direction of the school, they will change their routine to walk a bit longer than usual to get the message. It is a typical that people get distracted by things that interest them on the way to a destination.

Behaviour change is a long process. This application focuses on shifting the focus from promoting exercise to promoting social activity as a means to exercise. This is crucial for people in the precontemplation and contemplation stages. Users will focus on getting rewards and enjoying finding them. Eventually, they will come to a stage where they want to change their previous sedentary lifestyle and start a new more active one.

Based on the wireframe, I chose to develop a minimum viable product (MVP) on IOS platform. Due to restrictions on my time and knowledge, I could not build a location-based real-time database. I decided to make a cloud-based website that users could access by scanning QR codes. I created website pages through Skeleton (Version 2.0.4, Skeleton, 2017) framework and uploaded them to the server of Surge (a web publishing platform). I later generated QR codes through online generators and printed them on waterproof sticker paper. I put various markers in different locations in the city for users to scan with their cellphones. 


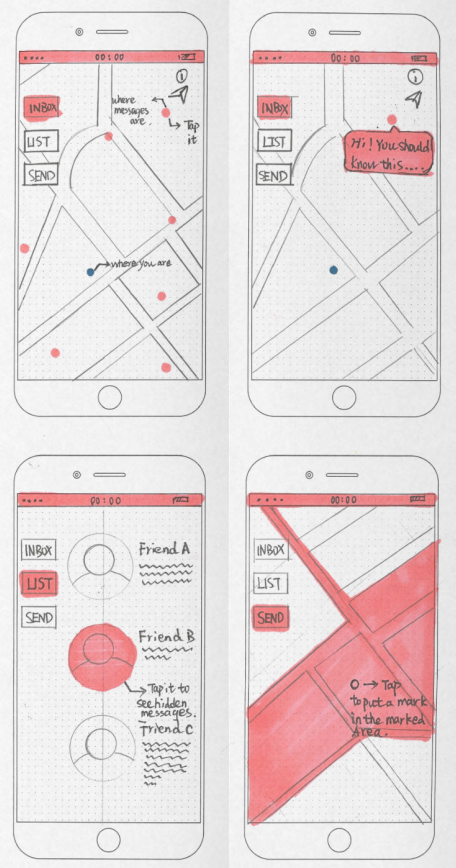

Figure 3.10. Low fidelity wireframes
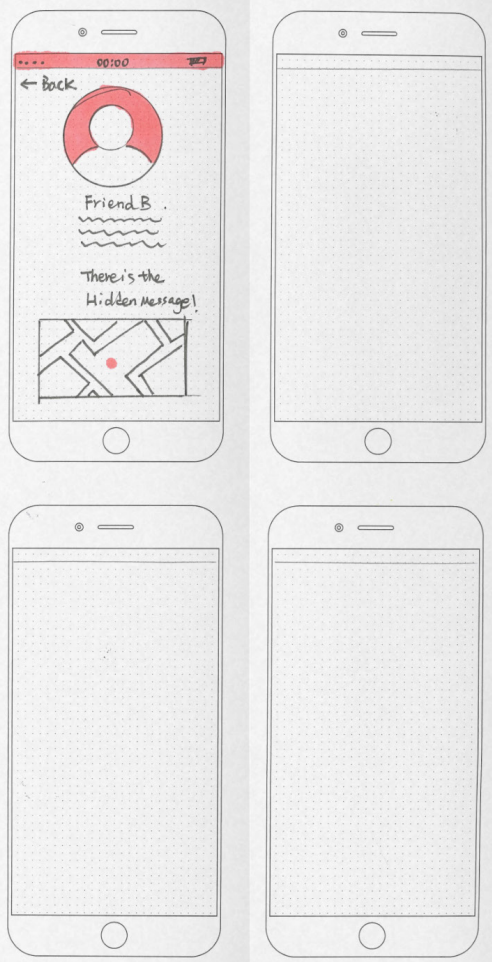

Figure 3.11. Low fidelity wireframes 


\subsubsection{Swift MVP and QR Code Scanner}

I used Mapbox Studio (Version v0.38.0, Mapbox, 2017) to generate a customized map, using green and blue as main colours. I later installed this map in my application.

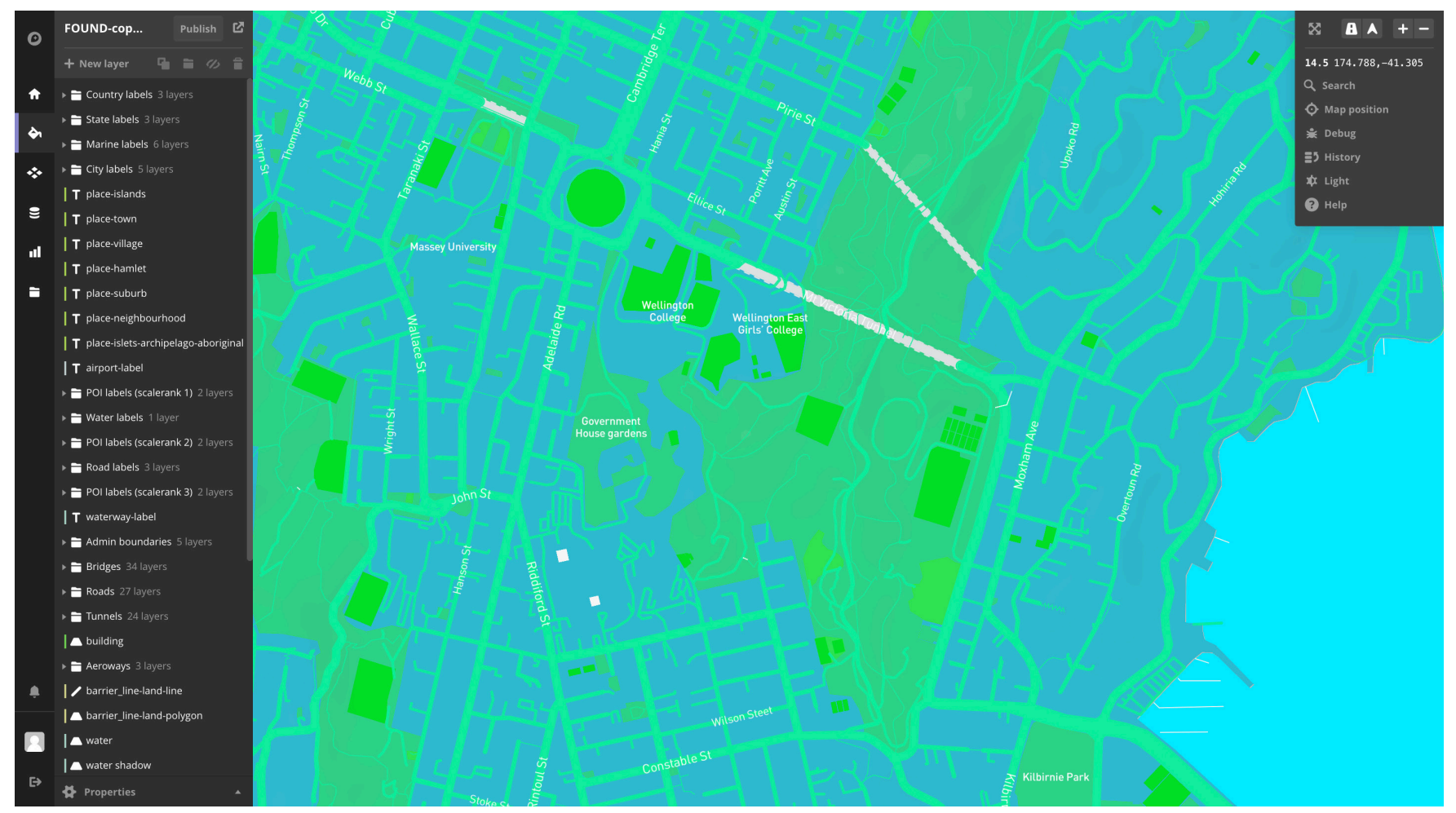

Figure 3.12. Screen shot of Mapbox Studio 
Figure 3.13. Inbox page

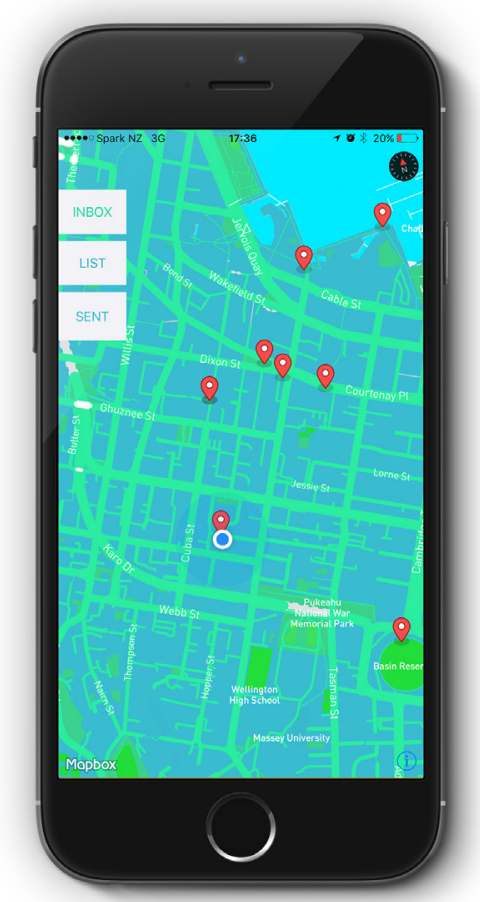

When a user enters the inbox screen, they will see the locations of messages nearby.
Figure 3.14. A hint appears

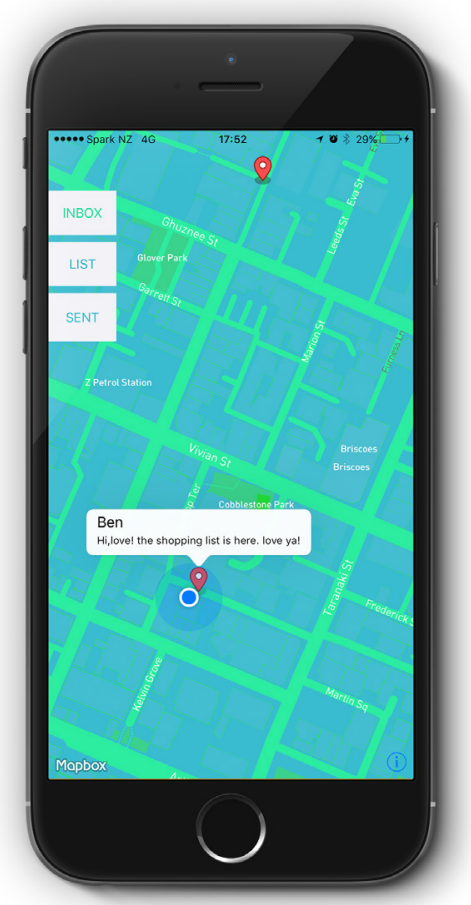

Long press a location marker, and an abstract will appear which gives a hint about the hidden information.

Figure 3.16. Hidden message page

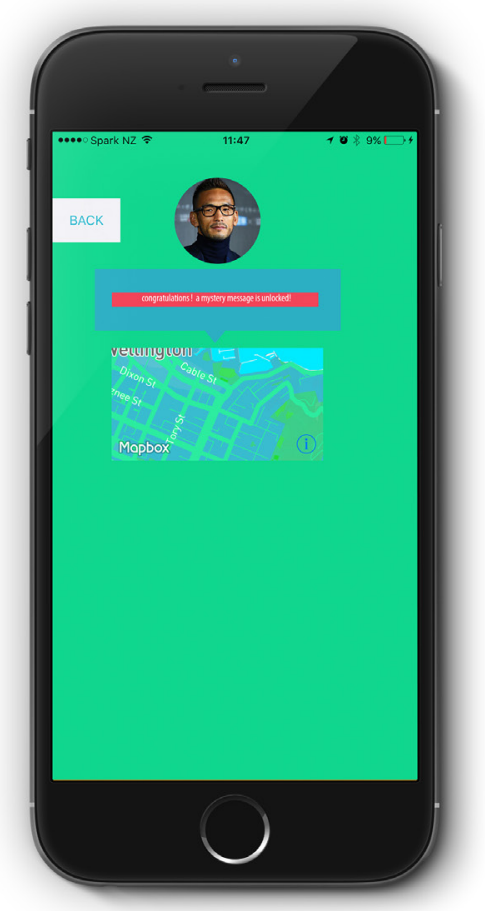

On the list screen, a user can review the message history and sent messages.

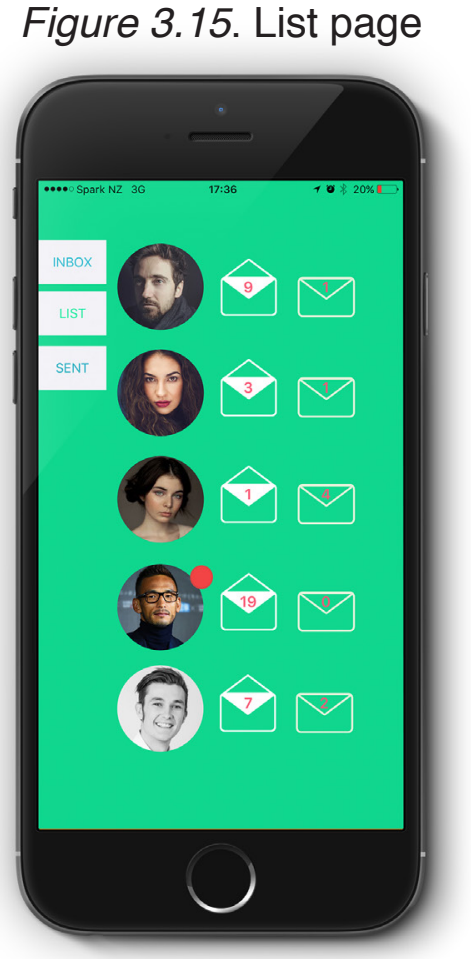

When a user has received a certain amount of messages from one user, they will be able to unlock a hidden message. 
Figure 3.17. Sent page

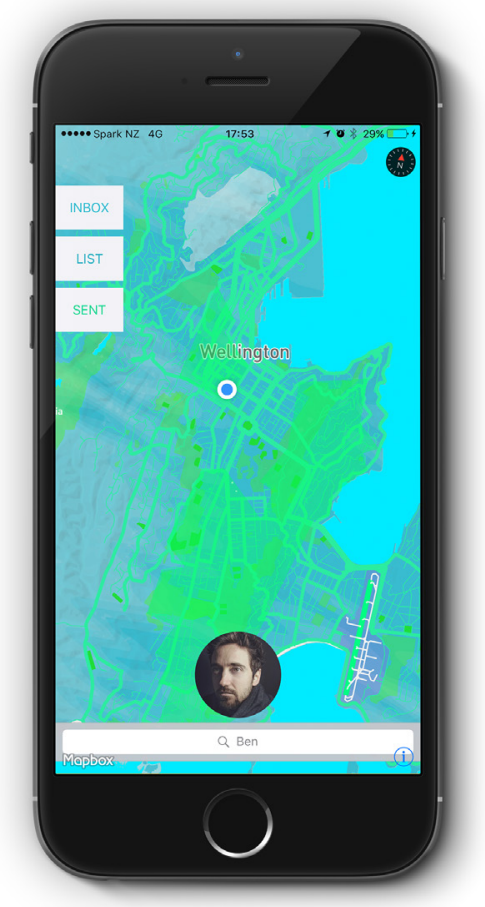

Open the sent screen, and a user may see a map where they can drop a pin.

Figure 3.19. Scan QRcode

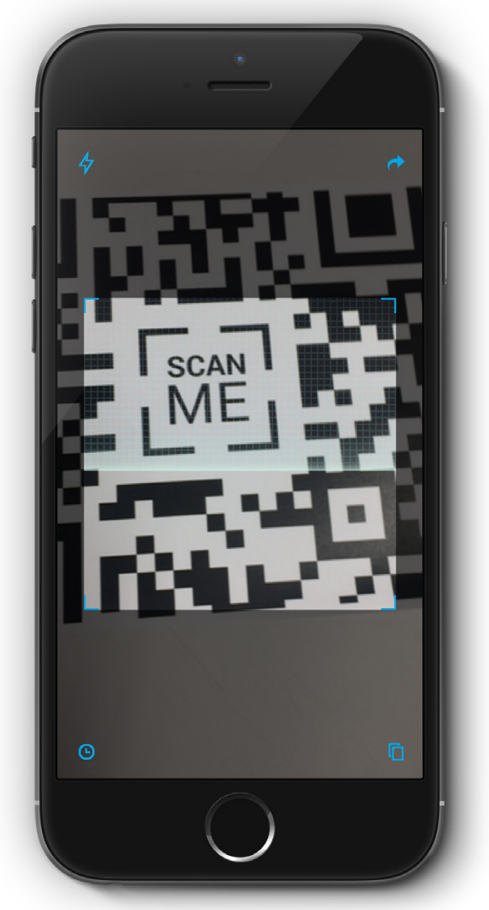

When a user comes to the location marked on the map, he or she can find a QR code to scan.
Figure 3.18. Green area for dropping pins

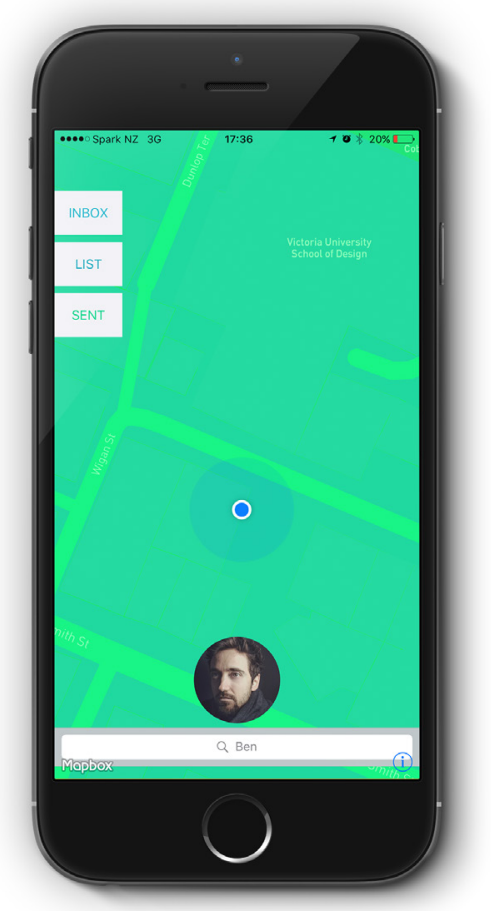

Each user has a unique map which marks their daily activity zone green. Others can drop messages within the green zone.

Figure 3.20. message page

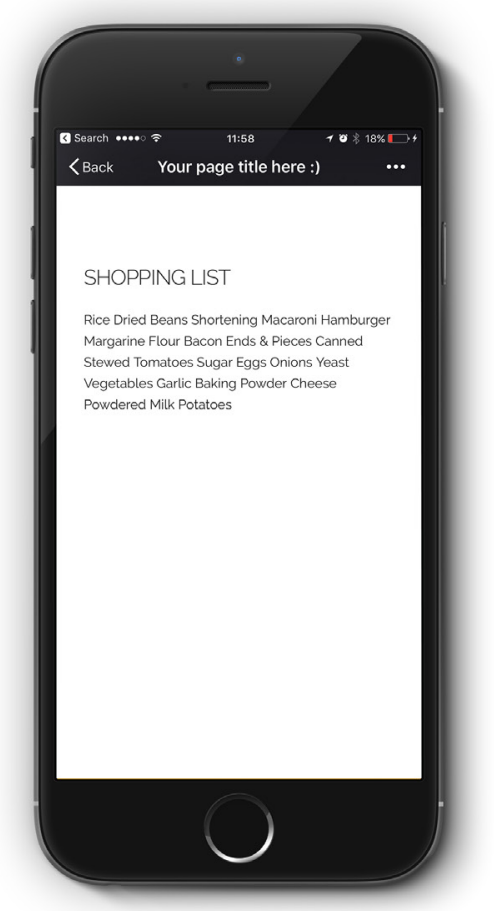

After scanning the sticker, a message will pop up and show the message. 


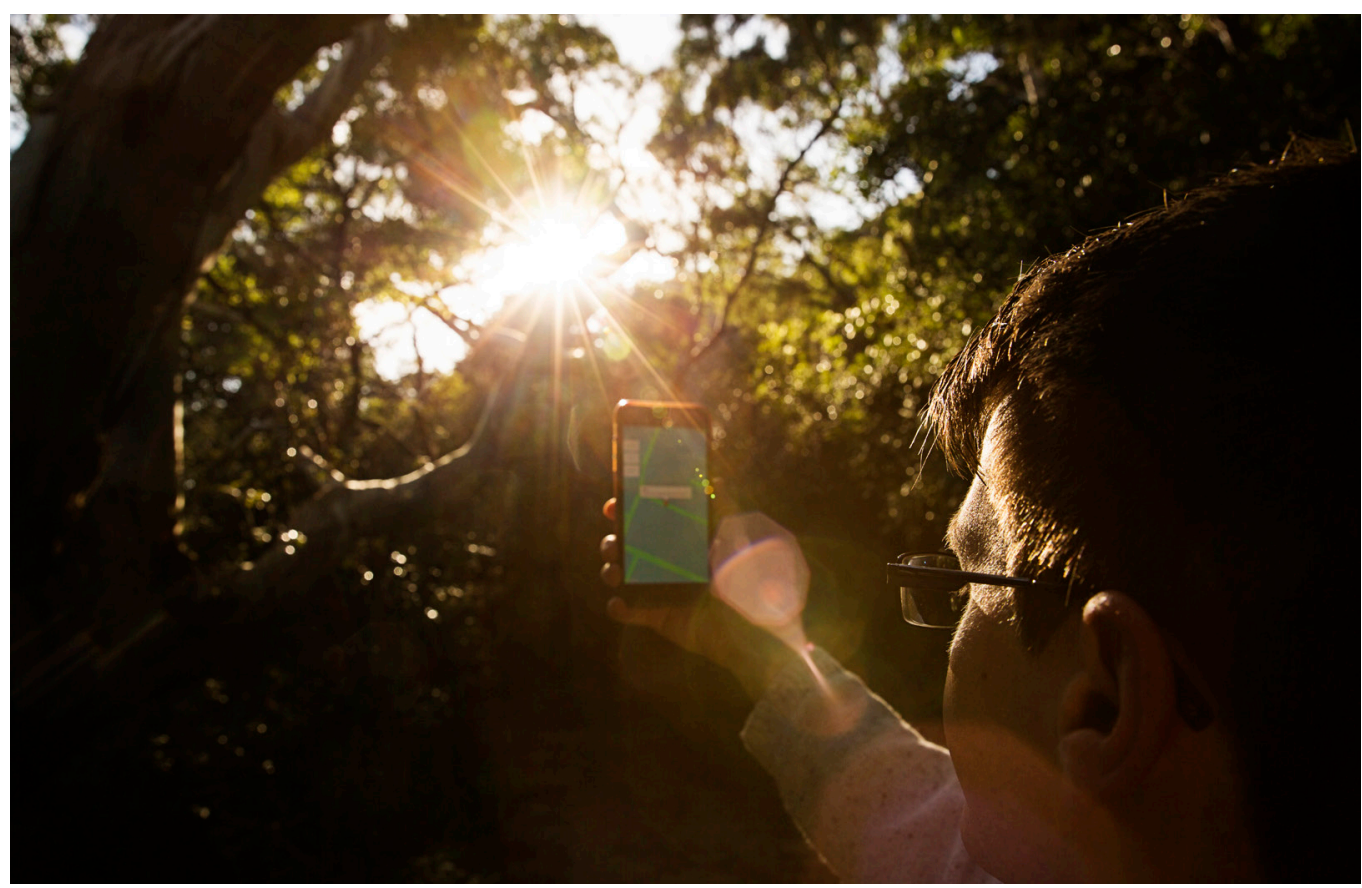

Figure 3.21. A user testing the MVP

\subsubsection{Contextual Interview}

I chose to recruit students in my design school so that I could easily observe them in their work space. I posted information online and requested their permission to conduct the testing and follow-up interview during their working hours. After getting consent from each participant, I observed them and conducted semi-structured interviews while they were using the prototype. The interview focused on how the users reacted to the design solution. After a half hour oneon-one testing session, I summarised the results of the testing in a table. I carried out six contextual interviews. The summary and findings of this research follows.

Here is a table of all six participants' interview feedback. I summarized and categorized their comments in different sessions as below.

\section{Colour scheme}

Participants gave positive feedback on the colour scheme. Most of them thought the green and blue colour was relaxing and that it motivated them to do more exercise. However, some reviewers thought that the text colour was too subtle and it confused them. The overall UI colour lacked contrast.

\section{Navigation}

Participants were confused at the start of the testing because the map was lacking navigation and tutorials to explain the function of the buttons and markers.

\section{UI}

Most users were confused and doubtful about the UI design. At first, the interface was different from existing IOS heuristics. The upper left navigation was different from bottom taband it was hard to tap on the button when users tried to operate the app with one hand. An interviewee also pointed out that the buttons and UI elements were not clear and accurate, which was uncomfortable. 


\section{Motivation for Exercise}

Most interviewees believed the application could motivate them to some extent. However, one interviewee explained that the application would not make her exercise because she was not planning to change her sedentary behaviour. She said that "she isn't a sports person and she will only do sports if this will help others as a result". Others were more concerned that there would not be enough other users to provide social support. Some interviewees also said that the application could offer challenges to motivate them to do exercise and keep them hooked.

\section{Motivate Others}

Most interviewees thought it would be interesting to use this application to send challenges to their friends even without intending to promote exercise. They also mentioned that the application needed a way to compare friends' status, encouraging them to compete with each other. The app's popularity and the size of its user base are what will motivate people to use it. People will only use the app if sending messages through it becomes a social norm like Facebook or Instagram.

\section{Gamification}

Interviewees said that the app was not gamified enough. The app needed a status bar to show a user's progress and awards. Users need to be able to compare progress.

\section{Interaction}

Users said the app lacked fun micro-interactions. One user said it was not "juicy" enough. The app did not have a notification function. Users had to check their location from time to time to find out where they were and if there were messages nearby. The messages on the map also needed markers and classification to make it easy for users to navigate.

Overall, the interviewees felt positive about the app's concept: Wander around cities and gather messages from friends. Most of them mentioned that they would like to use this app if their friends were using it at the same time. This raised my concern about how to distribute the app, because one of the core motivators in this app is social pressure. This app needs a large user base to succeed. However, this research does not focus on marketing and distribution. I will not discuss the solution to this issue in this paper but I am open to solving it in the future. Based on previous research, this app would eventually boost users' self-efficacy and trigger a positive attitude towards exercise.

From the feedback on the first iteration, I identified the improvements needed for the second, and I categorised them.

1. The screen where people send messages should provide more guidance to users. For example, people could choose different themes for their messages.

2. The daily activity zone should not be a hard limit on the freedom of users to set their markers. For example, people should be able to set markers on unexplored areas, even on the ocean to challenge each other

3. The app should use vibrations and notifications to indicate a user's location instead of making them check the map constantly

4. The app should be more fun (micro-interactions, and "juiciness")

The design should apply UI heuristics from iOS designer guidelines.

Appendix 2 is a table of all six participants' interview feedback. 


\subsubsection{Second Iteration}

The second iteration should focus on improving usability and UI based on feedback about the previous iteration. Due to the constraints on this study, I could not develop complicated functionality and build a matching real-time database for this app. Instead, I made an interactive mockup that vividly described the user's journey, and conveyed all of the basic functionality in Messagerunner. Since it was not a functional application built in iOS, normal participants may not give constructive suggestions. They may even feel confused about the lack of functionality. To compensate for this, I decided to carry out a contextual inquiry on UX professionals who have years of experience. Their expertise from working with static prototypes and mockups give them an edge in spotting usability issues and design problems. I used Framer (Version 94, Framer, 2017), which is a prototype tool that applies customized interaction to static UI components. I also used Sketch (version 44.1, Sketch, 2017) to generate static graphics for the UI components.

\subsubsection{Mockup}

In response to feedback on iteration one, I made the following changes:

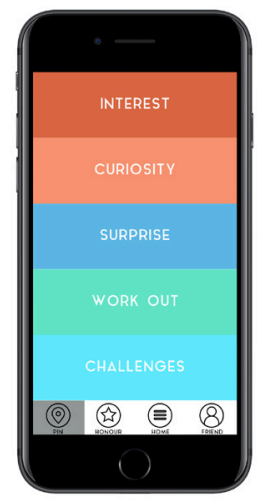

Figure 3.22. Pin page
1. The chosen locations should provide more extended purposes other than collecting messages. For example, people can set the locations according to the interest of recipients, which intrigues the internal motives. I set up a new tab called "Pin" on the menu at the bottom of the screen. Here, users can choose a theme for their message before "pinning" it to a location. The Pin tab features a collection of colourful buttons for themes. This tab should add diversity to messages and guide users. Recipients can see different coloured pins on their map depending on the chosen theme. They can plan their routine according to their preferences. For example: John sends a message containing information about a painting and he pins it to an art gallery under the "Interest" theme. Heather is interested in art, so she feels motivated by her hobbies to go to the gallery and check out the message. 


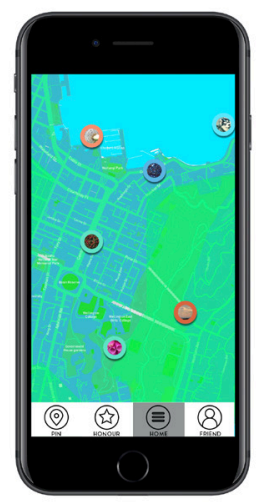

Figure 3.23. Home page

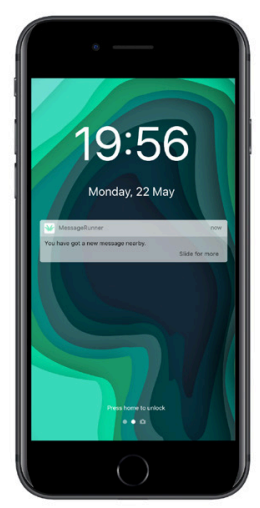

Figure 3.24. Lock screen notification
2. The daily activity zone should only be a reference insteading of limiting the freedom of users to set their markers. For example, people can set markers on unexplored area, even on the ocean to challenge each other. I kept the original map from the first iteration however I changed the default iOS location marker into a customised pin icon featuring a profile image. Pins vary in colours based on the themes users have set. Allowing profile images on pins encourages social interaction, as users can see who is pinning messages where. Unlike the previous design, users had the freedom to put pins anywhere to challenge each other. On the top right of this image there is a marker placed on the ocean. The recipient must swim or kayak to that place to check the message. This change could be motivative people who like challenges and exploration.

3. The application should use vibrations and notifications to indicate the location of users instead of making users to check their locations on the map constantly. I found out that a location-based push notification was too demanding of my time and resources. This feature requires that my app implement geofencing. A geo-fence a virtual geographical boundary using real world geography taken from a global positioning system (GPS) or radio frequency identification (RFID) (Rouse, 2017). To use this technology, I would have to build a real-time database that can store the locations of each individual Messagerunner user. After a user pins a message to a location, the database will set up a trigger. When a device that matches the data of the recipient appears within the pin's boundaries, the database will automatically send the stored message to the device alongside an alert. Because I lack the resources to build such a real-time database, I decided to use a static mockup to guide my interviewees through the app's UI and features. 
4. The design of the app should include juiciness (micro-interaction) and fun elements.

To add more fun to the app, I added more vibrant gameplay elements. In the honour page, I introduced a ranking system. Players would be awarded with stars, moons, and suns when they complete various tasks: After Heather walked an estimated 100,000 steps, she received an alert telling her she had earned a star. The star medal unlocked and appeared in a tab on her screen. Later, she had collected four stars, and this unlocked a moon medal. Finally, when she had earned four moon icons, she unlocked a sun medal, and so on. The more steps Heather walked, the more medals she collected. She found collecting medals satisfying, and other players could see her achievements on her profile page, which motivated her to the keep using the app. On her friends' list, Heather could also compare her achievements and recent activity to those of her friends.
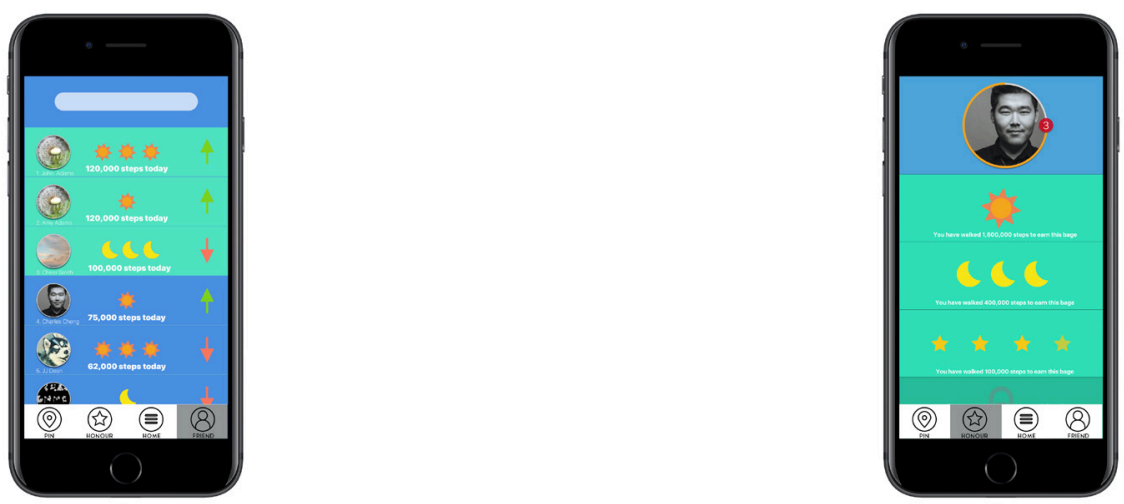

Figure 3.25. Friend page

Figure 3.26. Profile page 
5. The design should apply UI heuristics from iOS designer guidelines(Apple. (n.d.).). I made the following UI design adjustments according the iOS human interface guideline to generate an intuitive user interface design. 


\subsubsection{Contextual Interview (Appendix 3)}

I conducted four interviews with industry professionals. Here is a summary of the interviews.

The bottom tab bar design does not quite fit the industry standard:

- The home page button should be on the far left or in the middle of the tab bar. Since there are only four tab buttons, the home button should change place with the pin button.

- The icon for the home button is not appropriate. The hamburger button or hamburger menu is placed typically in a top corner of a graphical user interface. It usually navigates to a settings page. Users will feel confused when the hamburger button takes them to a home page and not to a settings page.

- The name "pin" is not clear for users to grasp. This page is about users sending messages to each other. The name should match the functionality.

- The "honour" button should be named "award" with which users are familiar.

The app needs a visual direction:

- The tab bar should have a matching design for the content of this app. This current design looks more like a wireframe.

- Different pages should have a consistent theme and design.

- The UI lacks a focus, and the colour scheme is too crowded. The colours don't work well together and don't define a clear theme.

- Icons in the app should match the content that they represent.

The app lacks usability:

- There should be notification tags on the bottom tabs.

- The honour content is hard to read.

- The app itself needs more sub-navigation at the top to show user status and to allow easy exit from the current page. Users get lost on some pages where they have to go back to the home page to exit.

- The swipe action is not too appropriate on the pin page.

- More easy access to documentation and tutorial.

- On the message page, there should be an exit button at the top right of the screen. The search bar at the top should not be there in the first place.

- The app should give people a sense of delight. The pins on the map should automatically pop-up and show people so that people can locate them and see how far away they are.

- The messaging page does not have a send button. If I typed the wrong message, I could accidentally send it by mistyping on the keyboard. 

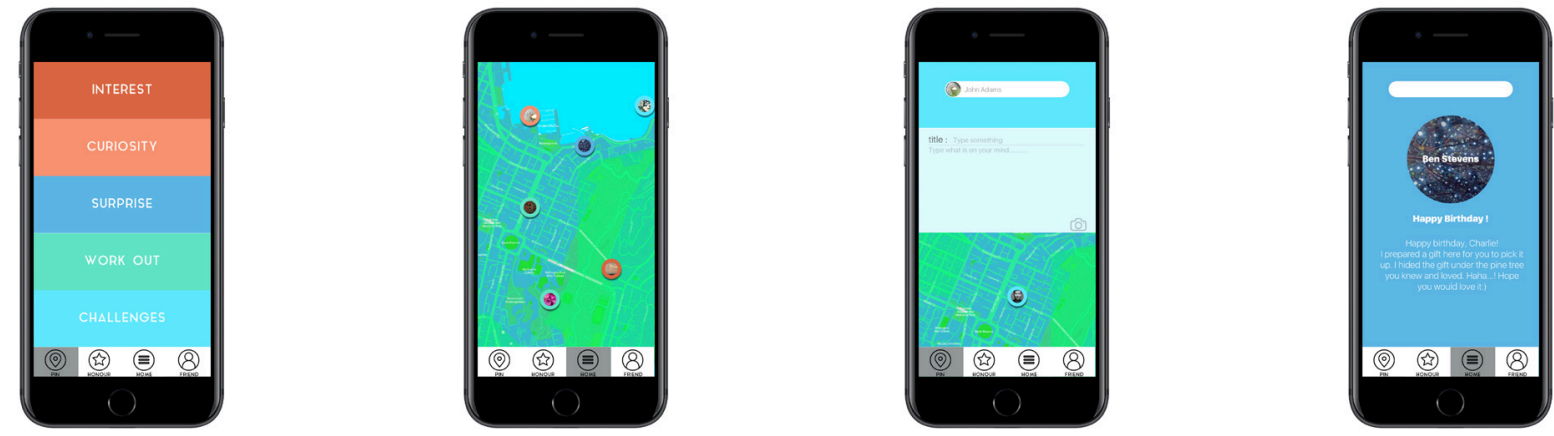

Figure 3.27. The unmatched design

Figure 3.28. The problematic navigation

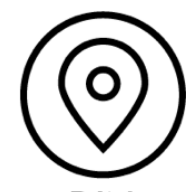

PIN

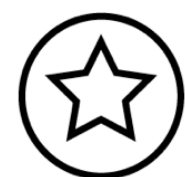

HONOUR

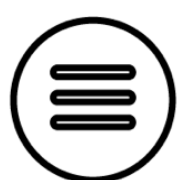

HOME

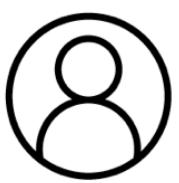

FRIEND

Figure 3.29. The Tab bar design

\subsubsection{Conclusion and Iteration}

The second iteration got great feedback from industry professionals. I found I could improve the usability of my app by working on the following areas: navigation, aesthetic, and consistency. The participants thought it was innovative and original to design an app using gamification theory to intervene against sedentary lifestyles. However, they also showed concern about the details of the UI and the overall usability of this app. 


\subsubsection{Third Iteration}

After the previous two iterations, I came to the final stage of my design process. The design documents for the third iteration follow.

Messagerunner is a geolocation-based social app that promotes physical health through gameplay. Users who share mutual friends can set up a quest like in a traditional board game. Instead of drawing dots on paper, users can set checkpoints in physical locations and store important messages hint at the next destination. Users can write motivational messages or parts of a story at different checkpoints to keep the process intriguing and fun. The first person who finishes the quest will collect a virtual award when they get to the final location. The app will store this journey in a memories tab that shows how many trophies they have earned. Users will achieve health benefits and break out of their comfort zone to challenge their sedentary behaviours.

\subsubsection{Colour Scheme}

Since this app aims to make exercise fun, the aesthetic is nostalgic and quirky. Users will quickly see the resemblance between the app and a traditional board game. I chose green as the dominant colour since both genders like it, and it represents health, tranquility, and nature. This should trigger users' instinct to explore and have adventures. I used green in both of my previous iterations, and I got positive feedback from the interviewees. I chose "\#62e494" as my theme colour, and I picked up the following colours as my colour scheme.

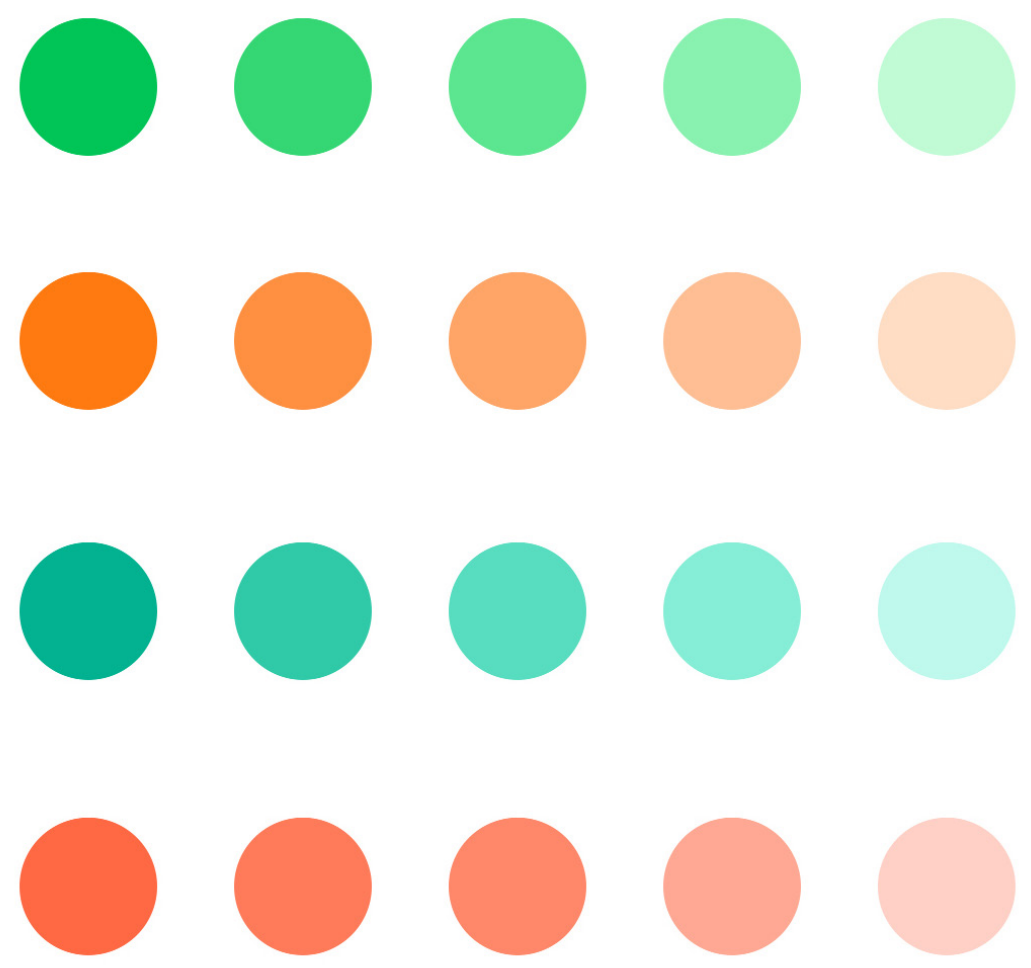

Figure 3.30. The colour scheme 


\subsubsection{Typography}

I want this application to have give people nostalgia about playing board games when they were kids. I used Kabel, a sans-serif typeface designed by German designer Rudolf Koch, as the main typeface for the app. This was the font used in classic board game Monopoly. I used this font in my logo design and the text of the app. However, Kabel is not suitable for paragraph text. I used Futura as my display font. Futura not only shares a similar geometrical structure with Kabel, but it also looks efficient and forward. These two fonts bring consistency and a board game aesthetic.

\subsubsection{Icons}

To unify the Ul's theme, I customized an existing iOS icon set. I aimed to make them fun, adopting a medieval RPG theme.
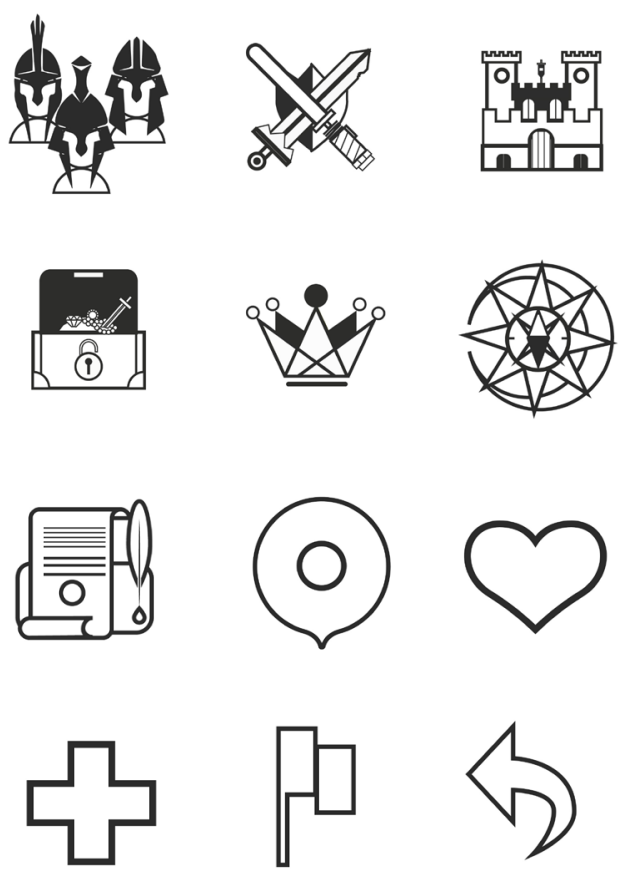

Figure 3.31. Icons in app

\section{kabel/futura}

$\mathrm{a} / \mathrm{a} b / \mathrm{bc} / \mathrm{c} \quad \mathrm{A} / \mathrm{AB} / \mathrm{BC} / \mathrm{C}$

$d / d e / e f / f \quad D / D E / E F / F$

g/gh/h i/i G/GH/HI/I

$\mathrm{j} / \mathrm{i} \mathrm{k} / \mathrm{k} \mathrm{l} / \mathrm{l} \quad \mathrm{J} / \mathrm{J} \mathrm{K} / \mathrm{KL} / \mathrm{L}$

$\mathrm{m} / \mathrm{m} \mathrm{n} / \mathrm{n} \mathrm{O} / \mathrm{o} \mathrm{M} / \mathrm{MN} / \mathrm{NO} / \mathrm{O}$

$p / p q / q r / r \quad P / P Q / Q R / R$

$\mathrm{s} / \mathrm{s} \quad \mathrm{t} / \mathrm{t} \quad \mathrm{u} / \mathrm{u} \quad \mathrm{S} / \mathrm{S} \quad \mathrm{T} / \mathrm{T} \quad \mathrm{U} / \mathrm{U}$

$v / v w / w x / x \quad V / V W / W X / X$

$y / y z / z \quad y / Y Z / Z$

Figure 3.32. Typography in app 
Figure 3.33. Drawing of the journey when the user first logins the app

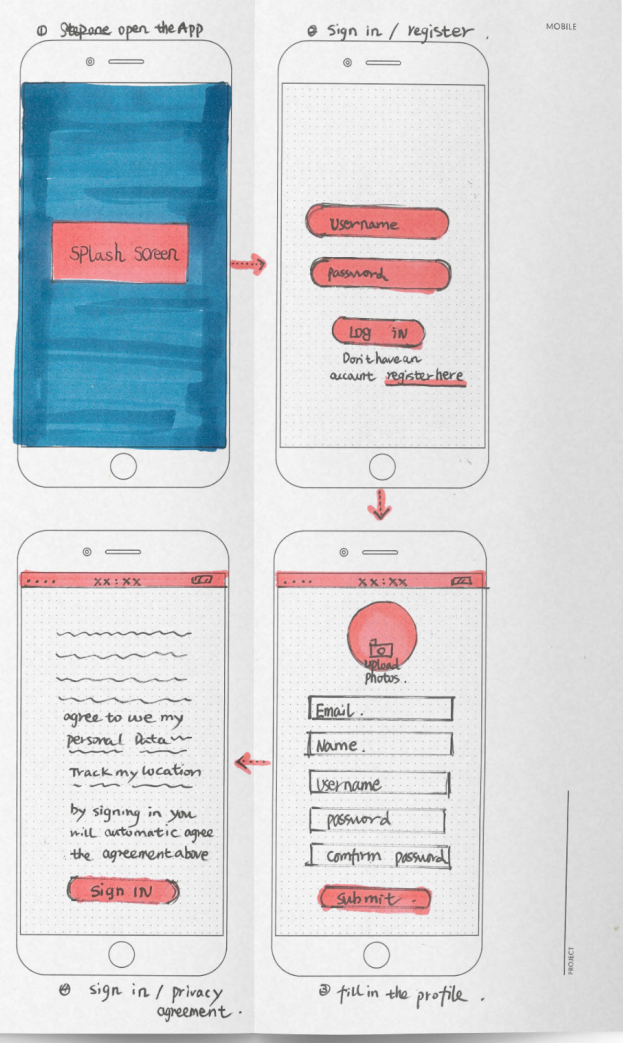

Sign in/Register

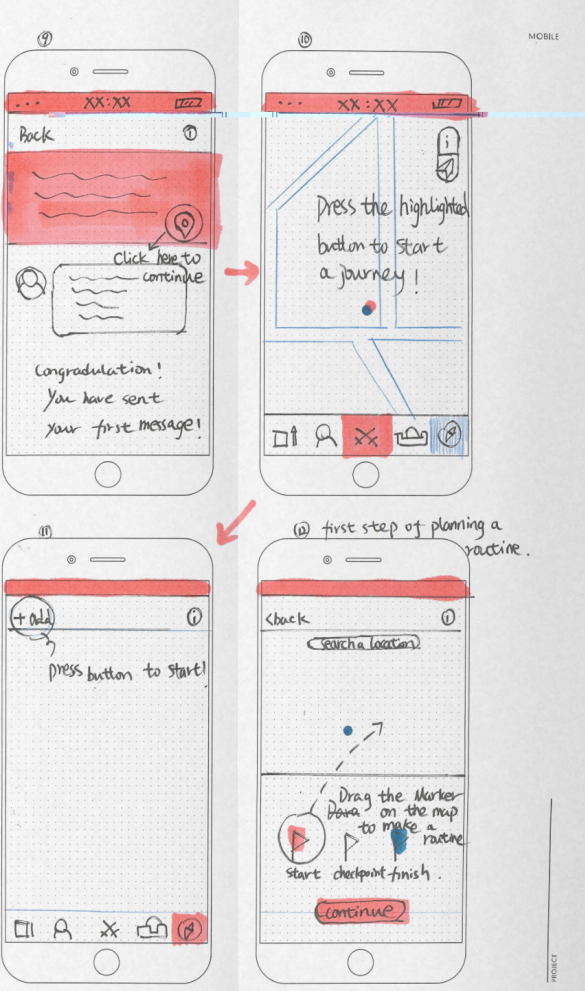

Q Open the home screen

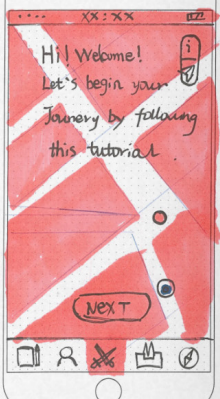

(6) Tutorial on receiving message.

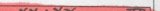

press the 4 -

icon to get the

direction and

receive the trist

message. whereysistod

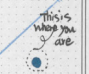

a1 $R \times x$ 네 (2)

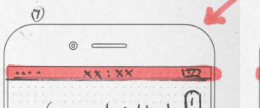

(2)
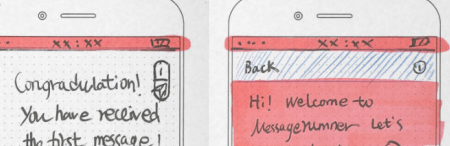

Hi! welcome to

Messacenumner let's

a new chapter. Qhaction

the tist mesage

$\rightarrow$

press the blank

to send a versage

click the

icon to

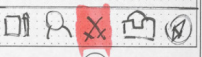

Dill $R \times x$ fित
Find and Receive
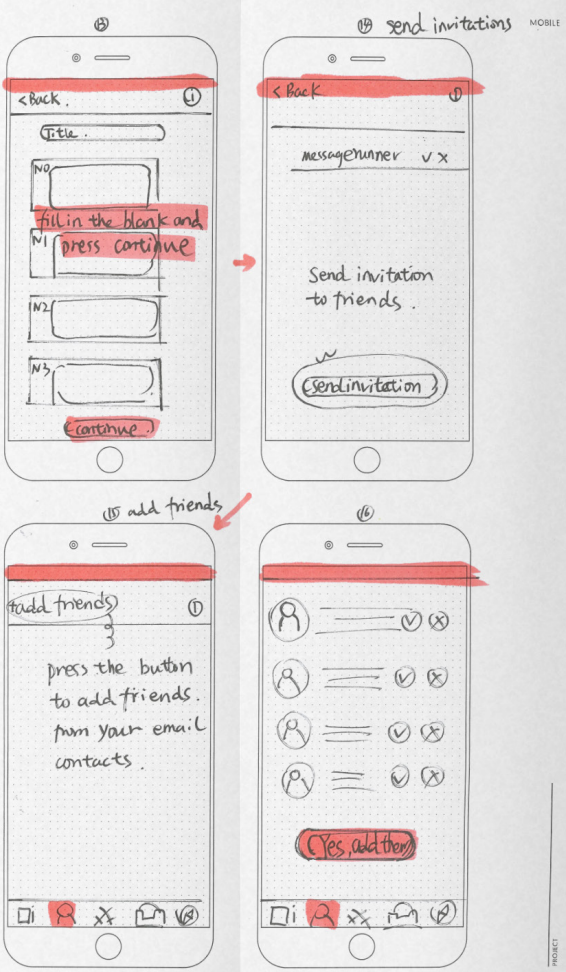


\subsubsection{User Journey}

When a user opens Messagerunner for the first time, they see the options to sign in or register. After they tap the register button, the interface invites them to fill in a profile and add some contacts. They then submit their profile. After that they consent to the user licensing agreement and sign in.

Once signed in, the user sees the Map screen (home) overlaid with a prompt to start the app's tutorial. This tutorial walks newcomers through the app's basic features. First, they will learn how to find and receive a message from a checkpoint on their map. The app will automatically generate this message and put it in a nearby location. The UI tells the user to tap on the highlighted navigation button to continue the tutorial. The user taps the button and sees the shortest path to the checkpoint. The app instructs the user to walk to that location.

When the user arrives at the marked location the UI tells them to click the checkpoint to continue. A new screen opens displaying the checkpoint's message. It also displays a field below where the user can reply to the original poster. The UI tells the user to post a reply. After the user has sent a reply, the UI tells them to tap the checkpoint's icon in the message. This sends back to the Map screen where they can see the checkpoint they just opened.

Now the user will learn how to make their own quest. A new prompt appears overlaying the Map screen. It tells them to tap the Quest tab to create a new quest. The UI tells uses to tap the Add New button to send their friends on a journey. The user then learns to tap a location on the Map screen to set a new checkpoint. The user now sees a button marked "Continue". After they tap this, they see a page where they can customise the information assigned to different checkpoints they have created. Another continue button appears on screen. The user taps it and they see a new screen where they can send their newly made quest to a placeholder friend.

After the user taps the Send button, the UI automatically transfers to the Party tab where they can add friends to the app. The user now sees a screen blank except for an "Add Friends" button. The app now draws a list of potential friends from the user's contacts and asks to link apps such as Facebook to access more contacts. The user adds the people they would like to, then taps Confirm. They have now finished the tutorial. 


\subsubsection{User Interface and User Experience}

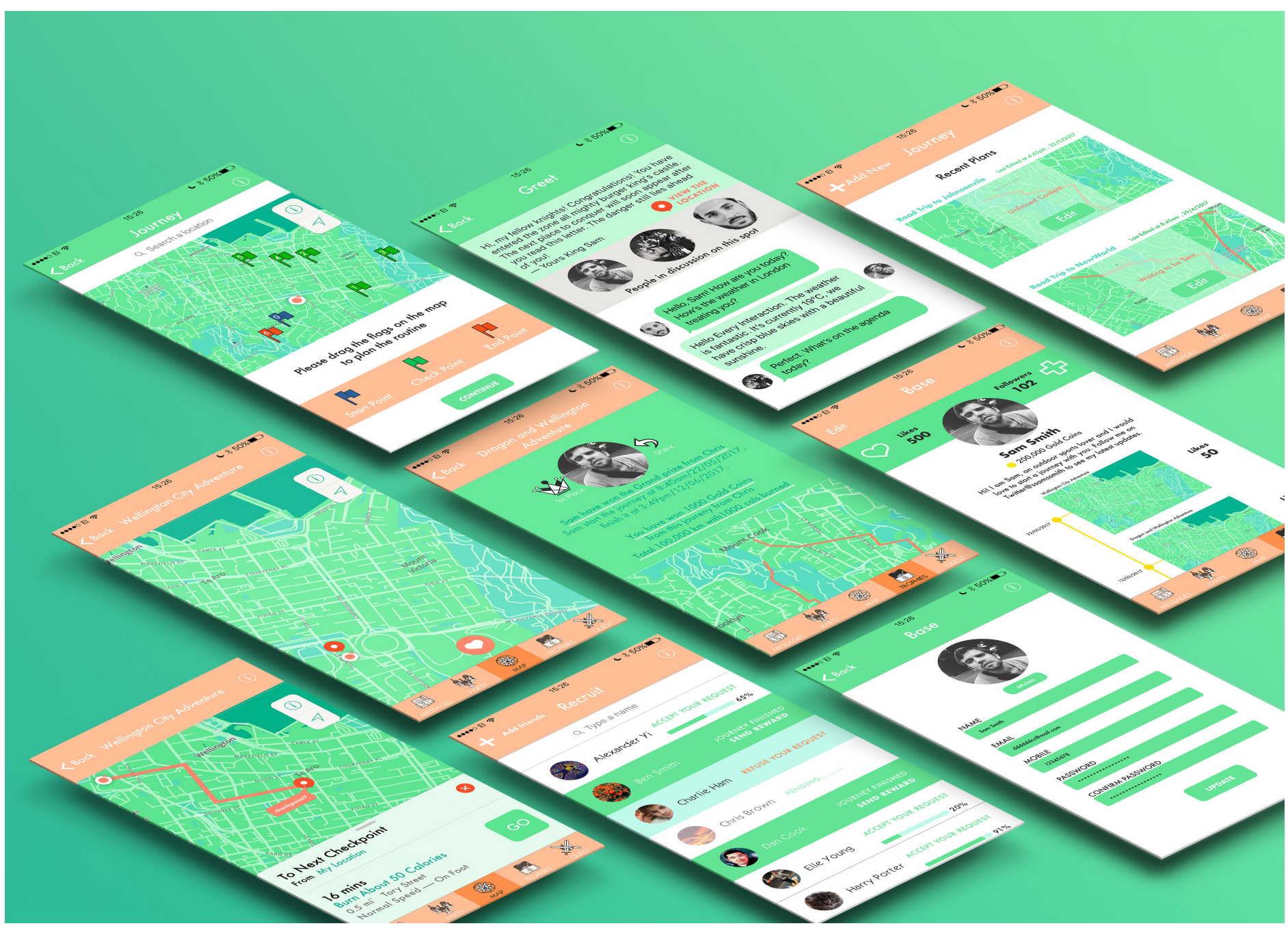

Figure 3.34. UI design of Messagerunner

\section{Minimalist Design}

Messagerunner has a sleek, flat design to minimise distractions and let the user concentrate on their tasks. The green-focused palette is comfortable to look at, and teal and orange accents allow the UI to highlight important information. The overall palette is tranquil and hopefully users will enjoy it. The UI design is concise. The content on the app is responsive to standard mobile screen sizes, and tested primarily on an iPhone 6 Plus with $414 \times 730$ " screen. 


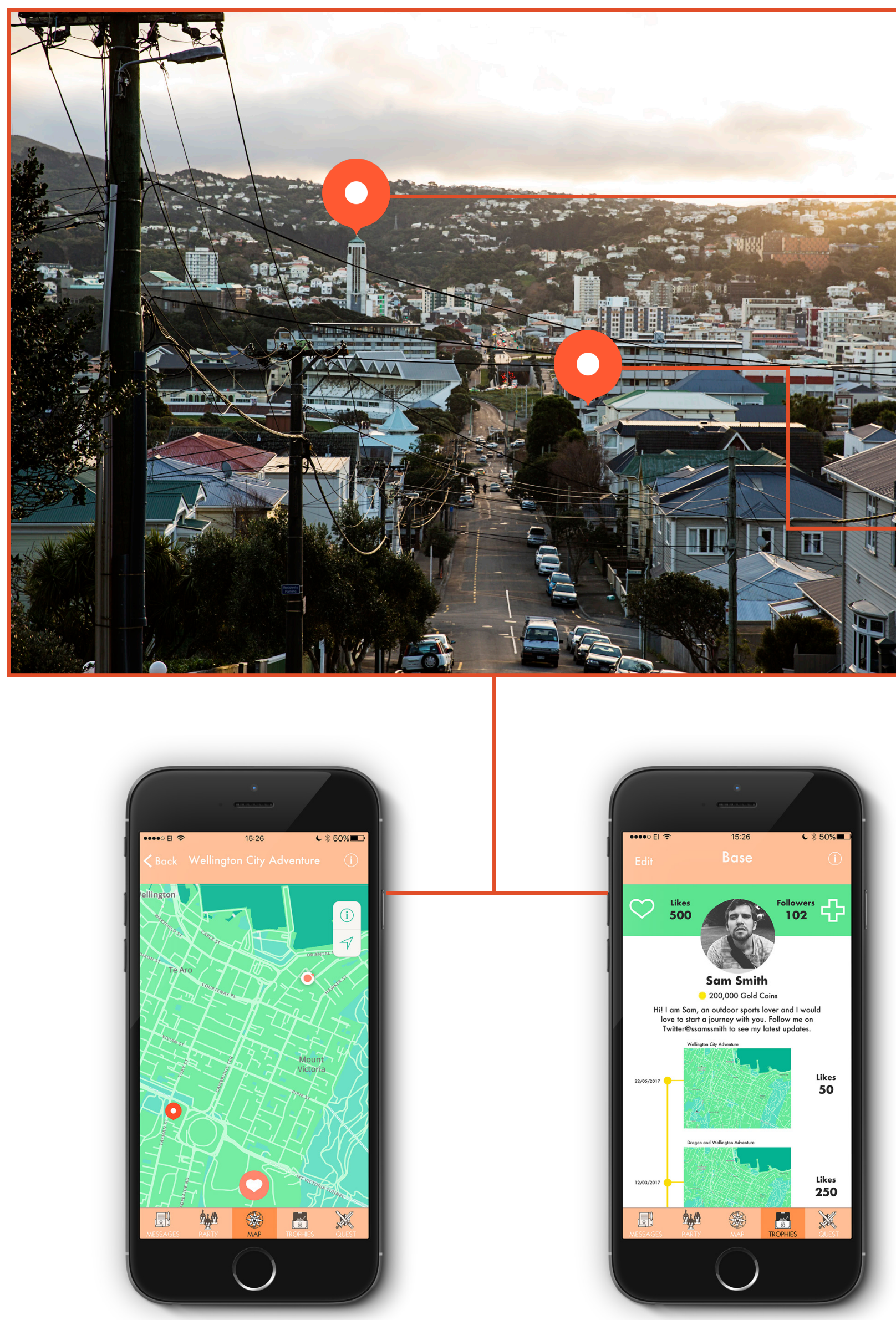



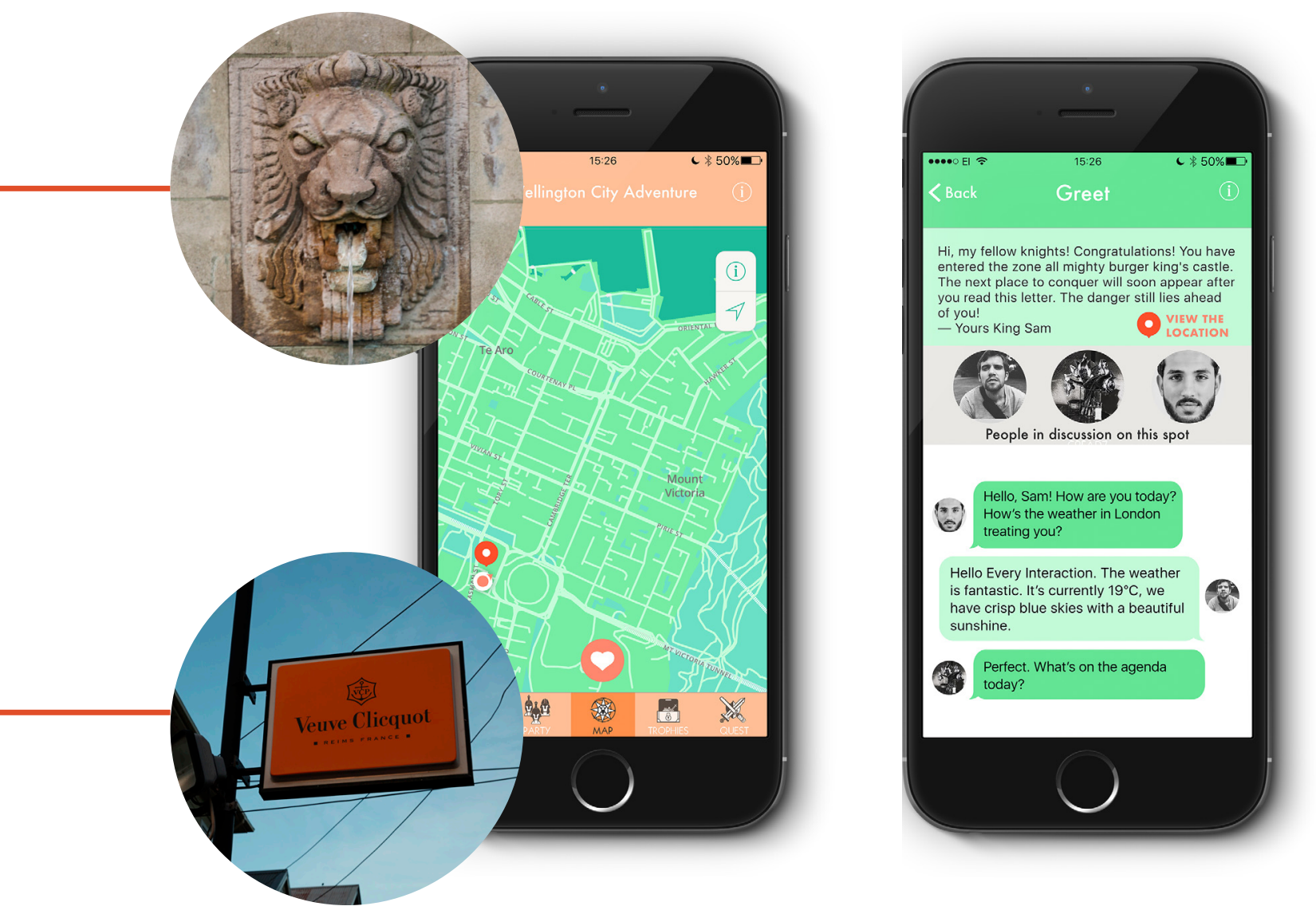

Figure 3.35. User found a message nearby, and they went to that location to read the message and start a conversation.

\section{Innovative social networking}

Messagerunner is a social networking app that aims to covertly promote physical health. The app aims to form a symbiotic relationship between socialising and exercising. This should allow users a different networking experience compared to Facebook, Snapchat, and so on. Messageruuner provides an opportunity to strengthen and build friendship through shared exploration and adventures. 


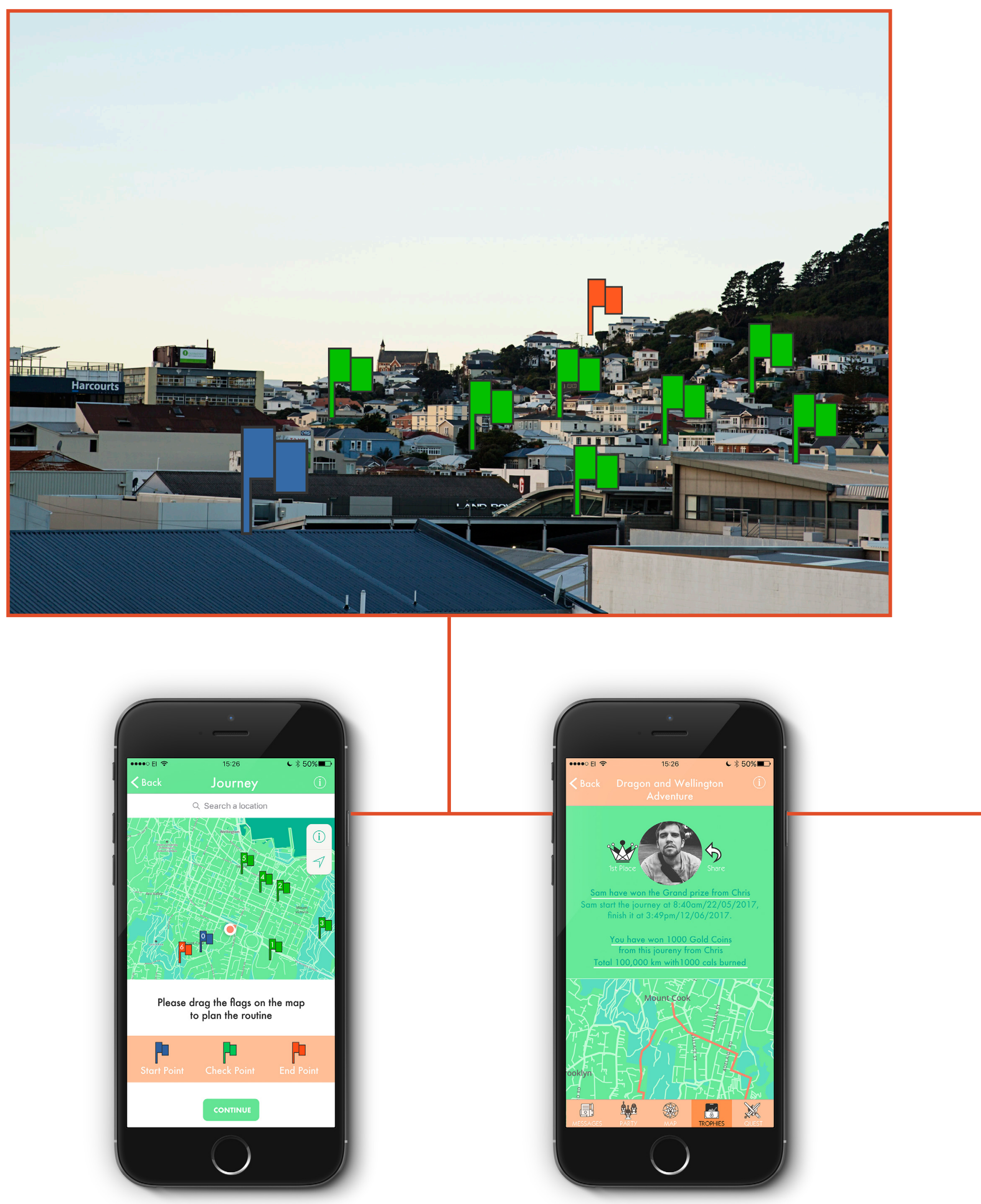

Figure 3.36. User set up a quest in Wellington and sent it to their friends. 


\section{Gamification}

The UI features elements and an aesthetic drawn from board games and medieval RPGs. For example, the mechanic allowing users to send messages to each other is reskinned as a quest, and represented by a sword and shield icon. The friends list is called party, as in the typical RPG party system. As established in my literature review, young adults prefer gamified apps to self-monitoring fitness apps. The app adopts game mechanics and introduces a reward and currency system. The currency system allows users to gain in-game currency called "gold coins" by finishing quests set by others. When users have enough coins, they can spend them to set up quests for others to finish. The more exercise a user does, the more coins they can get, and the more coins they can generate for others through setting up their own quests.

\section{Setting up a Quest}

The most exciting part of this app is setting up a quest for others to finish. This feature references traditional games like scavenger hunts and Dungeons \& Dragons. The map is generated from GPS data, and users who enjoy roleplaying can even set up chains of messages at different locations to form a story. The only limit is the users' creativity and imagination. When they get to the location, they can read the hidden message, and also start an in-app conversation to discuss their progress with the quest's creator. This feature allows other users to post motivational messages at checkpoints, increasing the chance that the user will finish the whole quest.

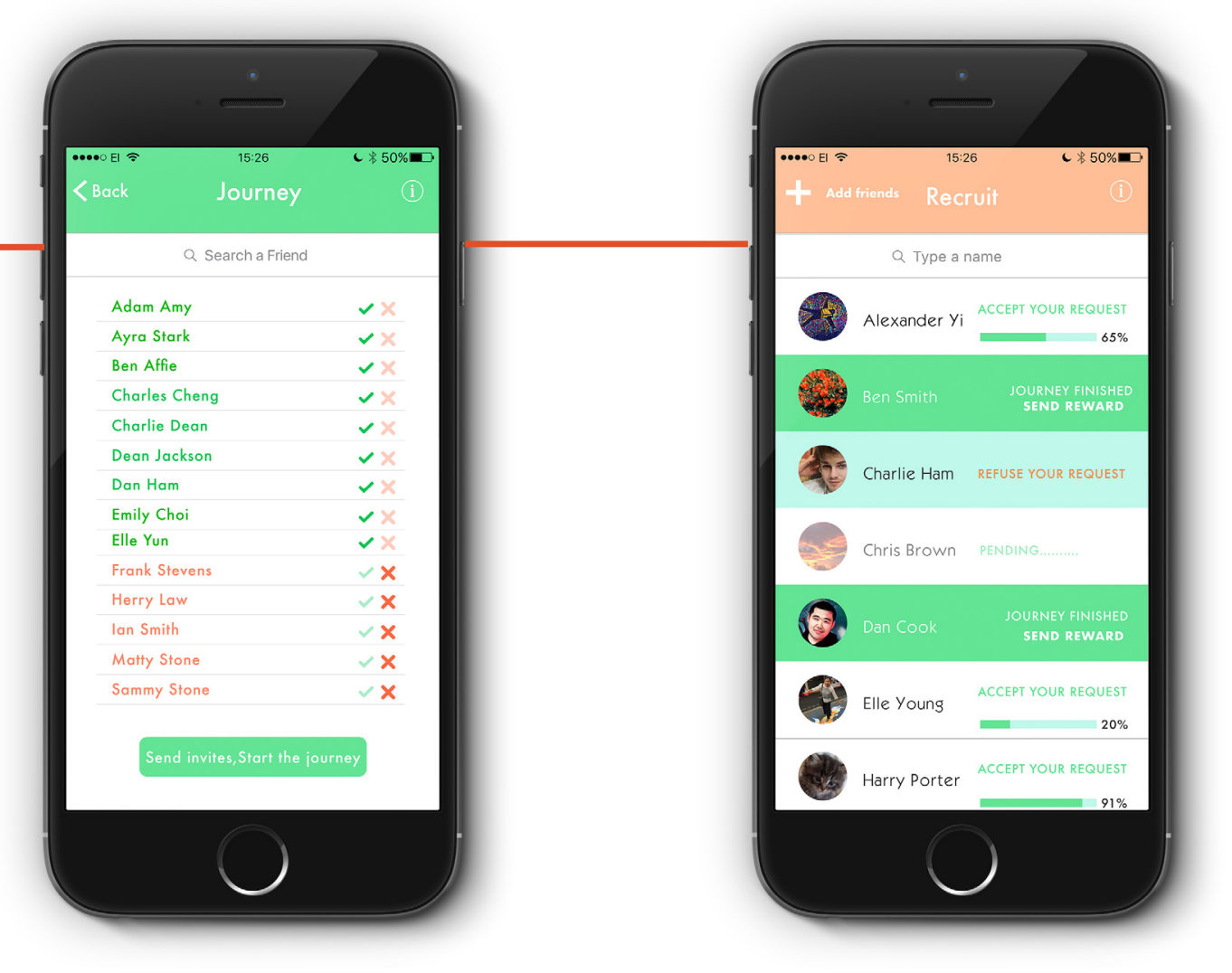




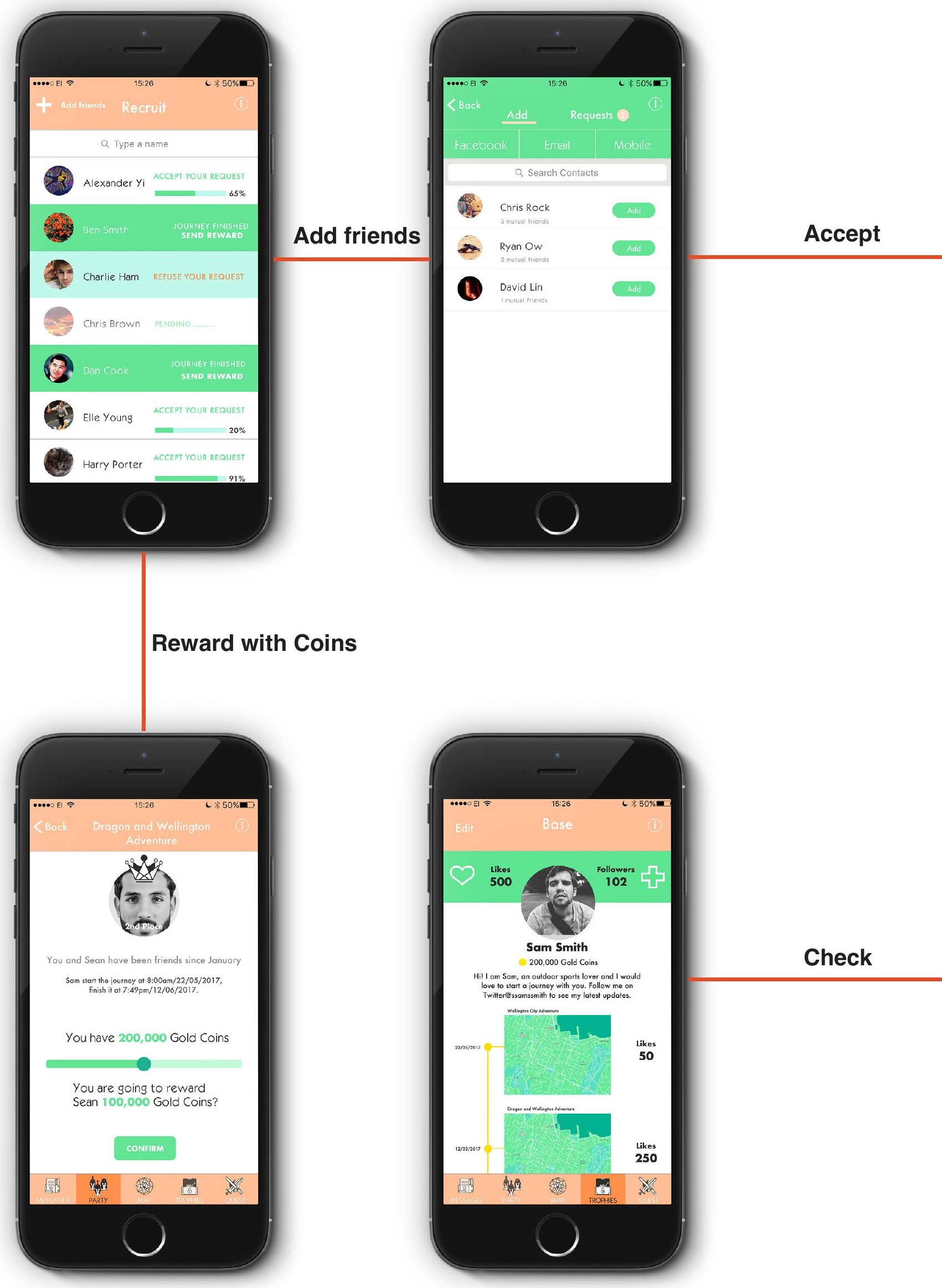

Figure 3.37. Users give and receive rewards from each other. 

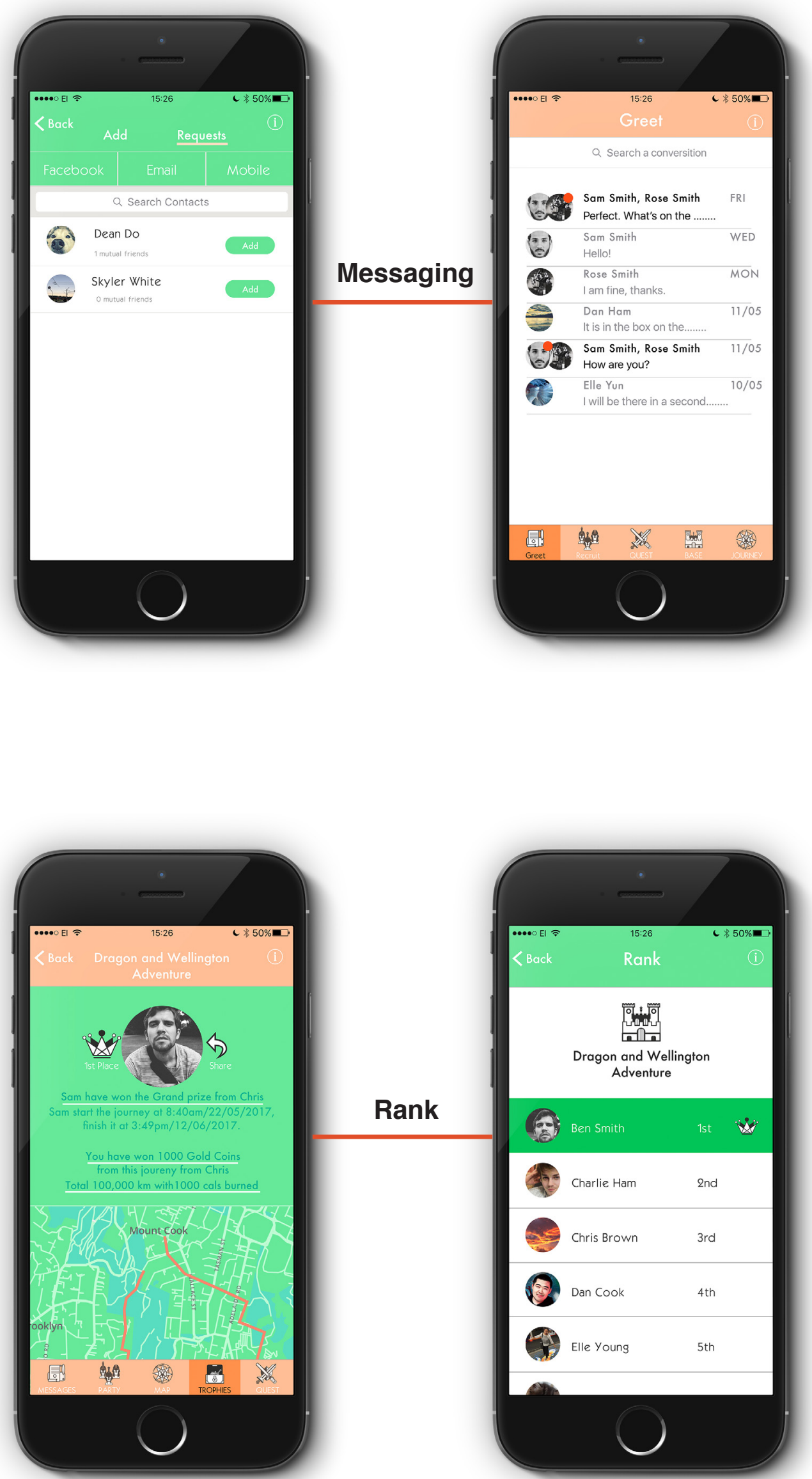
4. CONCLUSION 
Mobile apps, counselling, and psychotherapy are the main ways that young adults try to change their sedentary lifestyles. However, these interventions have pros and cons. This thesis proposes an app as a low cost challenge to sedentary lifestyles. This app integrates social media and gamification with prominent theories about behavioural change. The target audience is young adults. After analysing and summarising major theories about behavioural change, and also theories about gamification, I chose three keywords to guide my design: Progression, Self-efficacy, Flow. I made concepts, guided by these keywords, and also by several design precedents. The proposed app is a social media platform where users can only access messages by walking to the locations that the sender has chosen. This is different from the self-monitoring method that is used in common fitness apps.

My survey and interview showed that the majority of young adults are conscious about the consequences of inactivity, and they would like to improve their physical health. However, the survey and interview also showed that respondents lacked motivation and a plan to change their current sedentary lifestyles. The respondents reinforced my belief that social support and interaction is a strong motivator for behavioural change.

During the contextual inquiry, most participants showed curiosity about Messagerunner's main mechanic for promoting exercise. They noticed that this app was promoting exercise in an interactive way that differed from the majority of commercial fitness apps. Some respondents believed Messagerunner might make them walk more often, but they were uncertain how the app would gain a large enough user base to be fully functional. Due to the limits of the study, I could not set up a large-scale model test that include many users who friend each other and who send messages on a daily basis. The contextual inquiry found that users are more likely to travel to read a message if they think it will be interesting. Respondents to my interview also pointed out that this prototype may need more game mechanics and general fun. They believed that more gamification would make them more likely to engage with the app.

I used interviews as my primary user-testing method. There are certain aspects of this app that I can explore further with large-scale testing. The application is still in an early design stage. This means it has been difficult to test the usability of the app. However, my findings in this thesis are transferable to future research. I can see potential to use social interactions on digital platforms to change behaviours. This could apply to people in the various stages of behavioural change that I identified in my theoretical framework. 
The key to changing young adults' sedentary lifestyles is to make exercising easy, enjoyable, and rewarding. Young adults use apps, and this app could increase their self-efficacy by fostering slow, progressive change. By gamifying social interaction and exercise I aim to make these activities more fun. This should generate a flow experience as users increase in confidence and stamina.

I used interviews as my primary user-testing method. There are certain aspects of this app that I can explore further with large-scale testing. The application is still in an early design stage. This means it has been difficult to test the usability of the app. However, my findings in this thesis are transferable to future research. I can see potential to use social interactions on digital platforms to change behaviours. This could apply to people in the various stages of behavioural change that I identified in my theoretical framework.

The key to changing young adults' sedentary lifestyles is to make exercising easy, enjoyable, and rewarding. Young adults use apps, and this app could increase their self-efficacy by fostering slow, progressive change. By gamifying social interaction and exercise I aim to make these activities more fun. This should generate a flow experience as users increase in confidence and stamina.

Mobile apps have only been commonplace for less than a decade, however they have changed the lives of millions of people. When designers talk about a design solution, they usually discuss whether there is already "an app for that". The "mobile first" design strategy has influenced user interface (UI) and user experience (UX) design. Google and Apple have influenced the design of millions of apps by publishing design guidelines. It is important for UI and UX designers to understand that directives and precedents should not limit their creativity. The field of mobile design is quickly evolving and adopting new content every day. Developers should think innovatively, and consider about what users need and what would be the best solution to meet those needs.

Messagerunner indicates a direction for the future design of fitness apps. It is important to understand what users enjoy and what they value. Nostalgia and gamification are great motivators because they can turn exercise into a fun and engaging experience. Social interaction is a stronger motivator than self-monitoring. 
5. DISCUSSION 


\section{Social interaction as interventional method}

Messagerunner aims to build a friendly community that promotes an active lifestyle. This community should offer individuals motivation and moral support. Individuals want others in their peer group to think highly of them. They want "bragging rights", which medals and other in-app rewards confer, but which also represent physical exertion. Whether users are worried about physical health or not, success in the game and community indicates they are being less sedentary.

Both psychiatrists and mobile designers use social pressure as a motivator for behavioural change. The difference is that a psychiatrist applies social pressure to meet an individual patient's needs, whereas mobile designers work with general user personae built from the averaged statistics of a target group. The social features in most mobile fitness applications merely act as supplements to the core self-monitoring features. These apps usually allow users to compare their daily statistics with each other without providing a clear strategy for selfimprovement. This experience can be frustrating and discouraging for users who need social support and motivation for their progress.

Messagerunner gives users freedom, flexibility, and most importantly, customization. Instead of showing vague data analysis like most commercial apps, Messagerunner allows users to get tailored motivation from people who know them and are happy to see their progress. These kinds of interaction may encourage a long-term engagement between users and the app. This will increase users' daily activity and grow their self-confidence about exercising.

\section{Gamification as persuasive technology}

Today's young adults generally grew up playing video games. They like the nostalgia that gameplay mechanics can bring to an app. For example, Pokémon Go relies heavily on the popularity of the celebrated Nintendo game and TV series from the 1990s, Pokémon. Messagerunner does not have a direct connection to any game or television franchise, but contains generic gaming motifs such as treasure chests and coins. Messagerunner encourages players to discover uncharted territory around the city.

Messagerunner uses physical activity as a central component. Before players join a Quest together, they can discuss and choose a suitable distance that will not discourage them from finishing it. Users of should eventually reach a flow state where they enjoy the process of getting to further checkpoints. Users can collaborate to create a flexible and customised plan acceptable to all the members of their group. They will provide a variety of difficulty levels to match different individuals' stamina.

Messagerunner has mechanics that reflect those of many other games. For example, the checkpoint system can function in a similar way to boardgame tiles, guiding players around a pathway (eg, as in Monopoly, Snakes \& Ladders, or Mouse Trap). The messages at the checkpoints also allow users to play games like the traditional scavenger hunt, allowing the app to function as a platform for real-world social gaming.

Interviewees mostly expressed interest in the "scavenger hunt" mechanic. Some users liked the idea of discovering unfamiliar places or interesting messages and information. One interviewee even suggested that the markers could be put on the ocean to challenge their surfing skills. Since they understood the basic mechanics of many existing games, they quickly grasped the rules of Messagerunner.

Although Messagerunner is a game in a limited sense, I prefer to think of it as a tool to 
change behaviour using gameplay elements. I think users are likely treat this app as a social media platform than an exercise game.

\section{World wide users}

The World Health Organisation has ranked physical inactivity as the fourth leading risk factor for global mortality. This trend prevails in both developed and developing countries. From my experience growing up in China, a sedentary lifestyle is the norm for the majority of Chinese citizens. People usually spend over 10 hours a day sitting in a chair where they study or work in front of a computer screen. Illness related to inactivity is increasing in urban China. Countries like China do not have enough facilities and professionals to combat sedentary behaviour. However, China has more smartphone users than the US, Brazil, and Indonesia combined. As an article stated in 2016:

As of 2015 , about $54 \%$ of adults in 21 countries with developing economies are using the Internet, up from 45\% in 2013, according to a report from the Pew Research Center. An even larger increase has been the use of smartphones in developing economies, jumping from $21 \%$ in 2013 to $37 \%$ in 2015 . In countries with advanced economies, about $87 \%$ of adults use the Internet, and 68\% own a smartphone. (Beck, 2016).

Mobile app like Messagerunner can improve the health of people in these developing economies outside the limits of existing healthcare infrastructure. This could be a great opportunity, since most people in China choose to change their sedentary life by themselves, or with the support of their families and friends. If Messagerunner gained a large global user base it could have a significant impact on health in developing countries.

\section{Commercial fitness applications}

Most commercial fitness applications rely on users monitoring their own physical activity, and these apps are not effective for achieving long-term behavioural change. Some researchers suggest artificial intelligence (AI) can be a great solution since AI can learn from users' past behaviours and send messages conveying customised, motivational information. However, modern Al is still primitive, and it may not exercise judgement as well as the user's peers. It is important to note that social interaction has real life consequences. People are interacting with their friends and family online, but also in their real lives. Al cannot affect someone's life like a real person would do. It is normal to see users quit their fitness apps after a short period. This research provides an option that may allow users to change their behaviour without tedious self-monitoring that makes them quit.

Messagerunner gives more freedom to users than most commercial apps. Most of the content and interactivity of the app comes from users themselves. The app provides a framework for users to customise their journey alongside their peers. This has obvious benefits, but also some drawbacks. For example, users who are not creative may find it difficult to keep using the app. I hope that these users can sustain their engagement with the app thanks to the Quests that other users generate.

Commercial fitness applications focus on making revenue and expanding the number of their users. They rely heavily on replicating successful models and formulae, producing similar products that restrict the users' choices. Developers could benefit from providing users with more open-ended options for changing their behaviours. 
6. BIBLIOGRAPHY 
Adams, J. and White, M. (2003) Are activity promotion interventions based on the transtheoretical model effective? A critical review. British Journal of Sports Medicine,37, 106114.

Adams, J., \& White, M. (2004). Why don't stage-based activity promotion interventions work?. Health education research, 20(2), 237-243.

Abraham, C., \& Sheeran, P. (2003). Acting on intentions: The role of anticipated regret. British Journal of Social Psychology, 42(4), 495-511. doi:10.1348/014466603322595248

Ajzen, I., \& Fishbein, M. (2002). Understanding attitudes and predicting social behavior. Upper Saddle River, NJ: Prentice-Hall.

Ajzen, I. (2011). The theory of planned behaviour: Reactions and reflections. Psychology \& Health, 26(9), 1113-1127. doi:10.1080/08870446.2011.613995

Ali, S. (2011). Design an interface prototype for Elskift. Dk: Design a website using iterative design process. Retrieved from http://urn.kb.se/resolve?urn=urn:nbn:se:uu:diva-170735

Annesi, J. J., Faigenbaum, A. D., \& Westcott, W. L. (2010). Relations of Transtheoretical Model Stage, Self-Efficacy, and Voluntary Physical Activity in African American Preadolescents. Research Quarterly for Exercise and Sport,81(2), 239-244. doi:10.1080/02701367.2010.10599 671

Apple. (n.d.). iOS Human Interface Guidelines. Retrieved May 20, 2017, from https://developer. apple.com/ios/human-interface-guidelines/overview/design-principles/

Arteaga, S. M., Kudeki, M., Woodworth, A., \& Kurniawan, S. (2010). Mobile system to motivate teenagers physical activity. Proceedings of the 9th International Conference on Interaction Design and Children - IDC 10. doi:10.1145/1810543.1810545

Arsand, E., Tatara, N., Ostengen, G., \& Hartvigsen, G. (2010). Mobile Phone-Based SelfManagement Tools for Type 2 Diabetes: The Few Touch Application. Journal of Diabetes Science and Technology, 4(2), 328-336. doi:10.1177/193229681000400213

Bandura, A. (n.d.). Social Foundations of Thought and Action. The Health Psychology Reader, 94-106. doi:10.4135/9781446221129.n6

Baumgardner, E. F. (n.d.). American family watching TV in 1958. Retrieved from https:// commons.wikimedia.org/wiki/File:Family_watching_television_1958.jpg

Beck, Kellen. (2016). Smartphone and Internet usage is on the rise in developing economies. Retrieved from http://mashable.com/2016/05/10/internet-smartphonedeveloping/\#_OAqvujTPuqQ

Berkovsky, S., Coombe, M., Freyne, J., Bhandari, D., \& Baghaei, N. (2010). Physical activity motivating games. Proceedings of the 28th international conference on Human factors in computing systems - CHI '10. doi:10.1145/1753326.1753362

Blankenship, K. M., Friedman, S. R., Dworkin, S., \& Mantell, J. E. (2006). Structural Interventions: Concepts, Challenges and Opportunities for Research. Journal of Urban Health, 83(1), 59-72. doi:10.1007/s11524-005-9007-4 
Brauner, P., Valdez, A. C., Schroeder, U., \& Ziefle, M. (2013). Increase physical fitness and create health awareness through exergames and gamification. In Human Factors in Computing and Informatics (pp. 349-362). Springer Berlin Heidelberg.

Bravata DM, Smith-Spangler C, Sundaram V, Gienger AL, Lin N, Lewis R, Stave CD, Olkin I, Sirard JR. Using Pedometers to Increase Physical Activity and Improve Health A Systematic Review. JAMA.2007;298(19):2296-2304. doi:10.1001/jama.298.19.2296

David. (2016). 5 Best Fitness Apps for Android to Help You Lose Weight and Stay Healthy. Retrieved from http://thedroidguy.com/2016/10/5-best-fitness-apps-android-help-lose-weightstay-heathy-1065340

De Onis, M., Blössner, M., \& Borghi, E. (2010). Global prevalence and trends of overweight and obesity among preschool children. The American journal of clinical nutrition, 92(5), 12571264. doi: 10.3945/ajcn.2010.29786

Emily M. Simonavice And Matthew S. Wiggins. (2008). Exercise Barriers, Self-Efficacy, And Stages Of Change. Perceptual and Motor Skills, 107(7), 946. doi:10.2466/pms.107.7.946-950

Fogg, Brian J. Persuasive technology: using computers to change what we think and do. Ubiquity. 5. 89-120. doi: 10.1145/764008.763957

Foley, L. S., Maddison, R., Jiang, Y., Olds, T., \& Ridley, K. (2011). It's not just the television: survey analysis of sedentary behaviour in New Zealand young people. International Journal of Behavioral Nutrition and Physical Activity, 8(1), 132. doi: 10.1186/1479-5868-8-132

Foster, D., Linehan, C., \& Lawson, S. (2010). Motivating physical activity at work: Using persuasive social media extensions for simple mobile devices. Proceeding. 111-116. doi: $10.1145 / 1930488.1930510$

Glanz, K., Rimer, B. K., \& Viswanath, K. (Eds.). (2008). Health behavior and health education: theory, research, and practice. John Wiley \& Sons.

Glanz, K., Rimer, B. K., \& Viswanath, K. (2015). Health behavior: theory, research, and practice. San Francisco, CA: Jossey-Bass.

Global recommendations on physical activity for health. (n.d.). Retrieved April 20, 2017, from http://www.who.int/dietphysicalactivity/factsheet_recommendations/en/

Improve Your Habits by Playing a Game. (n.d.). Retrieved July 03, 2017, from https://habitica. com/static/features

Habitica press kit. (n.d.). Retrieved June 14, 2017, from https://habitica.com/static/press-kit

Heron, K. E., \& Smyth, J. M. (2010). Ecological momentary interventions: incorporating mobile technology into psychosocial and health behaviour treatments. British journal of health psychology, 15(1), 1-39. doi: 10.1348/135910709X466063

Hill,S., Barker,B., (2016). Run An Empire (Version 1.13.1) [Mobile application software]. Retrieved from http://www.runanempire.com/ 
Hinyard, Leslie J., and Matthew W. Kreuter. (2007). "Using narrative communication as a tool for health behavior change: a conceptual, theoretical, and empirical overview." Health Education \& Behavior 34(5). 777-792. Retrieved from http://journals.sagepub.com/doi/ abs/10.1177/1090198106291963

Tolstoy, L., Maude, A., \& Maude, L. (2012). How much land does a man need?: and other stories. Stilwell, Kan.: Digireads.com Pub.

Hunicke, R., LeBlanc, M., \& Zubek, R. (2004, July). MDA: A formal approach to game design and game research. In Proceedings of the AAAI Workshop on Challenges in Game AI 4(1). doi: 10.1.1.79.4561

Jackson, S. A., \& Csikszentmihalyi, M. (1999). Flow in sports. Champaign, IL: Human Kinetics. Jenova Chen, M. F. A. (2006). Flow in Games. Retrieved from http://www.jenovachen.com/ flowingames/

Jegers, K. (2007). Pervasive game flow. Computers in Entertainment, 5(1), 9. doi:10.1145/1236224.1236238

Johannes Brug, Mark Conner, Niki Harré, Stef Kremers, Susan McKellar, Sandy Whitelaw; The Transtheoretical Model and stages of change: a critique: Observations by five Commentators on the paper by Adams, J. and White, M. (2004) Why don't stage-based activity promotion interventions work?. Health Educ Res 2005; 20 (2): 244-258. doi: 10.1093/her/cyh005

Kadam P, Bhalerao S. Sample size calculation. International Journal of Ayurveda Research. 2010;1(1):55-57. doi:10.4103/0974-7788.59946.

Khalil, A., \& Glal, S. (2009). StepUp: A step counter mobile application to promote healthy lifestyle. 2009 International Conference on the Current Trends in Information Technology (CTIT). doi: 10.1109/ctit.2009.5423113

Khalil, A., \& Abdallah, S. (2013). Harnessing social dynamics through persuasive technology to promote healthier lifestyle. Computers in Human Behavior, 29(6), 2674-2681. doi: 10.1016/j. chb.2013.07.008

Kohl, H. W., Craig, C. L., Lambert, E. V., Inoue, S., Alkandari, J. R., Leetongin, G., ... \& Lancet Physical Activity Series Working Group. (2012). The pandemic of physical inactivity: global action for public health. The Lancet, 380(9838), 294-305.

Barker,B.,Hill, S. (2017). Run An Empire - The Strategy Running Game on the App Store. Retrieved from https://itunes.apple.com/nz/app/run-an-empire-the-strategy-running-game/ id1073986257?mt=8

Lister, C., West, J. H., Cannon, B., Sax, T., \& Brodegard, D. (2014). Just a Fad? Gamification in Health and Fitness Apps. JMIR Serious Games, 2(2). doi:10.2196/games.3413

Maitland, J., Sherwood, S., Barkhuus, L., Anderson, I., Hall, M., Brown, B., . . Muller, H. (2006). Increasing the Awareness of Daily Activity Levels with Pervasive Computing. 2006 Pervasive Health Conference and Workshops. doi:10.1109/pcthealth.2006.361667 
Niantic.(2016). Pokémon Go (Version 0.67.1). Retrieved from http://pokemongo.nianticlabs. com/en

Physical inactivity a leading cause of disease and disability, warns WHO. (n.d.). Retrieved April 27, 2017, from http://www.who.int/mediacentre/news/releases/release23/en/

Pokémon Go. (n.d.). In Wikipedia. Retrieved April 4, 2017, from https://en.wikipedia.org/wiki/ Pokémon_Go.

Prochaska, J. O. (2013). Transtheoretical model of behavior change. In Encyclopedia of behavioral medicine (pp. 1997-2000). Springer New York.

Renelle,T., Lesilie, S., Hsu, V., (2013). Habitica (Version 2.0) [Mobile application software]. Retrieved from https://habitica.com

Riemsma, R. P., Pattenden, J., Bridle, C., Sowden, A. J., Mather, L., Watt, I. S., \& Walker, A. (2002). A systematic review of the effectiveness of interventions based on a stages-of-change approach to promote individual behaviour change. Health Technology Assessment, 6(24). doi:10.3310/hta6240

Rouse, M. (n.d.). What is geo-fencing (geofencing)? - Definition from Whatls.com. Retrieved June 15, 2017, from http://whatis.techtarget.com/definition/geofencing

Run an Empire press Images. (n.d.). Retrieved June 18, 2017, from http://www.runanempire. com/press/images/

Sama, P. R., Eapen, Z. J., Weinfurt, K. P., Shah, B. R., \& Schulman, K. A. (2014). An evaluation of mobile health application tools. JMIR mHealth and uHealth, 2(2). e19.doi: 10.2196/mhealth.3088

Salmon, J., Tremblay, M. S., Marshall, S. J., \& Hume, C. (2011). Health Risks, Correlates, and Interventions to Reduce Sedentary Behavior in Young People. American Journal of Preventive Medicine, 41(2), 197-206. doi:10.1016/j.amepre.2011.05.001

Schoech, D., Boyas, J. F., Black, B. M., \& Elias-Lambert, N. (2013). Gamification for Behavior Change: Lessons from Developing a Social, Multiuser, Web-Tablet Based Prevention Game for Youths. Journal of Technology in Human Services,31(3), 197-217. doi:10.1080/15228835.2013 .812512

Schwarzer, R. \& Renner, B. (2000) Social-cognitive predictors of health behavior: action self-efficacy and coping self-efficacy. Health Psychology, 19 , 487-495. doi: 10.1037/02786133.19.5.487

Sevick, M. A., Dunn, A. L., Morrow, M. S., Marcus, B. H., Chen, G., \& Blair, S. N. (2000). Costeffectiveness of lifestyle and structured exercise interventions in sedentary adults. American Journal of Preventive Medicine, 19(1), 1-8. doi:10.1016/s0749-3797(00)00154-9

Sheppard, B., Hartwick, J., \& Warshaw, P. (1988). The Theory of Reasoned Action: A MetaAnalysis of Past Research with Recommendations for Modifications and Future Research. Journal of Consumer Research, 15(3), 325-343. Retrieved from http://www.jstor.org/ stable/2489467 
Schwimmer, J. B. (2004). Managing overweight in older children and adolescents. Pediatric annals. 33(1), 39-44. doi: 10.3928/0090-4481-20040101-11

Snyder, C. R., \& Lopez, S. J. (2009). Oxford handbook of positive psychology. Oxford University Press, USA.

Sumamo, E., Ha, C., Korownyk, C., Vandermeer, B., \& Dryden, D. M. (2011). Lifestyle interventions for four conditions: Type 2 diabetes, metabolic syndrome, breast cancer, and prostate cancer. Technology Assessment Report. Retrived from https://www.ncbi.nlm.nih.gov/ pubmedhealth/PMH0070532/

The New Zealand Physical Activity Report Card For Children And Youth. (2016). Retrieved from http://www.nihi.auckland.ac.nz/News/Articleld/74/2016-new-zealand-physical-activityreport-card-for-children-youth

Uber: The Transportation Game Changer. (n.d.). Retrieved April 23, 2017, from http:// royalportfolio.com/uber-the-transportation-game-changer/

Wearable Fitness Technology- Is It Right For You? (2015). Retrieved from http://mkfitness4life. com/2015/09/22/wearable-fitness-technology-is-it-right-for-you/

Wong, F. Y. (2017). Influence of Pokémon Go on physical activity levels of university players: a cross-sectional study. International Journal of Health Geographics, 16, 8. doi: 10.1186/s12942017-0080-1

Xu, H., Xian, Y., Xu, H., Liang, L., Hernandez, A. F., Wang, T. Y., \& Peterson, E. D. (2017). Does Pokemon Go Help Players be More Active? An Evaluation of Pokemon Go and Physical Activity. Retrieved from https://www.researchgate.net/publication/315510784_Does_Pokemon_ Go_Help_Players_be_More_Active_An_Evaluation_of_Pokemon_Go_and_Physical_Activity 


\section{Appendix 1}

\section{(3.3.1. Online Questionnaire)}

1. I have read the information form and agree to the conditions in the consent form (100\%)

2. How old are you?

- $20-25(66.7 \%)$

- $25-30(20 \%)$

- $30-35(0 \%)$

- 35-40 (0\%)

- 19 and under (13.3\%)

- 41 and above $(0 \%)$

3. On average, how much time do you spend on daily physical activity(walking, running, general exercise)?

- Below 30 minutes (13.3\%)

- 30 minutes to an hour (46.7\%)

- An hour to 2 hours (33.3\%)

- 2 hours to 3 hours $(6.7 \%)$

- 4 hours to 5 hours (0\%)

- 5 hours to 6 hours $(0 \%)$

- 6 hours or more $(0 \%)$

- Others (0\%)

4. Do you consider your current health status need improvement?

- Yes $(58.3 \%)$

- No $(26.7 \%)$

- Maybe (20\%)

5.Which aspects below may hinder you from sticking to a regular exercise schedule?

- I don't have enough time to exercise. (64.3\%)

- I think exercise is boring. (21.4\%)

- I'm self-conscious about how I look. (7.1\%)

- I'm too tired to exercise after work(study). (64.3\%)

- I'm too lazy to exercise. (35.7\%)

- I don't want to change my current schedule to make time for exercise. (28.6\%)

- I have no clear goals or directions for carrying out a workout schedule. $(35.7 \%)$

- I am afraid I will drop out and quit the schedule like so many times before. $(21.4 \%)$

- I have always planned a lot of goals to achieve which ends up with too many tasks to finish. $(7.1 \%)$

- My friends told me I am OK ,besides, exercise or fitness is a myth. (0\%)

- Others (0\%) 
6. Which of the physical activities would be convenient to you to carry out and keep up?

- Walking (50\%)

- Running (64.3\%)

- Swimming (14.3\%)

- Gym (42.9\%)

- Cross-fit (7.1\%)

- Exercise group (0\%)

- Tramping (21.4\%)

- Others $(21.4 \%)$

7. Which of the methods below have you used to motivate you to keep up exercising when you start to feel tired?

- Listen to work-out soundtrack (50\%)

- Take a break before next session (28.6\%)

- Share your progress with your workout buddies (28.6\%)

- Rethink Positive Thinking (21.4\%)

- Sign a Commitment Contract (0\%)

- Give Yourself a Real Reward (14.3\%)

- Get a paid coach to supervise you (7.1\%)

- Others $(7.1 \%)$

8. Do you have a smartphone?

- Yes $(100 \%)$

- No $(0 \%)$

9. Have you ever used the built-in fitness app or other exercise apps on your mobile?

- Yes $(60 \%)$

- No $(33.3 \%)$

- Maybe (6.7\%)

10. Do you consider using smartphones as your workout company is better than human company regardless of the potential costs?

- Yes $(64.3 \%)$

- No $(35.7 \%)$

11. Have you accessed one or multiple mobile apps below?

- Zombie Run (16.7\%)

- Pokemon GO (66.7\%)

- Fitbit $(25 \%)$

- Jawbone Up (0\%)

- Health (Apple) (8.3\%)

- S Health (8.3\%)

- Moves (8.3\%)

- Google Fit $(0 \%)$

- Nike+ (16.7\%)

- Others (8.3\%) 
12. Which of the following mobile technologies may make your exercise more fun?

- Interactive Storytelling (23.1\%)

- Pedometer $(53.8 \%)$

- $\operatorname{AR}(46.2 \%)$

- VR $(15.4 \%)$

- Social Media (38.5\%)

- Others $(7.7 \%)$

13. Are you planning or currently on a daily based exercise schedule?

- Yes $(33.3 \%)$

- No $(60 \%)$

- Others $(6.7 \%)$

14. What scenarios below do you think may make you discontinue your fitness plan?

- You have few or no company during the exercise session to share your progress. (26.7\%)

- You find your current workout is boring and easy since work-out plan is too simple and repetitive. (0\%)

- You find your current workout is difficult and hard to follow since work-out plans was above your level. (0\%)

- You lose track of your exercise schedule and you don’t know where you are heading at. $(6.7 \%)$

- You lack motivations for a while. (60\%)

- You have planned the whole schedule by yourself and lack support from friends or families who have similar goals. (13.3\%)

- You find your current workout plan is boring and easy since it is too sample and repetitive. $(20 \%)$

- Others $(6.7 \%)$

15. Please describe what would be a preferred setup for your potential exercise plan.

1. Someone could supervise me always

2. Good weather and a convenient distance

3. days per week gym + cardio and in between club sports training

4. No idea

5. regular weekly schedule with two or three other friends.

6 . I don't exercise because it's boring - running walking etc. If I could do some fun exercise which leads to building of other skills - like gymnastics so I could learn to do sweet flips, or tree climbing, i'd probably do it more

7. A tiny camera to capture where I exercise

8. 4 days a week. all include cardio with certain weights each day. legs one day, arms the next etc

9. something that tells me what to do everyday, like a checklist

10. Clearly laid out exercise plan based on personal performance

16. What do you think is the most unsatisfying feature of modern days fitness apps? Please give me an example if you could. 
1. Not yet gamified enough.

2. Lack of exercise library and unable to easily track my progress in reps and weights.

3. Poor usability.

4. I think technology distracts from the physicality of exercise, which is its most important part! Way too much shit to enter. EG calorie trackers, user has to enter every item. I would want something automated.

5. Bad UI.

6. When the explanations of how to do the exercises are not specific enough and the technique is wrong.

7. I don't use them enough to know.

8. Annoying notifications when you don't require them(S health).

17. What would be your most wanted feature in a fitness app that would attract you to use it for your fitness plan?

1. Link to my friends progress.

2. Gamification: high scores, long term goals, small achievements, etc.

3. Be able to set your current max weight for an exercise and your goal and the app plans a good progression.

4. No idea.

5. Something that I don't have to carry around with me while exercising. Something that gives and indication of progress over time, or reflects the effort l've put in over time.

6. Autonomy - it figures out what's best to me and tries to keep me too it, and adjusts when I don't keep up. Also time effectiveness - if I'm going to do boring exercise I want it as efficient as possible.

7. A beautifully designed social media app that all my friends use, that represents all types of exercise.

8. I like it when they are set times, so they have a countdown going down from say 30 seconds.

9. Something that maps my progress and motivates me.

10. A calendar sync function that works with Google Calendar or so you can input when and how long you want to exercise for and it will generate a workout and remind you when the time comes. 


\section{Appendix 2}

\section{(3.3.2.2. Contextual Interview)}

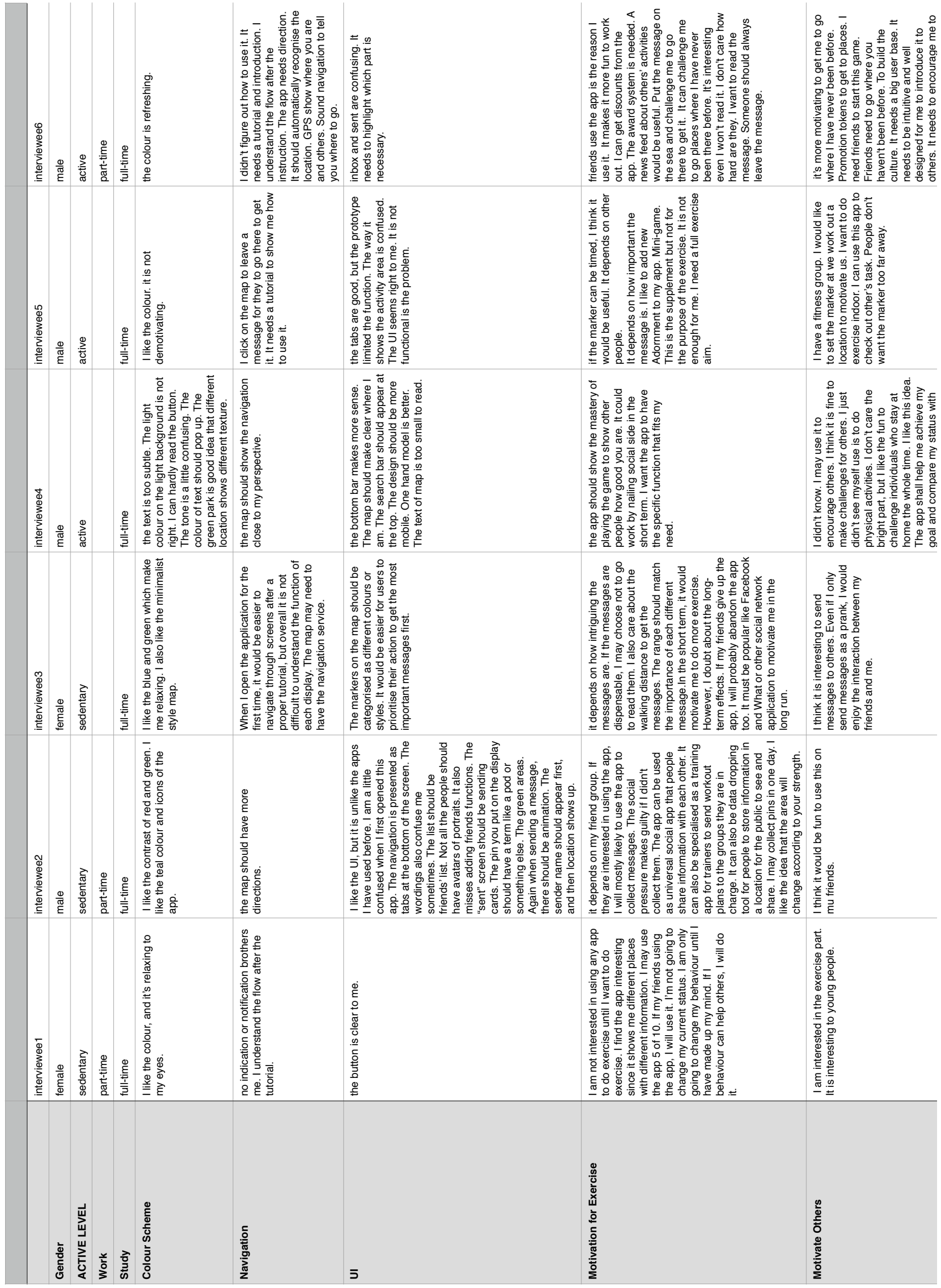




\begin{tabular}{|c|c|c|c|}
\hline 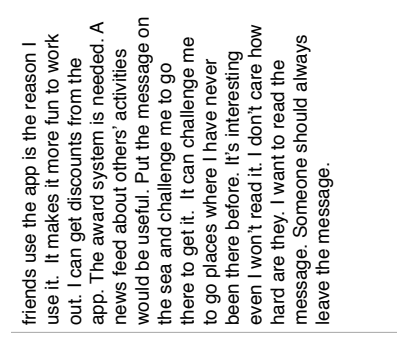 & 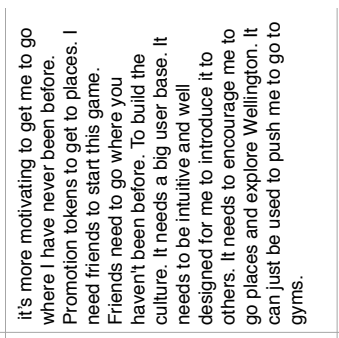 & 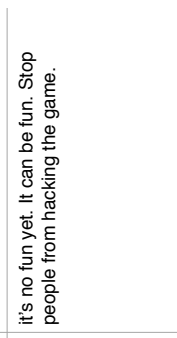 & 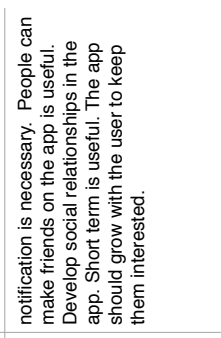 \\
\hline 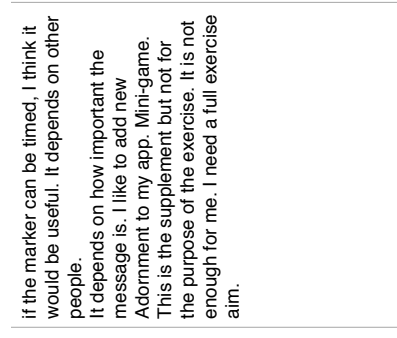 & 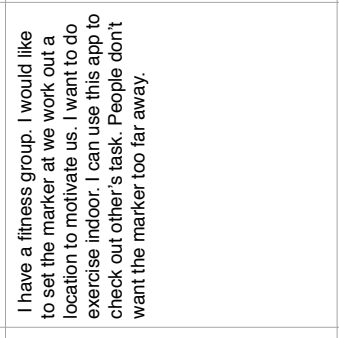 & 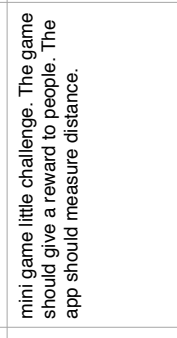 & 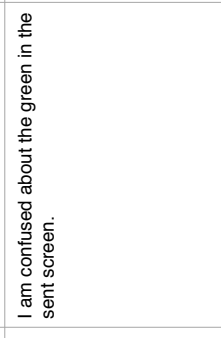 \\
\hline 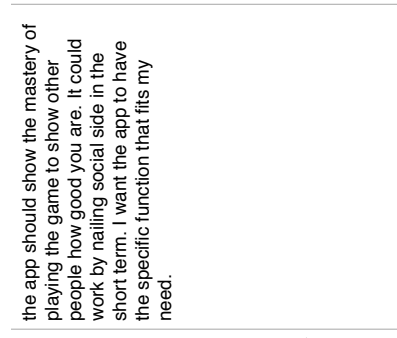 & 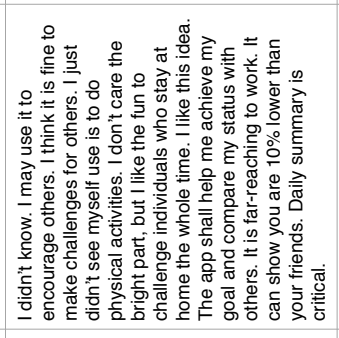 & 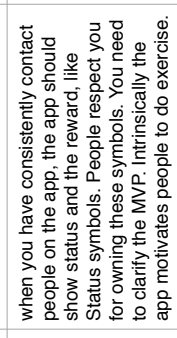 & 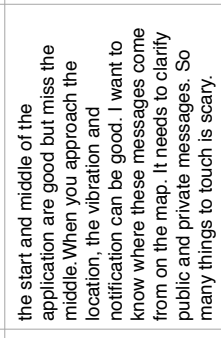 \\
\hline 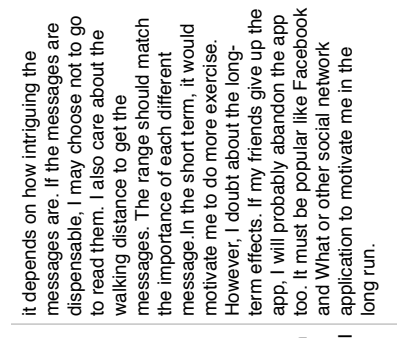 & 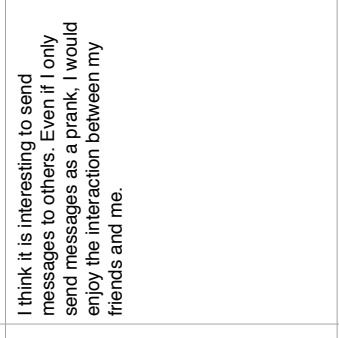 & 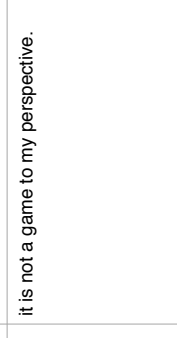 & 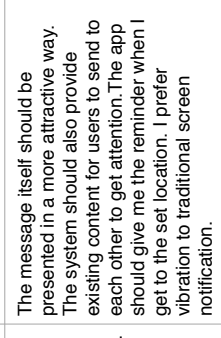 \\
\hline 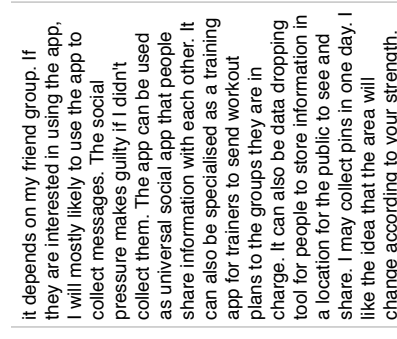 & 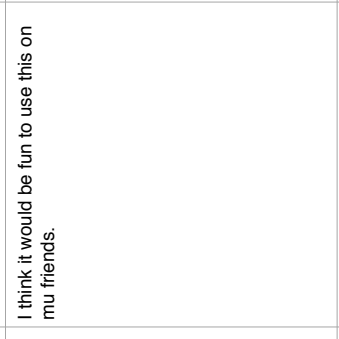 & 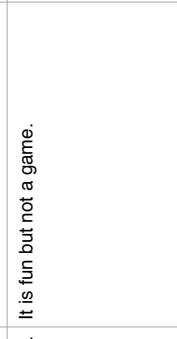 & 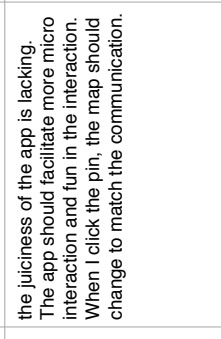 \\
\hline 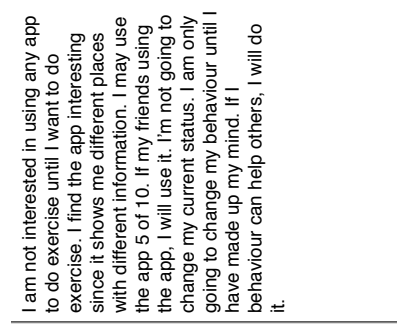 & 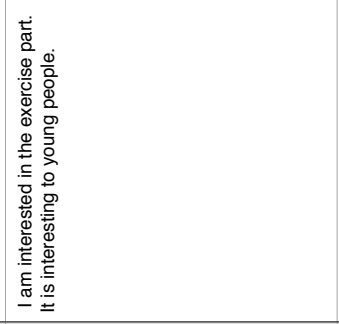 & 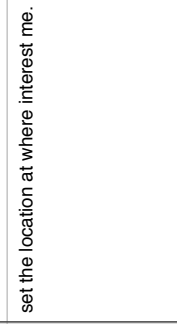 & 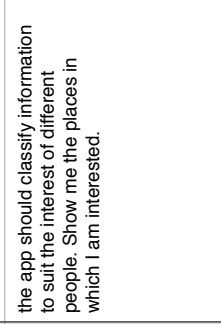 \\
\hline & $\stackrel{\circ}{2}$ & 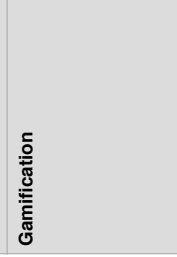 & \\
\hline
\end{tabular}




\section{Appendix 3}

\section{(3.3.3.2. Contextual Interview)}

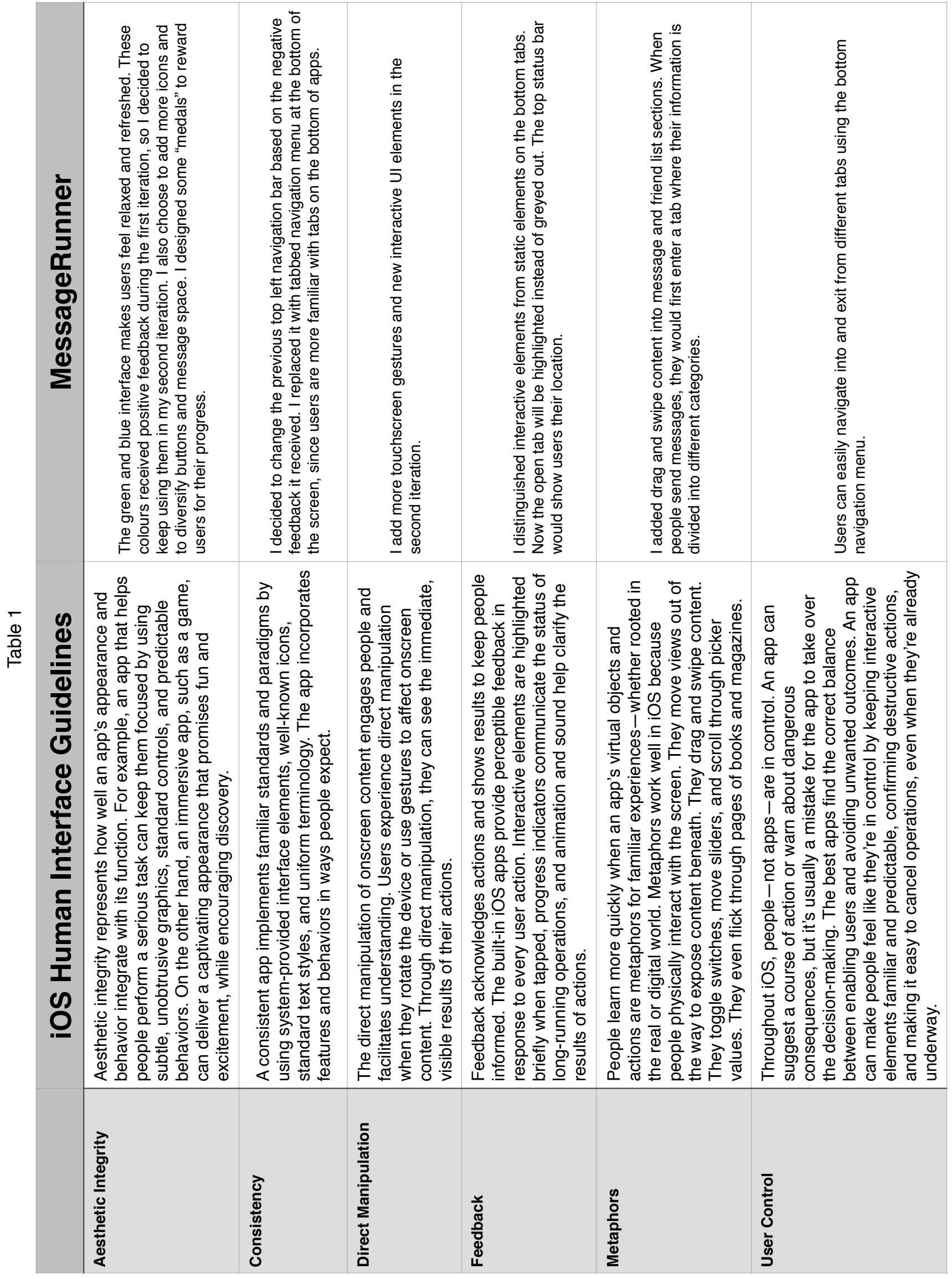


